Alma Mater Studiorum - Università di Bologna

DOTTORATO DI RICERCA IN

MECCANICA E SCIENZE AVANZATE DELL'INGEGNERIA

Prog. 4 Meccanica dei Materiali e Processi Tecnologici

\title{
CICLO XXIV
}

Settore Concorsuale di afferenza: 09/A3

Settore Scientifico disciplinare: ING-IND/14

\section{HYDROELASTIC IMPACTS OF DEFORMABLE WEDGES}

Presentata da: Ing. Riccardo Panciroli

Coordinatore Dottorato:

Prof. Vincenzo Parenti

Castelli

\author{
Relatore: \\ Correlatore: \\ Ing. Andrea Zucchelli
}

Esame finale anno 2012 



\section{Abstract}

This work investigates the slamming phenomenon experienced during the water entry of deformable bodies. Wedges are chosen as reference geometry due to their similarity to a generic hull section. Hull slamming is a phenomenon occurring when a ship re-enters the water after having been partially or completely lifted out the water. There are three more cases commonly defined as slamming in marine applications: bow-flare, wet-deck and green water slamming. These are all special cases of the general topic of water entry of a body. While the analysis of rigid structures entering the water has been extensively studied in the past and there are analytical solutions capable of correctly predicting the hydrodynamic pressure distribution and the overall impact dynamics, the effect of the structural deformation on the structural force is still a challenging problem to be solved. In fact, in case of water impact of deformable bodies, the dynamic deflection could interact with the fluid flow, changing the hydrodynamic load. This work investigates the hullslamming problem by experiments and numerical simulations of the water entry of elastic wedges impacting on an initially calm surface. The effect of asymmetry due to horizontal velocity component or initial tilt angle on the impact dynamics is also studied. The objective of this work is to determine an accurate model to predict the overall dynamics of the wedge and its deformations. More than 1200 experiments were conducted by varying wedge structural stiffness, deadrise angle, impact velocity and mass. On interest are the overall impact dynamics and the local structural deformation of the panels composing the wedge. Alongside with the experimental analysis, numerical simulations based on a coupled Smoothed Particle Hydrodynamics (SPH) and FEM method are developed. Ranges of applicability of a simplified model neglecting the air are found. The experimental results provide evidence of the mutual interaction between hydrodynamic load and struc-

tural deformation. It is found a simple criterion for the onset of fluid structure interaction (FSI), giving reliable information on the cases where FSI should been taken into account. 



\section{Contents}

Abstract

\begin{tabular}{lll}
\hline Contents & iii
\end{tabular}

\begin{tabular}{ll}
\hline List of Figures & v
\end{tabular}

List of Tables xiii

\begin{tabular}{lr}
\hline Preface & 1
\end{tabular}

\begin{tabular}{lll}
\hline 1 & Introduction & 1
\end{tabular}

1.1 Theoretical studies . . . . . . . . . . . . . . . . . . . 1

1.2 Hydroelasticity during slamming $\ldots \ldots \ldots$. . . . . . . . 6

$1.3 \quad$ Air cushioning effect in water entry . . . . . . . . . . . . . . 10

1.4 Experimental studies . . . . . . . . . . . . . . . . . . . 11

$1.5 \quad$ Scope of present investigation $\ldots \ldots \ldots \ldots \ldots$

$\begin{array}{llr}2 & \text { Experimental set-up } & 15\end{array}$

2.1 Description of models and tests . . . . . . . . . . . . . . . 15

2.2 Specimens $\ldots \ldots \ldots \ldots \ldots$

\begin{tabular}{lll}
\hline 3 & Experimental Results & 21
\end{tabular}

4 Smoothed Particle Hydrodynamics (SPH) 31

$4.1 \quad$ Equation of state $\ldots \ldots \ldots \ldots$

4.2 Validation of the numerical model . . . . . . . . . . . . . . . . 32

4.3 Non Reflecting Boundaries . . . . . . . . . . . . . . . . . . . . . . . 37

Hydroelastic impacts of deformable wedges 
4.4 Comparison with analytical models $\ldots \ldots \ldots$

\begin{tabular}{|lll}
5 & Water entry of asymmetric wedges & 41
\end{tabular}

$5.1 \quad$ Asymmetric wedges with pure vertical velocity . . . . . . . . . . 42

5.1 .1 Impact dynamics of asymmetric wedges . . . . . . . . . . 42

$5.1 .2 \quad$ Hydrodynamic pressure . . . . . . . . . . . . . . . . 44

$5.2 \quad$ Asymmetric wedges with horizontal velocity component . . . . . . 49

5.3 Notes on the water entry of rigid bodies . . . . . . . . . . . . . 52

$6 \quad$ Numerical simulations of deformable wedges 53

6.1 Hydroelasticity . . . . . . . . . . . . . . . . . . . . . . 54

6.2 Influence of the structural deformation on the hydrodynamic pressure . . . . . . . . . . . . . . . 55

6.3 Impact dynamics . . . . . . . . . . . . . . . . . . . . . . . . 64

6.4 Stresses evaluation $\ldots \ldots \ldots$. . . . . . . . . . . . . . . . 68

6.5 Hydroelastic effect . . . . . . . . . . . . . . . . . 70

\begin{tabular}{|lll}
\hline 7 & Comparison between experiments and numerical results & 71
\end{tabular}

$\begin{array}{lll}8 & \text { Conclusions } & 75\end{array}$

\begin{tabular}{ll}
\hline References & 77
\end{tabular}

\begin{tabular}{ll}
\hline Appendix & I
\end{tabular}

\begin{tabular}{llll}
\hline I & Experimental results & I
\end{tabular}

I.1 Aluminium wedges $\ldots \ldots \ldots \ldots \ldots$. . . . . . . . . . . . . . II

I.2 Composite wedges - Mat . . . . . . . . . . . . . . . . . . X X

I.3 Composite plates - Woven . . . . . . . . . . . . . . . . . . XVIII 


\section{List of Figures}

1.1 Von Karman's momentum approach. Where $\beta$ is the deadrise angle, $\xi$ the penetration depth, $r$ the wetted distance from the wedge edge. The cross-hatched region represents a half disk of water of radius $r$ moving with the wedge. . . . . . . . . . . . . . . 2

1.2 Von Karman solution. Acceleration and Velocity of a wedge varying the deadrise angle $\beta$. Total wedge mass: $20 \mathrm{~kg}$ per unit width. . . . 3

2.1 Picture of the drop weight machine seen from the bottom of the water tank . . . . . . . . . . . . . . . . 16

2.2 Picture of the sledge $\ldots \ldots \ldots \ldots$

2.3 Picture of two composite panels of different width: $250 \mathrm{~mm}$ and 150 mm. . . . . . . . . . . . . . . . . 17

2.4 Conceptual scheme of the wedge used for experiments. $\mathrm{L}=$ panel length. $\beta=$ deadrise angle. Dashed line: undeformed panels, solid line: expected deformation during impact. . . . . . . . . . . . 18

2.5 Sketch of a wedge clamped on two sides. Dashed line: initial configuration, solid line: expected deformation during impact. . . . . . . 19

2.6 Nodal mode shapes of a dry panel (left) and relative deformation (right). The comparison of the two graphs shows that the position of the nodes is different. The location of the strain gauges was chosen as $25 \mathrm{~mm}$ and $120 \mathrm{~mm}$ from the wedge tip. . . . . . . . . . 20

3.1 Example of a composite (W2) wedge, $2 \mathrm{~mm}$ thick, $\beta=30^{\circ}, V_{0}=$ $2.77 \mathrm{~m} / \mathrm{s}$ (left) and $6.28 \mathrm{~m} / \mathrm{s}$ (right). Strain recorded at $25 \mathrm{~mm}$ (top) and $120 \mathrm{~mm}$ (bottom) from the wedge tip. . . . . . . . . . . 21 


\section{Contents}

3.2 Repeatability of the water impacts of a wedge (W2) with deadrise angle $\beta=30^{\circ}$ entering the water at various impact velocities. . . . 22

3.3 Comparison between Von Karman solution (dashed line) and recorded accelerations (solid lines) during the water impacts of a wedge (W2) with deadrise angle $\beta=30^{\circ}$ entering the water from various impact

height (from left to right, top to bottom : $50 \mathrm{~cm}, 75 \mathrm{~cm}, 100 \mathrm{~cm}$,

3.4 Comparison between Von Karman (dashed line) solution and recorded accelerations (solid lines) during the water impacts of a wedge (W2) with deadrise angle $\beta=20^{\circ}$ entering the water from various impact

height (from left to right, top to bottom : $50 \mathrm{~cm}, 75 \mathrm{~cm}, 100 \mathrm{~cm}$,

3.5 Comparison between the predicted time $t *$ and the experimental one for a composite wedges (W2) with deadrise angle of $30^{\circ}$ (left) and $20^{\circ}$ (right) $\ldots \ldots \ldots \ldots \ldots \ldots \ldots$

$3.6 \quad$ Experimental recorded acceleration and strains. Aluminium panel

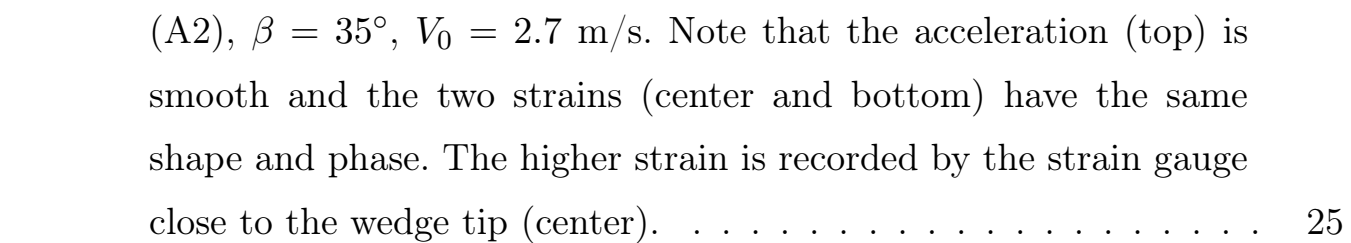

3.7 Experimental recorded acceleration and strains. Composite panel (W2), $\beta=20^{\circ}, V_{0}=3 \mathrm{~m} / \mathrm{s}$. In this case the acceleration (top) show high oscillations (compared to Von Karman solution, dashed \begin{tabular}{|c|}
\hline line) and the strains (center and bottom) do not present the same \\
\hline
\end{tabular}

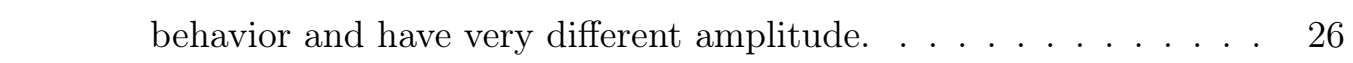

3.8 Experimental recorded strains for variable drop heights. Composite \begin{tabular}{|c|}
\hline panel (V2), $2 \mathrm{~mm}$ thick. $\beta=10^{\circ}$ (top, left), $\beta=15^{\circ}$ (top, right), \\
\hline$\beta=20^{\circ}$ (bottom, left), $\beta=25^{\circ} \mathrm{m} / \mathrm{s}$ (bottom, right). . . . . . . 2 27
\end{tabular}

$3.9 \quad$ Experimental recorded strains for variable drop heights. Composite panel (V2), $2 \mathrm{~mm}$ thick. $\beta=20^{\circ}$ (left), $\beta=30^{\circ}$ (right). . . . . . 27 


\section{Contents}

3.10 Experimental recorded strains for variable deadrise angle. Auminium Panel (A2), $2 \mathrm{~mm}$ thick. $V_{0}=3 \mathrm{~m} / \mathrm{s}$ (top, left), $V_{0}=4.2 \mathrm{~m} / \mathrm{s}$ (top, right), $V_{0}=5.2 \mathrm{~m} / \mathrm{s}$ (bottom, left), $V_{0}=6 \mathrm{~m} / \mathrm{s}$ (bottom, right). . . 28

3.11 Experimental recorded strains for variable drop heights. Composite panel (W2), $2 \mathrm{~mm}$ thick. $\beta=20^{\circ}$ (left), $\beta=30^{\circ}$ (right) $\ldots \ldots .28$

3.12 Nondimensional recorded maximum strain $\epsilon_{m}$, presented as a function of a parameter $R$. Where EI is the bending stiffness, $z_{a}$ is the thickness and $L$ is the panel length. . . . . . . . . . . . . . . . . . 29

4.1 Acceleration response of a wedge entering the water varying the bulk speed of sound. . . . . . . . . . . . . . . . . . . 32

4.2 Dam-break geometry. The blue region is the fluid, initially at rest, whose right boundary is suddently removed to let the water occupy a larger tank. $H=$ initial water depth, $L=$ initial water length, $W$ = water tank length once the boundary is removed. . . . . . . . . 33

4.3 Numerical solution of the surge front position vs. time. . . . . . . . 33

4.4 Left: sketch of the water column loaded at the free surface by a constant pressure. Center and right: Lagrange diagram. Analytical solution for the reflection of a pressure wave during time. . . . . . . 35

4.5 Analytical solution of the pressure due to a wave propagation at the top (blue line), middle (green line) and bottom (red line) of a water column. . . . . . . . . . . . . . . . . . . . . . . . 35

$4.6 \quad$ Numerical pressure fluctuation reduction varying the linear artificial viscosity coefficient. Blue line: Top, Green line: middle, Red line: bottom of the water column. . . . . . . . . . . . . . . . . . 36

4.7 $\quad$ Displacement and velocity during slamming of a rigid wedge entering the water with an initial velocity of $4 \mathrm{~m} / \mathrm{s}$ varying the Bulk artificial viscosity term $\alpha . \ldots \ldots \ldots \ldots$

4.8 Position of a pressure wave generated by the water entry of a cylinder before and after it reaches the boundaries: Non-reflecting boundaries (left, the wave is absorbed) vs. rigid boundaries (right, the wave is reflected). . . . . . . . . . . . . . . . . . . 37 


\section{Contents}

4.9 Acceleration and Velocity of a wedge varying the deadrise angle $\beta$. Total wedge mass: $20 \mathrm{~kg}$ per unit width. SPH simulations with rigid wedges. . . . . . . . . . . . . . . . . . . . . . . 39

4.10 Pressure in time at the fluid/structure interface for a wedge of 500 $\mathrm{kg} / \mathrm{m}$, deadrise angle $30^{\circ}$ and initial velocity $V_{0}=4 \mathrm{~m} / \mathrm{s}$. Blue line: Wagner analytical solution. Red line: numerical results. . . . . . . 39

5.1 Sketch of the asymmetric wedge entering the water. . . . . . . . . 41

5.2 Impact dynamics of an asymmetric wedge entering the water at 6 $\mathrm{m} / \mathrm{s}$. Deadrise angle $\beta=25^{\circ}$, tilt angle $5^{\circ}$. . . . . . . . . . . . . . . 43

$5.3 \quad$ Impact dynamics of an asymmetric wedge entering the water at 8 $\mathrm{m} / \mathrm{s}$. Deadrise angle $\beta=25^{\circ}$, tilt angle $5^{\circ}$. . . . . . . . . . . . . . 43

5.4 Impact dynamics of an asymmetric wedge entering the water at 4 m/s. Deadrise angle $\beta=25^{\circ}$, tilt angle $15^{\circ}$. . . . . . . . . . . . . . 43

5.5 Impact dynamics of an asymmetric wedge entering the water at 6 $\mathrm{m} / \mathrm{s}$. Deadrise angle $\beta=25^{\circ}$, tilt angle $15^{\circ}$. . . . . . . . . . 44

5.6 Asymmetric wedge entering the water at $6 \mathrm{~m} / \mathrm{s}$. Deadrise angle $\beta=25^{\circ}$, tilt angle $5^{\circ}$. . . . . . . . . . . . . . . . . . . . . . . . . 45

5.7 Asymmetric wedge entering the water at $8 \mathrm{~m} / \mathrm{s}$. Deadrise angle $\beta=25^{\circ}$, tilt angle $5^{\circ}$. . . . . . . . . . . . . . . . . . . . . . . . . 46

5.8 Asymmetric wedge entering the water at $2 \mathrm{~m} / \mathrm{s}$. Deadrise angle $\beta=25^{\circ}$, tilt angle $15^{\circ}$. . . . . . . . . . . . . . . . . . . . . . . . . 47

5.9 Asymmetric wedge entering the water at $4 \mathrm{~m} / \mathrm{s}$. Deadrise angle $\beta=25^{\circ}$, tilt angle $15^{\circ}$. . . . . . . . . . . . . . . . . . . . . . . . . . 47

5.10 Asymmetric wedge entering the water at $6 \mathrm{~m} / \mathrm{s}$. Deadrise angle $\beta=25^{\circ}$, tilt angle $15^{\circ}$. . . . . . . . . . . . . . . . . . . . . . . . . . 48

5.11 Asymmetric wedge entering the water at $4 \mathrm{~m} / \mathrm{s}(\mathrm{y})+2 \mathrm{~m} / \mathrm{s}(\mathrm{x})$. Deadrise angle $\beta=25^{\circ}$, tilt angle $15^{\circ}$. . . . . . . . . . . . . . . . . 49

5.12 Asymmetric wedge entering the water at $6 \mathrm{~m} / \mathrm{s}(\mathrm{y})+1 \mathrm{~m} / \mathrm{s}(\mathrm{x})$. Deadrise angle $\beta=25^{\circ}$, tilt angle $15^{\circ}$. . . . . . . . . . . . . . . . . 50

5.13 Asymmetric wedge entering the water at $4 \mathrm{~m} / \mathrm{s}(\mathrm{y})+4 \mathrm{~m} / \mathrm{s}(\mathrm{x})$. Deadrise angle $\beta=25^{\circ}$, tilt angle $5^{\circ}$. . . . . . . . . . . . . . . . . 51 


\section{Contents}

5.14 Asymmetric wedge entering the water with combined horizontal (4 $\mathrm{m} / \mathrm{s})$ and vertical $(4 \mathrm{~m} / \mathrm{s})$ velocity. Deadrise angle $\beta=25^{\circ}$, tilt angle $5^{\circ}$. The horizontal component of the velocity is on the left direction . . . . . . . . . . . . . . . 5 51

$6.1 \quad$ Wedge deformation over time. $10^{\circ}$ deadrise angle, $4 \mathrm{~mm}$ thick, 4 $\mathrm{m} / \mathrm{s}$ initial velocity. . . . . . . . . . . . . . . . . 55

6.2 Wedge deformation over time. $10^{\circ}$ deadrise angle, $2 \mathrm{~mm}$ thick, 4 $\mathrm{m} / \mathrm{s}$ initial velocity. . . . . . . . . . . . . . . . . . . 55

6.3 Impact pressure along the wedge over time. Deadrise angle $30^{\circ}$, mass $20 \mathrm{Kg} / \mathrm{m}$.. Comparison between rigid wedge (blue line) and elastic wedge (black line, Aluminium wedge 2mm thick). results are similar at the beginning of the impact but diverges rapidly after 10

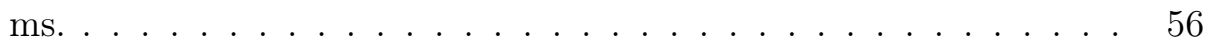

6.4 Adimensional impulse over time for various deadrise angles and impact velocities: $2,4,6$ and $8 \mathrm{~m} / \mathrm{s}$ (left to right, top to bottom). . . 57

6.5 Pressure at the fluid/structure interface during the impact of a rigid wedge (blue line), a deformable aluminium wedge (red line) and a deformable composite wedge (black line) entering the water at 4 $\mathrm{m} / \mathrm{s}$. Deadrise angle $30^{\circ}$.

6.6 Deformation of the aluminium $(\mathrm{A})$ and composite $(\mathrm{V})$ wedge during the impact. . . . . . . . . . . . . . . . . . . . . . . . 59

6.7 $\quad$ Pressure at the fluid/structure interface during the impact of wedges entering the water at $2 \mathrm{~m} / \mathrm{s}$. Deadrise angle $30^{\circ}$. $\ldots \ldots \ldots$

6.8 Deformation of the wedges during the impact. $V_{0}=2 \mathrm{~m} / \mathrm{s}, \beta=30^{\circ}$. $\quad 60$

6.9 Pressure at the fluid/structure interface during the impact of a wedges entering the water at $6 \mathrm{~m} / \mathrm{s}$. Deadrise angle $30^{\circ}$. . . . . . 61

6.10 Deformation of the wedges during the impact. $V_{0}=6 \mathrm{~m} / \mathrm{s}, \beta=30^{\circ}$. 61

6.11 Pressure at the fluid/structure interface during the impact of an aluminium wedges entering the water at $6 \mathrm{~m} / \mathrm{s}$. Deadrise angle $20^{\circ}$. 62

6.12 Pressure at the fluid/structure interface during the impact of an aluminium wedges entering the water at $3 \mathrm{~m} / \mathrm{s}$. Deadrise angle $10^{\circ}$. 62 


\section{Contents}

6.13 Pressure at the fluid/structure interface during the impact of an aluminium wedges entering the water at $4 \mathrm{~m} / \mathrm{s}$. Deadrise angle $10^{\circ}$. 63

6.14 Pressure at the fluid/structure interface during the impact of a rigid wedge (blue line), a deformable aluminium wedge (red line) and a deformable composite (W2) wedge (black line) entering the water at $6 \mathrm{~m} / \mathrm{s}$. Deadrise angle $30^{\circ} . \ldots \ldots \ldots \ldots$

6.15 Deformation of the composite wedge (W2) impact ing at $6 \mathrm{~m} / \mathrm{s}$. Note that due to the severe impact the wedge is highly distorted. . 64

6.16 Deformation in time of a composite wedge (W2) entering the water at $6 \mathrm{~m} / \mathrm{s}$. The time step of the plots is the same one of figures 6.14 and 6.15 . Note that, due to the high structural deformation, after $10 \mathrm{~ms}$ the wedge is wetted by the jet flow, leading to the high differences between the theoretical pressure for rigid wedges and the - simulated one. . . . . . . . . . . . . . . . . . . . . . 64

6.17 Acceleration and Velocity of a wedge varying the particle refinement. Total wedge mass: $20 \mathrm{~kg}$ per unit width. Deadrise angle $10^{\circ} .65$

6.18 Acceleration and Velocity of a wedge varying the particle refine\begin{tabular}{|c|c|c|}
\hline ment. Total wedge mass: $20 \mathrm{~kg}$ per unit width. Deadrise angle $20^{\circ}$. & 66
\end{tabular}

6.19 Acceleration and Velocity of a wedge varying the particle refinement. Total wedge mass: $20 \mathrm{~kg}$ per unit width. Deadrise angle $30^{\circ} .66$

6.20 Hydroelasticity effect on the impact dynamics of aluminium wedges $4 \mathrm{~mm}$ thick of different deadrise angles entering the water at $4 \mathrm{~m} / \mathrm{s}$. From Left to right: $10^{\circ}, 20^{\circ}, 30^{\circ}$ deadrise angle. . . . . . . . . . 67

6.21 Hydroelasticity effect on the impact dynamics of aluminium wedges $4 \mathrm{~mm}$ thick of different deadrise angles entering the water at $2 \mathrm{~m} / \mathrm{s}$. From Left to right: $10^{\circ}, 20^{\circ}, 30^{\circ}$ deadrise angle. . . . . . . . . . . 67

6.22 Impact dynamics varying plate stiffness, deadrise angle from left to right: $10^{\circ}, 20^{\circ}, 30^{\circ}, V_{0}=2 \mathrm{~m} / \mathrm{s}$. . . . . . . . . . . 67

6.23 Impact dynamics varying plate stiffness, deadrise angle from left to right: $10^{\circ}, 20^{\circ}, 30^{\circ}, V_{0}=4 m / s$.

6.24 Stresses at different distances from the wedge tip for fine and rough particle refinement. $\beta=30^{\circ}, V_{0}=4 \mathrm{~m} / \mathrm{s} \ldots \ldots \ldots$ 


\section{Contents}

6.25 Stresses at different distances from the wedge tip for fine and rough particle refinement. $\beta=10^{\circ}, V_{0}=4 \mathrm{~m} / \mathrm{s} \ldots \ldots \ldots$

6.26 Stresses at different distances from the wedge tip increasing the hydroelastic effect. A4-4 (left), A2-4 (center), V2-4 (right). $\beta=30^{\circ}$ $\left(V_{0}=4 m / s\right) \ldots \ldots \ldots \ldots \ldots \ldots \ldots$

6.27 Maximum impact dynamics variation between SPH results and Von Karman results. Acceleration $a\left[\mathrm{~m} / \mathrm{s}^{2}\right]$ (left), Velocity $v[\mathrm{~m} / \mathrm{s}]$ (center) and Displacement $w[\mathrm{~mm}]$ (right). . . . . . . . . . . . . 70

$7.1 \quad$ Recorded strains and numerical solution of an aluminium wedge $2 \mathrm{~mm}$ thick, deadrise angle $\beta=30^{\circ}$. Initial velocity $3 \mathrm{~m} / \mathrm{s} \ldots \ldots .72$

7.2 Recorded strains and numerical solution of an aluminium wedge $2 \mathrm{~mm}$ thick, deadrise angle $\beta=30^{\circ}$. Initial velocity $4 \mathrm{~m} / \mathrm{s} \ldots 72$

7.3 Recorded strains and numerical solution of an aluminium wedge $2 \mathrm{~mm}$ thick, deadrise angle $\beta=15^{\circ}$. Initial velocity $4 \mathrm{~m} / \mathrm{s}$. Note that after $20 \mathrm{~ms}$ the experimental recorded strain show longer period of vibration compared to the numerical results. . . . . . . . . . . 73

7.4 Recorded strains and numerical solution of an aluminium wedge $2 \mathrm{~mm}$ thick, deadrise angle $\beta=15^{\circ}$. Initial velocity $5 \mathrm{~m} / \mathrm{s}$. As in Figure 7.3 , in the numerical solution the wedge vibrates at higher frequency beyond $20 \mathrm{~ms}$ of impact. . . . . . . . . . . . . . 73

7.5 Aluminium wedge deformation over time. $15^{\circ}$ deadrise angle, $2 \mathrm{~mm}$ thick, $V_{0}=5 \mathrm{~m} / \mathrm{s}$. At about $20 \mathrm{~ms}$ of impact a void in the fluid is formed. Beyond this instant, since no air is implemented in the model, the numerical solution differs from the experimental results. $\quad 74$ 


\section{Contents}




\section{List of Tables}

$2.1 \quad$ Plates material properties. . . . . . . . . . . . . . . . . . . . . . . . . 19

$2.2 \quad$ First three dry natural frequencies of the panels used for experiments. 20

$4.1 \quad$ Gruneisen model constants for water. . . . . . . . . . . . . . . . . . 32 



\section{Chapter 1}

\section{Introduction}

The hull slamming problem is of particular interest for shipbuilding industries due to the high impact load that is generated by the impact of a body on an incompressible fluid. When a vessel sails in rough seas, its forefoot can rise above the water surface. As the vessel re-enters the water, impulsive pressures are imparted to the hull structure due to the relative motion of the sea and ship. In these cases the hull literally slams into the water surface. The duration of the slamming event is in the order of milliseconds. These loads might damage the entire ship or, because of their short duration, excite dynamic response of the local structure of the hull and cause the structure to vibrate. This work focuses on hull slamming; however, there are three more phenomena that are defined as slamming in marine applications: (i) the impact of the bow on water induced by the ship motions in waves, (ii) the horizontal impact of steep waves or breaking waves on the ship hull and (iii) the water impact induced by water run-up and green water on the deck.

\subsection{Theoretical studies}

The first analytical solution to solve the impact dynamics of rigid bodies entering the water was presented by Von Karman [1], who developed a formula capable to predict the maximum force acting on a rigid body entering the water, in order to make a stress analysis on the members connecting the fuselage with the floats of a seaplane. As example, to study the water entry of a rigid wedge, Von Karman considered a wedge of unit thickness, mass $M$, and deadrise angle $\beta$ entering the water with initial velocity $V_{0}$. Von Karman's work is based on some simplification, 
i.e.: (i) the flow is inviscid and irrotational, (ii) surface tension, gravity and structural elasticity effects are neglected, (iii) no air is entrapped between the structure and the fluid. In this method, as the body hits the water it is assumed that the mass of a half disk of water of radius $r$ is moving with the wedge (as shown in figure 1.1), resulting in an added mass $m=\frac{\pi}{2} \rho r^{2}=\frac{\pi}{2} \rho \frac{\xi^{2}}{\tan ^{2}(\beta)} \gamma^{2}$, where $\gamma$ is a coefficient accounting for the water pile up at the intersection with the free surface that varies with the deadrise angle. The value of $\gamma$ can be evaluated as suggested in [2, for example. In this model, velocity and acceleration of the body are given by:

$$
\dot{\xi}=\frac{V_{0}}{1+\frac{\pi}{2} \rho \frac{\gamma^{2} \xi^{2}}{M \tan ^{2}(\beta)}} \quad ; \quad \ddot{\xi}=\frac{\pi \rho \gamma^{2}}{M V_{0} \tan ^{2}(\beta)} \xi \dot{\xi}^{3}
$$

In von Karman's model (Eq1.1.1), the impact force reaches its maximum value

$$
F^{*}=\left(\frac{5}{6}\right)^{3} \frac{V_{0}^{2}}{\tan (\beta)} \sqrt{\frac{2 \pi}{5} \rho M \gamma^{2}}
$$

when the velocity is

$$
\dot{\xi}^{*}=\frac{5}{6} V_{0}
$$

the penetration depth is

$$
\xi^{*}=\sqrt{\frac{2 M}{5 \pi \rho \gamma^{2}}} \tan (\beta)
$$

and the time is

$$
t^{*}=\frac{16}{15} \frac{\xi^{*}}{V_{0}}
$$

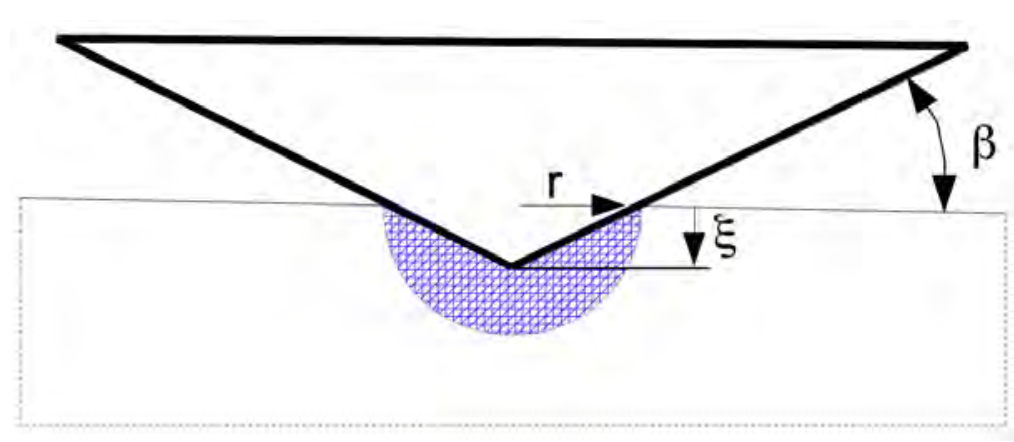

Figure 1.1: Von Karman's momentum approach. Where $\beta$ is the deadrise angle, $\xi$ the penetration depth, $r$ the wetted distance from the wedge edge. The cross-hatched region represents a half disk of water of radius $r$ moving with the wedge. 
Eq. 1.1.2 shows that the maximum force increases with the square of the velocity and the square root of the mass of the wedge. $F^{*}$ is inversely proportional to $\tan (\beta)$ so that it decreases as $\beta$ increases and it becomes infinite as the deadrise angle tends to zero. When $\beta$ becomes small, $r$ becomes very large, the added mass becomes infinite and the wedge stops instantly. Eq. 1.1.3 shows that the velocity is $5 / 6$ times the initial velocity when the force reaches its maximum. Eq. 1.1.4 shows that the penetration depth at that particular instant is proportional to the square root of the mass and to $\tan (\beta)(\tan (\beta)=0$ implies no penetration). Combining Eqs. 1.1.4 and 1.1.5 gives

$$
t^{*}=\frac{16}{15} \frac{\tan (\beta)}{V_{0}} \sqrt{\frac{2 M}{5 \pi \rho \gamma^{2}}}
$$

This shows that the force reaches its maximum at a time that is inversely proportional to the initial velocity and increases with $\tan (\beta)$. Figure 1.2 shows the overall acceleration and velocity of a wedge of $20 \mathrm{Kg}$ per unit with entering the water at $4 \mathrm{~m} / \mathrm{s}$ for various deadrise angles. It is shown that decreasing the deadrise angle from $30^{\circ}$ to $5^{\circ}$ leads to an increase of the maximum acceleration and a reduction of the characteristic time $t^{*}$.
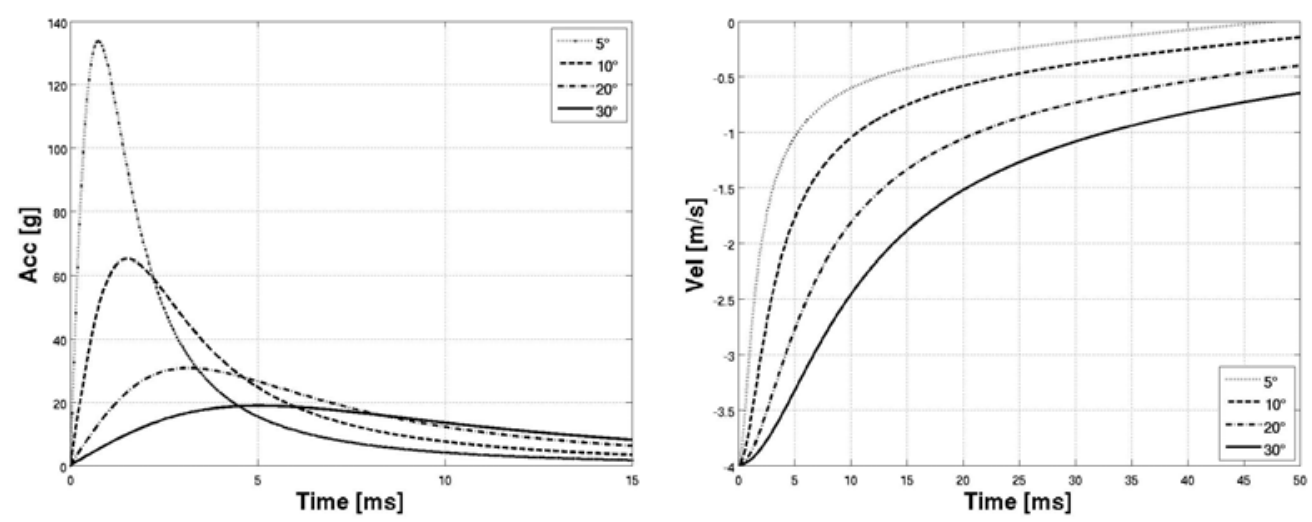

Figure 1.2: Von Karman solution. Acceleration and Velocity of a wedge varying the deadrise angle $\beta$. Total wedge mass: $20 \mathrm{~kg}$ per unit width.

Wagner [3] later extended Von Karman's method to predict the pressure distribution at the fluid/structure interface during the impact. In this model, the 
pressure along the wedge is given by:

$$
\frac{p(x)}{\rho}=\ddot{\xi} \sqrt{r^{2}-x^{2}}+\frac{\pi}{2} \frac{\dot{\xi}^{2} r}{\tan (\beta) \sqrt{r^{2}-x^{2}}}-\frac{1}{2} \frac{\dot{\xi}^{2} x^{2}}{r^{2}-x^{2}}
$$

Equation 1.1.7 shows that the pressure becomes infinite when $\beta$ tends to zero and there is a singularity near the end when $x$ tends to $r$. The maximum impact pressure $p_{\max }$ is obtained by defining $d p / d c=0$ and assuming the acceleration of the body $\ddot{\xi}$ to be negligible. This gives

$$
p_{\max }=\frac{1}{2} \rho V^{2}\left[1+\frac{\pi^{2}}{4} \cot ^{2} \beta\right]
$$

which occurs at the location

$$
x=L\left[1-\frac{4 \tan ^{2} \beta}{\pi^{2}}\right]^{\frac{1}{2}}
$$

since $p_{\max }$ occurs some time $t$ after the instant of impact $t_{0}, V$ is used in equation 1.1 .8 since it might not be the impact velocity $V_{0}$. At the keel of the wedge, $x=0$. From eq. 1.1.7, the impact pressure at that point is

$$
p_{\text {keel }}=\frac{1}{2} \rho V^{2} \pi \cot (\beta)+\ddot{\xi} \rho L
$$

if $\ddot{\xi}$ can be neglected,

$$
p_{\text {keel }}=\frac{1}{2} \rho V^{2} \pi \cot (\beta)
$$

These analytical models were developed for the analysis of the water entry of rigid bodies and are not capable of accounting for hydroelastic effects, since the changes of the fluid motion due to the structural deformation are not accounted. Thus, Wagner's and Von Karman's solutions will be used to validate the SPH model in the case of slamming of rigid bodies, while the validated numerical model will be used to study the water entry of elastic wedges, since hydroelastic effects might appear.

Since Wagner developed the first analytical solution to evaluate the pressure during water-entry problems, much effort has been devoted to slamming problems, resulting in an impressive amount of papers: more than 200 papers were listed in the Ship Structure Committee report SSC-385 [4].

In the literature are presented many analytical methods that extend Wagner's method to different shapes (e.g. [5, 2] ) and most of them are very effective when 
dealing with the water entry of simple-shaped structures impacting the surface with pure vertical velocity. However, these analytical models are limited to the analysis of simple geometries impacting onto a free and initially calm surface. Yettou [6] developed an analytical solution to symmetrical water impact problems, showing a very good agreement between experimental results and analytical solutions of the water entry of rigid wedges. Some of these solutions are even capable of accounting for oblique impacts (e.g. [7-13]). It is reported in the literature that there are particular conditions (entry velocity, deadrise angle and tilt angle) where the fluid detaches from the wedge apex (i.e. the keel) introducing difficulties in evaluating the pressure at the interface by analytical formulations. Xu [14] defined two types of asymmetric impact. Type A flow is the one when there is small asymmetry and the flow moves outward along the contour on both sides of the vertex. Type B flow occurs when there is large asymmetry and the flow detaches from the body contour at the vertex on one side. Chekin [15] concluded that there was only one unique combination of wedge angle and impact angle from which no separation of flow from the vertex would occur. For a given wedge and wedge orientation, any other impact angle would force separation. Defining $U_{0}$ the horizontal velocity and $W_{0}$ the vertical velocity, the ratio $\frac{U_{0}}{W_{0}}$ at which the flow separation appears is less for bodies of larger deadrise angles. For small asymmetry impacts, the cavity flow during the water-entry is limited to a very small region. Furthermore, the flow that separates from the apex quickly re-attaches to the wedge. A symmetric body impacting with horizontal velocity will produce a flow similar to asymmetric impact with only vertical velocity when rotation about the $\mathrm{x}$-axis is not allowed. In [7], Judge at al performed experiments on wedges where asymmetry and horizontal impact velocity are present and compared the results with an analytical solution, showing good agreement for low angles of asymmetry and small ratios of horizontal to vertical impact velocity.

Some models are even capable of accounting for the hydroelastic coupling [1620]. However, in order to fully describe impact forces and resulting structural response, other different phenomenon (like entrapped air, hydroelastic interaction, compressibility effects, and non-linear free surface mechanics) must be considered. It is the lack of understanding with regard to these phenomenon that presents 
the largest need for further investigation. There is, therefore, a dire need to develop accurate prediction methods for hydrodynamic loads in order to reduce the probability of structural failure.

\subsection{Hydroelasticity during slamming}

The forward speed of a vessel has a significant effect upon the severity of slamming and it is recognized that slamming is the primary reason for voluntary speed reduction for ships sailing in rough seas [21]. To correctly predict the slamming load is becoming more important as the marine technology advances, since the vessels speed is continuously increasing due to the introduction of lighter structures and faster propellers. As the sailing speed increases, so does the hydrodynamic force caused by the impact of a surface wave on the hull. As a consequence, the structural deformations might be larger.

While structural analysis of sailing yachts has relied for years on a static or quasi-static approach, there is an increasing necessity for trying to evaluate dynamic loads and their effect in a more precise way [22]. For design purposes, the tendency has always been to represent these loads by an equivalent static pressure uniformly distributed over the panels. When the duration of the pressure pulse is considerably longer than the natural period of the panels, this pressure can simply be taken as the spatial average of the real hydrodynamic load. Alternatively, if the panel is expected to show a non negligible dynamic response, the equivalent pressure would be defined as that pressure which, if applied to the panel, will result in the same deformation and same maximum stress produced by the actual loading. Hydrodynamic impact loading cannot be modeled as a quasi-static phenomenon as wave bending. It is an impulsive phenomenon involving high pressures acting over a body surface during very short time periods relative to the natural rate of response of the structure. It is the lack of understanding with regard to the chain of events occurring during the impulse time that presents the greatest problem. Furthermore, impulse loading can involve complex mathematics dealing with three-dimensional fluid modeling. The formulas for this type of model at present can be solved by making assumptions about the temporal and spatial distribution of forces, and it is these assumptions that may introduce inaccuracies. 
Water impacts of elastic bodies might highly differ from the impact of rigid bodies. In fact, during the water entry of elastic bodies, the fluid motion might interact with the structural deformation, phenomena known as hydroelasticity 1 . Furthermore, during the impact of flat-bottom or low deadrise angles $2^{2}$ air can be trapped between the structure and the fluid. In the next sections it will be described the air entrapment phenomena, the hydroelastic effects, and the analytical and numerical methods to study the water entry of rigid and flexible wedges.

Due to the mutual interaction between the fluid motion and the structural deformation, the hydrodynamic loads that elastic bodies are subjected during the water entry might differ from the loads acting on rigid bodies[24]. The concept is that the impact pressure is related to the movement of the impact region with respect to the water [25]. In particular, as mentioned in [19], the evolution of the wetted body area in time is an important characteristic of the impact, which strongly affects the magnitude of the loads. Elastic structures with low deadrise angles are the most subjected to changes in the impact dynamics respect to rigid structures, since a small deflection of the structure might result in a big difference of the wetted surface and consequently the hydrodynamic load. Such problems are still difficult to analyze and compute.

Carcaterra and Ciappi [26] studied the water entry problem of elastic wedges simplifying the deformable wedge as two rigid plates connected by a rotational spring of constant stiffness. They show how the hydrodynamic force is affected by the deformation of the wedge. It was found that during the initial phase of the impact the deadrise angle decreases due to the structural deformation. When the deadrise angle becomes smaller, the wetted surface is increased and an increment of the hydrodynamic load, with respect to the rigid wedge case, is observed. When the wetted front crosses the center of gravity line, an opposite moment contribution arises that tends to contrast the deadrise decrement. Alternate closing and opening

\footnotetext{
${ }^{1}$ By definition, hydroelasticity of marine structures is the branch of science concerned with the motion and distortion of deformable bodies responding to environmental excitations in the sea 23 .

${ }^{2}$ The deadrise angle is defined as the angle between the tangent at the impact surface of a falling body and the horizontal line of the fluid which the body strikes; a flat bottom has a zero deadrise angle.
} 
of the wedge was predicted. They showed that this phenomenon could be observed only if the natural period of oscillations is small compared to the characteristic time of application of the hydrodynamic force. They observed that the mass of the plates composing the wedges has an influence on the stresses at the beginning of the impact, when the inertia induces the deadrise angle to decrease, even if the hydrodynamic load itself is pushing the wedge to close and increase its deadrise angle. A similar effect was experimentally found by Arai and Miyanki [27].

Hydroelasticity is the dynamic interaction between water and a structure (sometimes called fluid-structure interaction). Water entry is only one example of it. Faltinsen in his review 28] on hydroelastic slamming show that the structural engineers often use an equivalent design pressure that has no physical meaning, even if it can predict the same maximum strain in the structure reached during the dynamic event. The equivalent pressure load would be an order of magnitude smaller than the maximum physical pressure. Kapsenberg [29] reported that, in case of hydroelastic phenomena, the magnitude of the deformation of an elastic body might be lower than the one expected from classical beam theory and neglecting hydroelastic effects can, in the extreme case, result in an over-prediction of the deformation (and hence the stress) by a factor of 10. Furthermore, in case of small deadrise angles, compressibility and air cushions will occur during slamming and local hydroelastic effects have to be considered.

Several scientists [27/37] investigated the water impact of elastic structures, showing that the hydroelastic effects are governed by deadrise angle, panels thickness and impact velocity. Hydroelasticity is a challenging problem to be solved analytically due to the difficulties in coupling the fluid motion and the elastic deformation and a reliable numerical solution is particularly needed due to its flexibility of treating complex shapes and coupling between deforming bodies and fluid motion. Hirdaris [38] suggests that particle-based methods, as other numerical methods, are expected to become increasingly used in the future, but currently suffers of lack of computational efficiency.

In the literature there are many attempts of numerical solutions of waterentry problems. Many of these are very effective when dealing with the water entry of complex geometries, sometimes even considering oblique impacts (e.g. [7]), 
but mainly focusing on rigid structures. To study more realistic situations, many numerical methods capable of coupling the fluid dynamics with the structural response have been used [16, 17, 20, 33, 39]. Korobkin [19] developed a method to study hydroelastic impacts of deformable wedges directly coupling Wagner's theory for fluid flow and a finite element representation of the structure, showing good results for moderate impact velocity and low to moderate deadrise angles. The computational time increases with the number of structural modes considered; this makes it feasible to be applied only to low impact loads, where a low number of modes is necessary.

Seddon and Moatmedi [40] review the literature on the water entry problems for aerospace structures from 1929 to 2003 and show that very few efforts were made to develop solutions for non-vertical impacts, three-dimensional bodies, or deformable bodies. The majority of the work on these problems is experimental. They suggest that Smoothed Particle Hydrodynamics (SPH) can possibly be a tool to study these problems, but that a large amount of work is required to validate such models. One of SPH's major advantages is the ease of treating fluids presenting a free surface, together with the possibility to interact with FEM models, while its major limitation is the very expensive computational time due to the high number of particles needed to model the fluid, which limits its application to relatively small two dimensional models [41,44]. As an example, in [43] 21 millions particles are needed to obtain results similar to Wagner's solution for the water entry of a rigid wedges. Anghileri et al. [45] used the SPH method to study the water entry of a rigid cylinder and a rigid wedge, showing a good approximation of the impact force.

Shao [46] performed a sensitivity analysis by refining the particle spacing. It was found that the spatial resolution can have a relatively large influence on the flow in the water splash-up region (the water entry produces a water jet piling up the wedge panels during impact, see e.g. [47]), but it has less influence on the falling velocity of the object and the fluid forces. The finer the particle resolution is, the better the detailed flow structures can be resolved, but at the cost of more computational time. For the pressure evaluation at the fluid/structure interface, many articles show results that are inaccurate and lack details, to the point that 
this technique cannot be considered to be fully suitable for this purpose 42 44]. In general, the pressure values suffer noise due to numerical fluctuations. An averaging therapy on the pressure field has been recently proposed in the literature (see i.e. [48]). Molteni [49] proposed the introduction of a proper diffusive term in the continuity equation to increase the smoothness and the accuracy of pressure profile. They showed that this corrective method does not alter the match of the numerical solution with the analytical one. However, no fluid/structure interaction problems are treated in their study. Kapsenberg [50] reported that SPH is a very robust method and impressive results are obtained for very violent phenomena. However, work on verification of the results (convergence with respect to particle size and time step) is not yet at the level of the normal CFD. Kapsenberg also reports that the main problems related to the SPH method are wave propagation and a robust treatment of the fluid/structure interface, while computer requirements are an order higher than for normal CFD methods.

Alongside with hydroelasticity, during the water entry of flat-bottom structure with relatively high velocity, air can be trapped in between the fluid and the structure. The next section describes this phenomenon.

\subsection{Air cushioning effect in water entry}

Trapping of air in the fluid during the water impacts is common in case of impact of flat-bottom structures [51]. In [52] the two-dimensional impact tests of a rigid flat-bottom model indicates that the maximum impact pressure is nowhere near the theoretical infinitely large hydrodynamic pressure or near the theoretical acoustic pressure. With the assumption that no air is trapped in the fluid during the slamming event of a flat structure, an approximate value of the maximum impact pressure is [53]:

$$
p_{\max }=\rho c V_{0}
$$

where $p$ is the pressure, $\rho$ is the fluid density, $c$ is the speed of sound in the fluid, and $V_{0}$ is the impact velocity. However, evidence resulting from investigation reveals that the impact of flat structures is cushioned by the presence of trapped air between the falling body and the water. If all the air is forced to escape during a flat-bottom drop, it is necessary that the air velocity is infinite just before impact 
occurs. It is consequently necessary that some air is trapped between the water and the structure: as the body approaches the surface of the water and the air cannot escape fast enough, the pressure deforms the surface of the water before contact is made. Then, a large air bubble is trapped under the body. This causes the impact pressure to be reduced. This event is maximum for a flat-bottom structure, but this effect appears (with lower magnitude) for low deadrise angles (up to about $10^{\circ}$ ). The cushioning effect of the compressible air trapped between the impact body and the water surface reduces the impact pressure to about onetenth of the acoustic pressure. Evidence resulting from Chuang [25] investigation supports the thesis that Wagner's hydrodynamic impact theory does not apply to the impact of wedge-shaped bodies with small deadrise angles. This is because, as for a flat-bottom impact, the cushioning effect of trapped air must be taken into account. Furthermore, Chuang experiments showed that a deformable body affords considerable relief from the impact load. Since it is quite possible that a certain amount of air is trapped also during the impact of a wedge-shaped body with very small deadrise angle $\beta$, experiments (described in chapter 2 ) were designed in order not to include this effect.

\subsection{Experimental studies}

As reported in [50], an enormous amount of work has been devoted to a proper measurement and prediction of the peak value of the impact pressure. For the analysis of the global response of a hull, this value has no consequences since the duration of the peak is very short, therefore, it contains very little impulse, while the hull girder is excited with a force of relatively long duration owing to the relatively low speed at which this pressure pulse travels over the hull. The short-duration slamming peak is only important for very special applications like structures made of flexible panels and very stiff supports.

Most of the experimental studies found in the literature deal with the investigation of the water entry of rigid bodies. The major attention is given to the evaluation of the impact dynamics and the pressure at the fluid/structure interface (e.g. [45]). As an example, Engle [54] studied the water entry of rigid wedges measuring the pressure at the fluid/structure interface. Results based on peak 
pressures at different impact velocities compared well with Wagner's and Chuang [25] theories. These methods can predict the impact dynamics of rigid bodies, but are not accurate when the structure is deforming under the hydrodynamic force due to hydroelastic effects. Some authors attempted to experimentally investigate the parameters affecting hydroelasticity during slamming. Bereznitski [31] studied the effect of hydroelasticity as a function of different parameters: stiffness of the structure, presence of entrapped air between the structure and the water surface, and penetration of water at different deadrise angles. It was found that the ratio between the impact duration and the period of first mode of vibration of dry structure is the key factor in taking the decision when the solution of the structural response should include hydroelastic effects. Similar results were reported by other scientists [32 35].

Faltinsen [28, 30] showed that, due to hydroelasticity, cavitation may occur since pressures becomes negative relative to atmospheric pressure during the second half of the first wet natural oscillation period; ventilation might also appear, i.e. air can be caught in an air pocket in the water leading the air flow to interact with the water flow. Recently Huera and Huarte [55] experimentally studied the hydrodynamic load on panels entering the water at speeds higher than $5 \mathrm{~m} / \mathrm{s}$ and low deadrise angles, showing that for angles lower than $5^{\circ}$ air entrapment is important and asymptotic solutions tend to overestimate the hydrodynamic loads.

At present, experiments show that there are particular conditions where hydroelastic, air entrapment, cavitation and ventilation phenomena might occur during slamming. However, a reliable tool to predict the occurrence and the magnitude of such phenomena is missing.

\subsection{Scope of present investigation}

This study presents an extended experimental campaign on the water entry of deformable wedges. Experiments investigate the water-entry of composite and aluminium flexible wedges varying thickness, deadrise angle and impact velocity.

Results of the impact-induced accelerations are compared with analytical solutions for rigid structures: assuming that the wedge is rigid, the impact dynamic can be evaluated by Von Karman's approach, while the pressure distribution along the 
edge can be determined using Wagner's formula. The evaluated pressure can be used to calculate the stresses in the panels provided that deflections remain small and do not induce changes in the fluid flow. Instead, this study examines cases where the deformation of the wedge is very large. This affects the fluid flow and consequently the pressure distribution along the edge, introducing hydroelastic effects.

The second and the third chapter describe the experiments conducted on the water entry of deformable wedges. The impact-induced acceleration is recorded by an accelerometer while strain gauges located at various locations on the wedge measure the overall local deformation.

Alongside with the experimental campaign, numerical simulations are developed by a coupled SPH / FEM numerical model and the computed structural deformations are compared with the experimental results. The numerical model is presented in the fourth chapter and above. First, it is presented the validation of the coupled FEM/SPH model by analyzing its capability to correctly reproduce the pressure waves propagation and the overall fluid motion. Second, it is investigated the water-entry problems of rigid bodies, whose results are compared with Von Karman and Wagner's analytical solutions, showing that SPH is actually capable of correctly simulating the impact dynamics. However, the accuracy of the solution in terms of pressure at the fluid-structure interface was found to be highly influenced by various parameters like: element size, artificial bulk viscosity and non-reflecting boundary conditions. Once the solution method has been validated, the research moves to the investigation of hydroelastic effects on the impact dynamics and the structural deformation during the impact of deformable bodies. At last, numerical results are compared with experiments about water-entry of elastic wedges of varying thickness, deadrise angle and impact velocity.

The experimental results show that the relative importance of hydroelasticity is strictly related to the ratio between the time necessary for the structure to get completely wet during the water entry (also called wetting time) and the natural period of the structure. The numerical simulations reveal that SPH is actually capable of correctly replicating the structural deformations even for low mesh refinement. On the other hand a low refinement gives a poor approximation 
pressure field all over the fluid/structure interface. However, this lack of accuracy seems to have negligible effect on the structural deformation.

Being able to model the fluid with a low mesh refinement means lower computational time which is, from the practical point of view, the most delicate point for the applicability of the SPH technique to full-scale three-dimensional simulations, which is a necessary step to be achieved in order to be able to use this method in the design purposes. 
Chapter 2

\section{Experimental set-up}

As shown in the previous sections, hydroelasticity in water-entry problems has been studied by many authors, both by experimental campaigns and by numerical simulations (e.g. [28, 32, 34, 35, 56]). However, their interest mostly focused on the analysis of the pressure at the fluid/structure interface rather than the structural deformation itself. Furthermore, all the structures used in the experiments are stiff and present very little structural deformation. The hydroelastic effects are consequently low.

Therefore, an experimental apparatus was designed to perform slamming tests of wedges of various stiffness and to compare them with the theoretical results shown in the previous sections and numerical simulations. The time history of the hydrodynamic force applied on the wedge and the strains at several locations on the panel are measured. The design of machine and specimens was chosen in order not to present air trapping effects, as described in section 1.3 .

\subsection{Description of models and tests}

A drop weight machine with a maximum drop height of $4.5 \mathrm{~m}$ was specially designed and built at the DIEM laboratories. The machine is composed by an aluminium frame $2 \mathrm{~m}$ long, $1.8 \mathrm{~m}$ wide and $6 \mathrm{~m}$ high, holding two prismatic rails guiding an aluminium sledge. The rails have a maximum vertical run of $4.0 \mathrm{~m}$ so that the wedge can fall from variable heights leading to different entry velocities. Teflon insets minimize the friction between the sledge and the prismatic rails. The sledge can hold wedges up to $350 \mathrm{~mm}$ long (per side) and $800 \mathrm{~mm}$ wide. The 
falling body hits the fluid at the center of a tank 1.2 meters wide, 1.8 meters long and $1.1 \mathrm{~m}$ deep. The tank was filled with water only up to $0.6 \mathrm{~m}$ to prevent the water waves generated during the impact to overflow. Figure 2.1 shows a picture of the drop weight machine seen from inside the tank, while Figure 2.2 shows the aluminium sledge. The drop heights, which are defined as the distance between the keel and the water surface, ranged from $0.5 \mathrm{~m}$ to $3 \mathrm{~m}$ at $0.25 \mathrm{~m}$ increments.

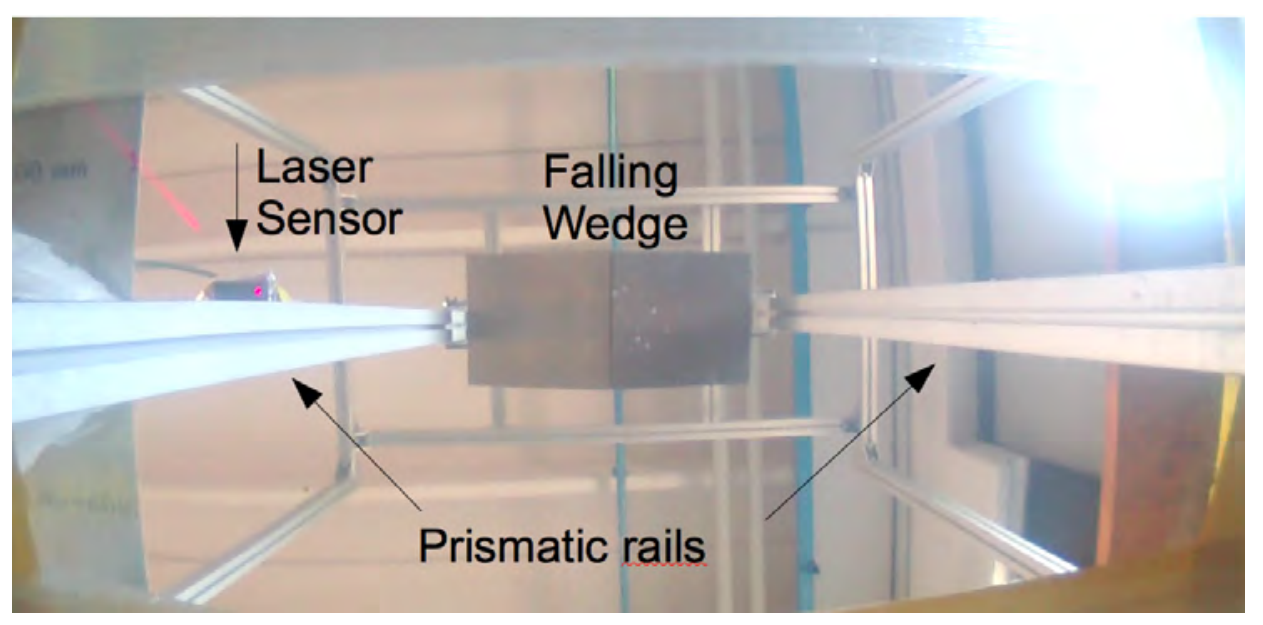

Figure 2.1: Picture of the drop weight machine seen from the bottom of the water tank.

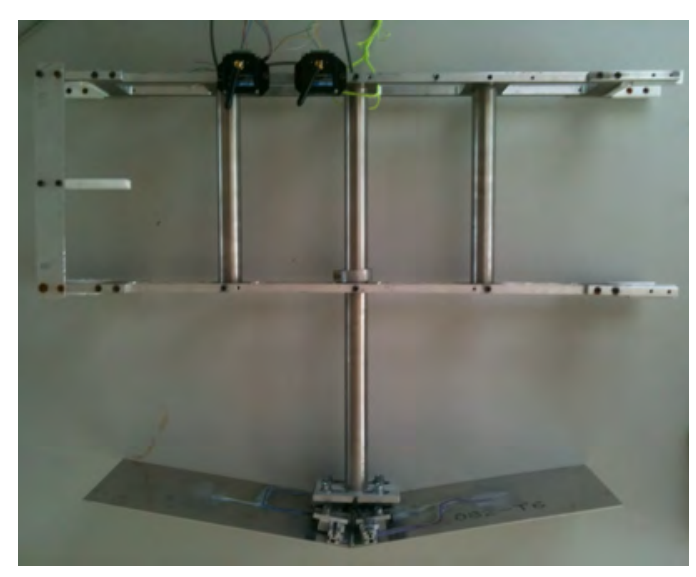

Figure 2.2: Picture of the sledge

Impact acceleration was measured by a V-Link Microsrain wireless accelerometer $( \pm 100 g)$ located on the tip of the wedge. All reported accelerations are refer- 
enced to $0 \mathrm{~g}$ for the free-falling phase. The sampling frequency has been set to its maximum of $4 \mathrm{kHz}$. Entering velocity was also recorded by a laser sensor ( $\mu \epsilon$ ILS 1402) recording the sledge position over $350 \mathrm{~mm}$ of ride at a frequency of $1.5 \mathrm{kHz}$. The entry velocity is obtained by the numerical differentiation of the position. The maximum impact height is $4 \mathrm{~m}$, corresponding to a maximum impact velocity of $8.8 \mathrm{~m} / \mathrm{s}$. This maximum impact velocity cannot be reached during experiments due to the large wedge dimensions offering a high air resistance. Friction on the prismatic rails was found to be negligible compared to the air resistance.

One of the main requirements was to be able to easily test a high number of wedges with different stiffness and deadrise angle without having a large number of specimens. Thus, wedges were designed to be composed by two panels (Fig. 2.3) joined together on one side (keel) by a mechanism capable to change the deadrise angle smoothly from $0^{\circ}$ to $50^{\circ}$. The impact angles were measured at rest with a digital level providing $0.1^{\circ}$ resolution. Figure 2.4 shows a conceptual sketch of the wedge.

In nautical applications, composite hulls are usually made by panels whose edges are clamped to the main frame (a sketch of this configuration can be seen

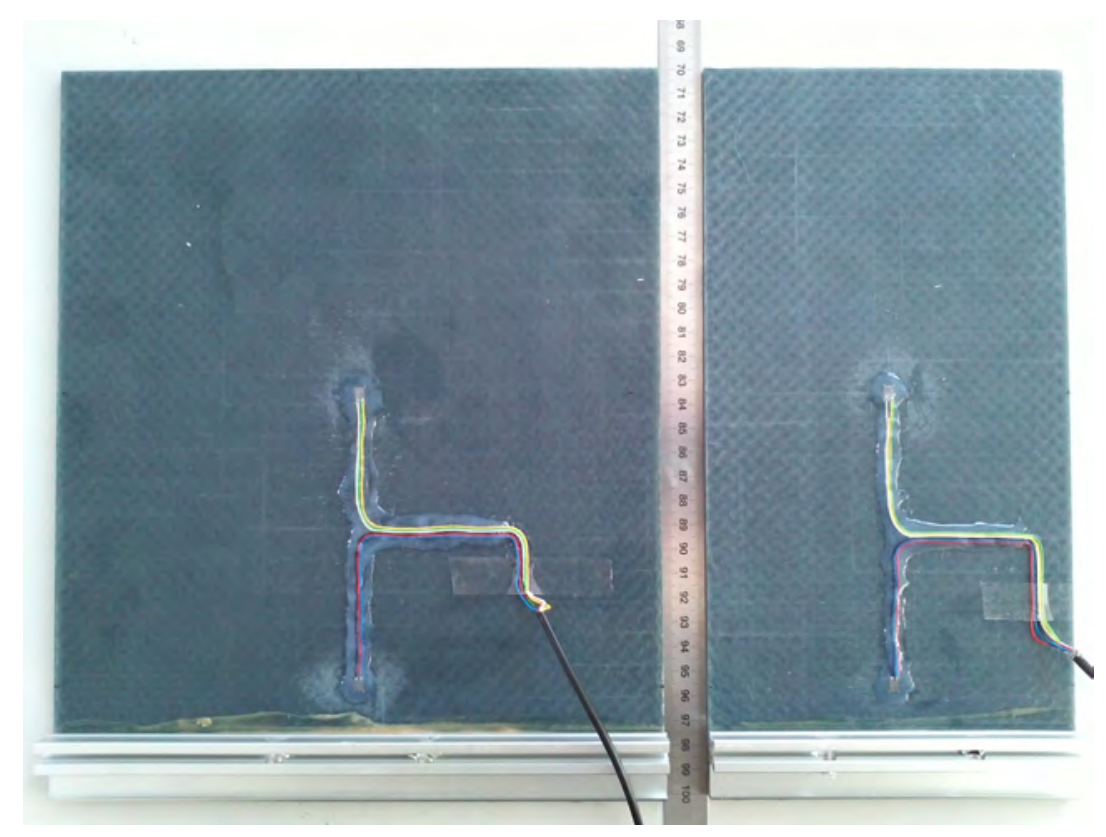

Figure 2.3: Picture of two composite panels of different width: $250 \mathrm{~mm}$ and $150 \mathrm{~mm}$. 
in figure 2.5). Locking all the edges of the panel has the effect of increasing the first natural frequency. However, in the literature [28, 30,35] it was found that hydroelastic effects increase while increasing the entry velocity and decreasing the ratio between the wetting time and the first natural frequency. This means that hydroelasticity is most prone to appear for structures having longer natural period. Consequently hydroelastic effects appear at lower impact velocity in case of flexible structures than for stiff structures. From the experimental point of view there are two main advantages when using wedges with a longer first natural period:

- experiments can be conduced at lower velocities

- deformations are larger and consequently easier to measure

For these reasons, wedges are designed as two panels rigidly connected only at the keel edge. All the others edges are free to deform.

\subsection{Specimens}

In the literature [28] it is shown that hydroelasticity is influenced by the ratio between the wetting time and the panel's lower natural frequency. To investigate this phenomena, different stiffness to area density ratios are needed. Thus, aluminium (A), E-glass (mat) / vinylester (V) and E-Glass (woven) / epoxy (W) panels of various thickness $(2 \mathrm{~mm}$ and $4 \mathrm{~mm}$ ) were used. All wedges are made by two panels $300 \mathrm{~mm}$ long, while two different width of $150 \mathrm{~mm}$ and $250 \mathrm{~mm}$ were used. Aluminium and Composite panels material properties are listed in table 2.1.

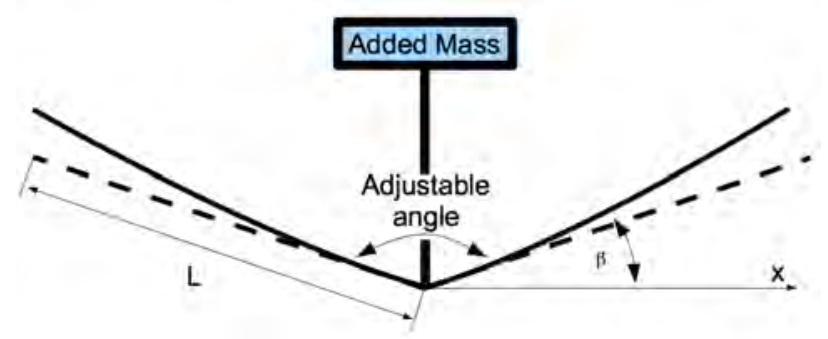

Figure 2.4: Conceptual scheme of the wedge used for experiments. $\mathrm{L}=$ panel length. $\beta=$ deadrise angle. Dashed line: undeformed panels, solid line: expected deformation during impact. 


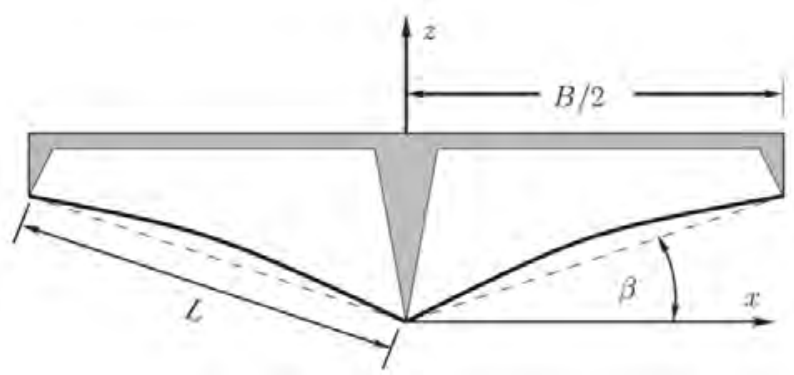

Figure 2.5: Sketch of a wedge clamped on two sides. Dashed line: initial configuration, solid line: expected deformation during impact.

Composite panels were produced by VARTM by infusion of vinylester resin on E-Glass fibre mat, while the E-glass (woven $0^{\circ} / 90^{\circ}$ ) $/$ epoxy panels were produced in autoclave.

Table 2.1: Plates material properties.

\begin{tabular}{|c|c|c|c|c|}
\hline Material & Abbr. & $E_{1}=E_{2}[G P a]$ & $\nu_{12}$ & $\rho\left[\mathrm{kg} / \mathrm{m}^{3}\right]$ \\
\hline $6068 \mathrm{~T} 6$ & $\mathrm{~A}$ & $68 \mathrm{GPa}$ & 0.32 & 2700 \\
E-Glass (mat)/Vinylester & $\mathrm{V}$ & $20.4 \mathrm{GPa}$ & 0.28 & 2050 \\
E-Glass (woven)/Epoxy & $\mathrm{W}$ & $30.3 \mathrm{GPa}$ & 0.28 & 2015 \\
\hline
\end{tabular}

All panels were equipped with two strain gauges per side, located at $25 \mathrm{~mm}$ and $120 \mathrm{~mm}$ from the reinforced tip, as shown in Figure 2.3. The reinforced tip is $27 \mathrm{~mm}$ long and is used to connect the two panels to the aluminium sledge.

The position of the strain gauges was chosen on the basis of a dry modal analysis: they were placed far from the nodes (referred to the deformation) of the first three mode shapes, whose frequencies are listed in Table 2.2. Note that the nodal position referred to the strains are not the same one of the modal shapes, as visible in Figure 2.6 . 

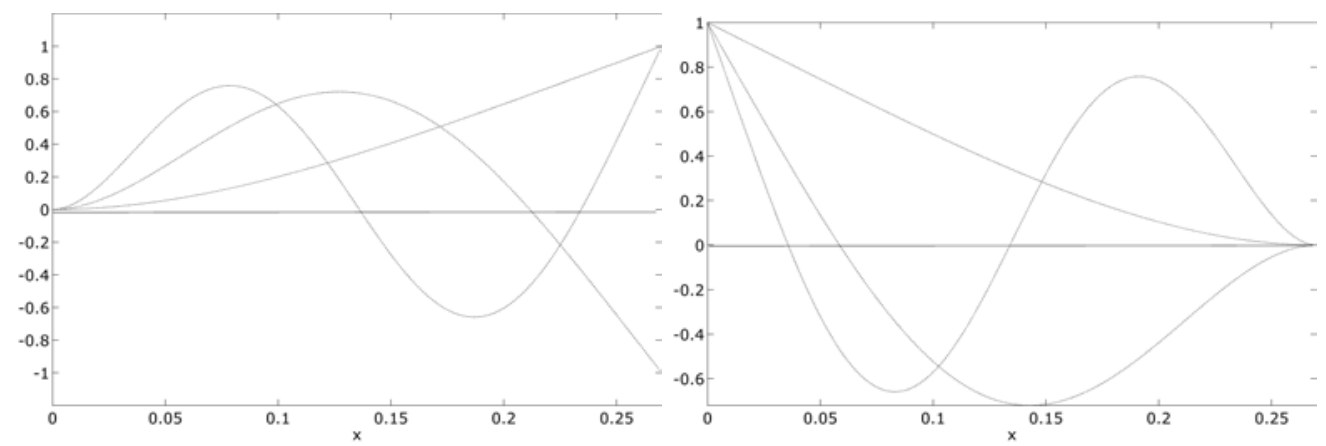

Figure 2.6: Nodal mode shapes of a dry panel (left) and relative deformation (right). The comparison of the two graphs shows that the position of the nodes is different. The location of the strain gauges was chosen as $25 \mathrm{~mm}$ and $120 \mathrm{~mm}$ from the wedge tip.

Table 2.2: First three dry natural frequencies of the panels used for experiments.

\begin{tabular}{|c|c|c|c|}
\hline Abbr. & Material & Thickness & $\omega_{1}, \omega_{2}, \omega_{3}[\mathrm{~Hz}]$ \\
\hline \hline A2 & Aluminium & $2 \mathrm{~mm}$ & 18.01112 .89316 .12 \\
\hline A4 & Aluminium & $4 \mathrm{~mm}$ & 36.03225 .79632 .24 \\
\hline \hline V2 & Fibreglass & $2.0 \mathrm{~mm}$ & 9.7761 .22171 .44 \\
\hline V4 & Fibreglass & $4.0 \mathrm{~mm}$ & 19.73123 .67346 .29 \\
\hline \hline W2 & Fibreglass & $2.2 \mathrm{~mm}$ & 19.69123 .40345 .54 \\
\hline W4 & Fibreglass & $4.4 \mathrm{~mm}$ & 37.80236 .94663 .44 \\
\hline
\end{tabular}


Chapter 3

\section{Experimental Results}

For each configuration of material, plate thickness, impact height and deadrise angle, experiments were repeated three times to guarantee the accuracy of the measures and to verify the repeatability of the tests. A total of more than 1200 experiments have been conducted, only a few of these results are presented in the main text. Further results are listed in the Appendix. Figures 3.1 and 3.2 show the results of a composite wedge (W2) with deadrise angle of $30^{\circ}$ for various impact velocities. The experimental results of the three tests show high repeatability both in terms of acceleration and stresses over time. The scatter on the maximum acceleration recorded during the three repetitions is below $\pm g$ for all the impact cases.
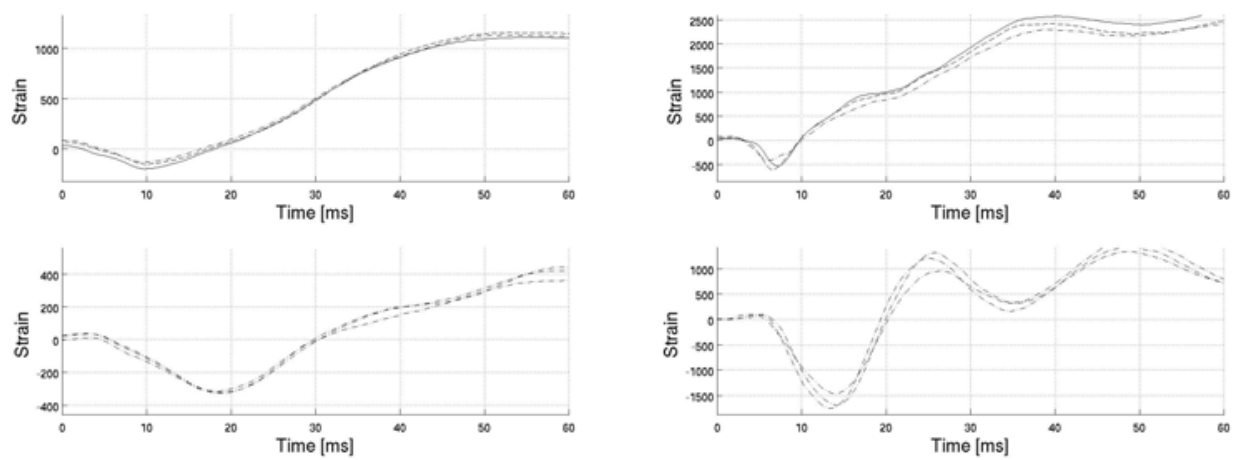

Figure 3.1: Example of a composite (W2) wedge, $2 \mathrm{~mm}$ thick, $\beta=30^{\circ}, V_{0}=2.77 \mathrm{~m} / \mathrm{s}$ (left) and $6.28 \mathrm{~m} / \mathrm{s}$ (right). Strain recorded at $25 \mathrm{~mm}$ (top) and $120 \mathrm{~mm}$ (bottom) from the wedge tip.

Figures 3.3 and 3.4 show the comparison of the acceleration between Von 

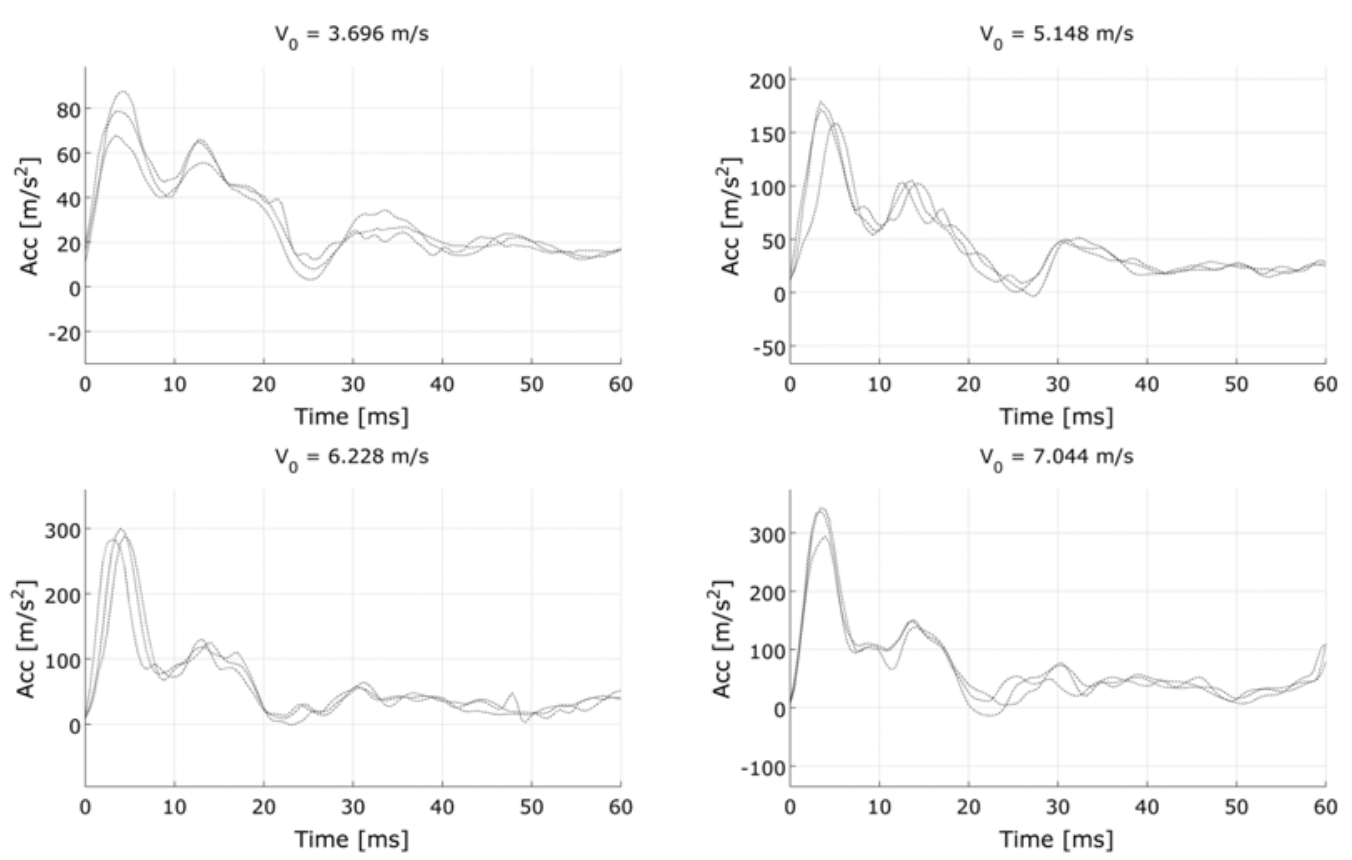

Figure 3.2: Repeatability of the water impacts of a wedge (W2) with deadrise angle $\beta=30^{\circ}$ entering the water at various impact velocities.

Karman's solution and the three repeated tests for a composite wedge (W2) of $\beta=20^{\circ}$ and $\beta=30^{\circ}$ entering the water at different velocities. Results show that in all cases Von Karman's formula is capable of predicting the maximum acceleration (thus the maximum impact force), although the time the maximum acceleration is reached is not the same one. In fact, while in Von Karman's model (as shown in section 1.1 the maximum force is reached at a time $t^{*}=\frac{16}{15} \frac{\tan (\beta)}{V_{0}} \sqrt{\frac{2 M}{5 \pi \rho \gamma^{2}}}$, during experiments the maximum impact force is rather reached always at the same time. Figure 3.5 shows the comparison between the analytical prediction of the time $t^{*}$ and the experimental results for composite wedges (W2) with deadrise angle of $30^{\circ}$ (left) and $20^{\circ}$ (right). 

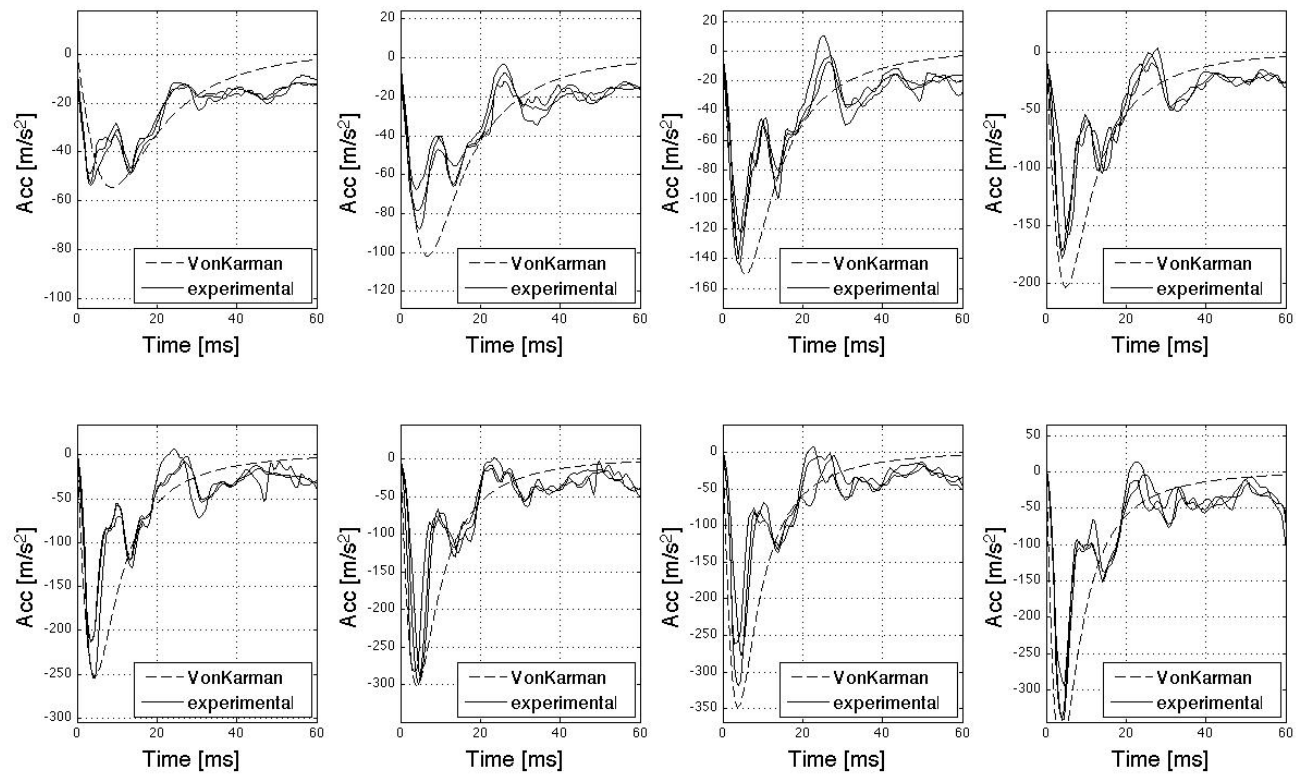

Figure 3.3: Comparison between Von Karman solution (dashed line) and recorded accelerations (solid lines) during the water impacts of a wedge (W2) with deadrise angle $\beta=30^{\circ}$ entering the water from various impact height (from left to right, top to bottom : $50 \mathrm{~cm}, 75 \mathrm{~cm}, 100 \mathrm{~cm}, 125 \mathrm{~cm}, 150 \mathrm{~cm}, 175 \mathrm{~cm}, 200 \mathrm{~cm}, 225 \mathrm{~cm}$ ). 

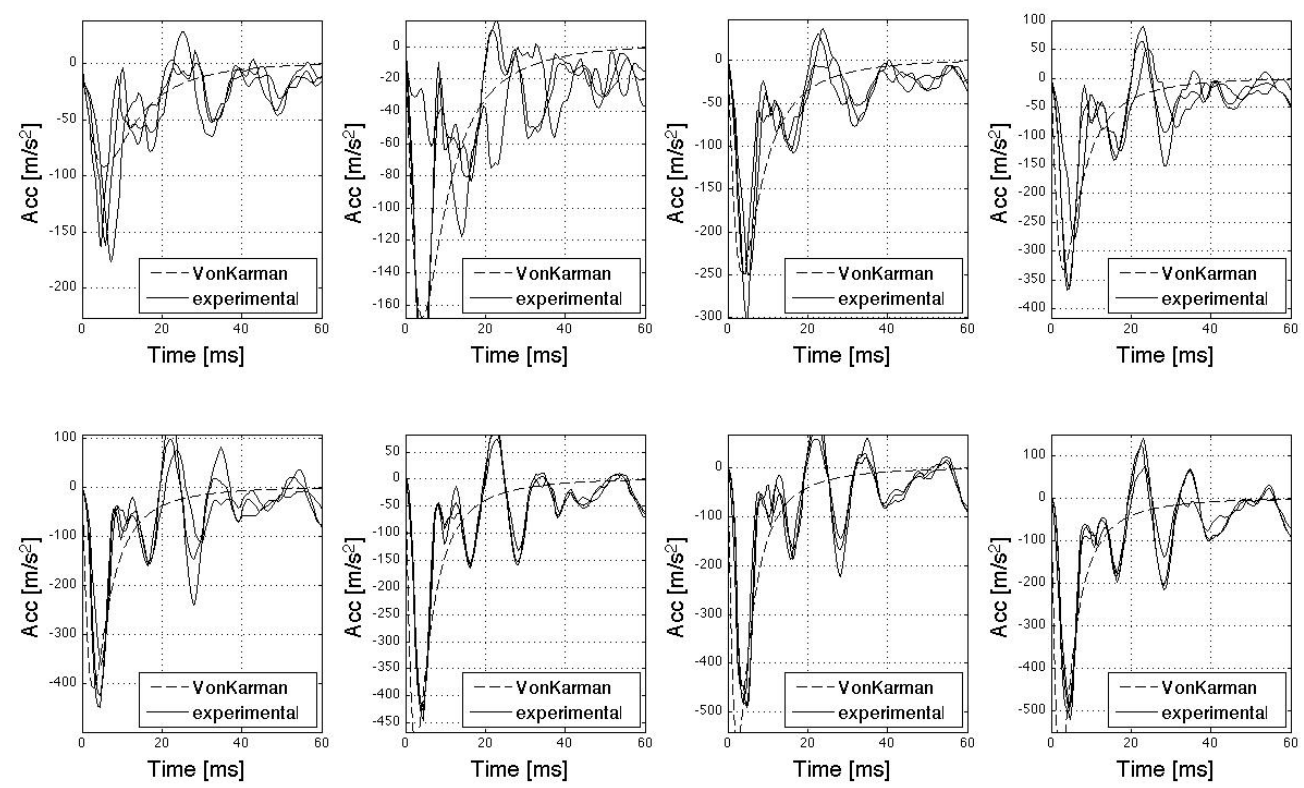

Figure 3.4: Comparison between Von Karman (dashed line) solution and recorded accelerations (solid lines) during the water impacts of a wedge (W2) with deadrise angle $\beta=20^{\circ}$ entering the water from various impact height (from left to right, top to bottom : $50 \mathrm{~cm}, 75 \mathrm{~cm}, 100 \mathrm{~cm}, 125 \mathrm{~cm}, 150 \mathrm{~cm}, 175 \mathrm{~cm}, 200 \mathrm{~cm}, 225 \mathrm{~cm}$ ).
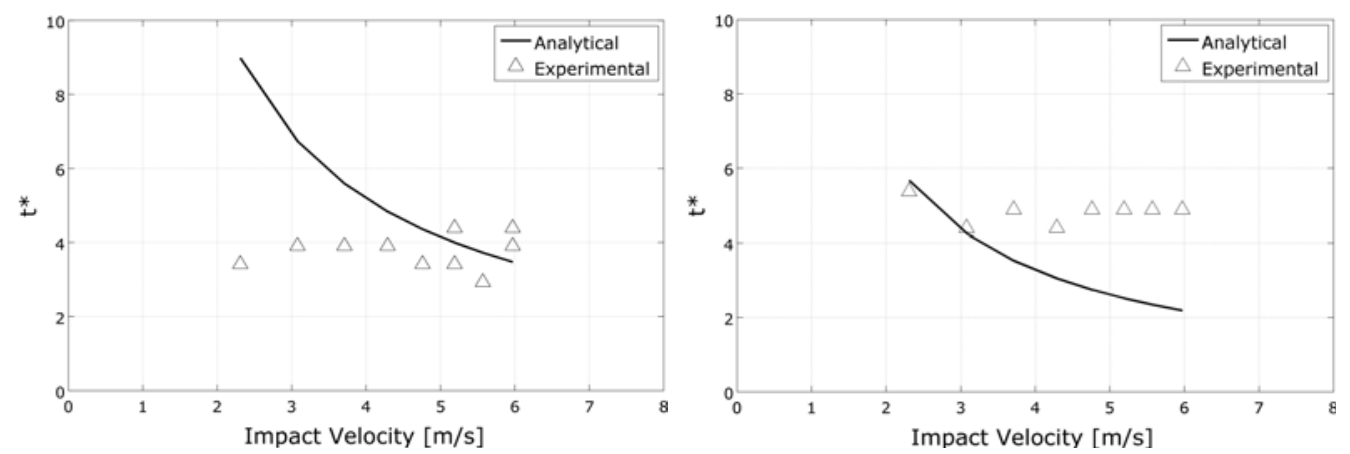

Figure 3.5: Comparison between the predicted time $t *$ and the experimental one for a composite wedges (W2) with deadrise angle of $30^{\circ}$ (left) and $20^{\circ}$ (right) 
Note that the maximum sampling frequency during experiments is $4 \mathrm{kHz}$, i.e the time history has a definition of $0.25 \mathrm{~ms}$. This definition corresponds to the maximum error on the evaluation of the beginning of the impact and of the instant of maximum acceleration. Consequently, the evaluation of $t *$ can be affected by an error of $\pm 0.5 \mathrm{~ms}$, which is evident in Figure 3.5 .
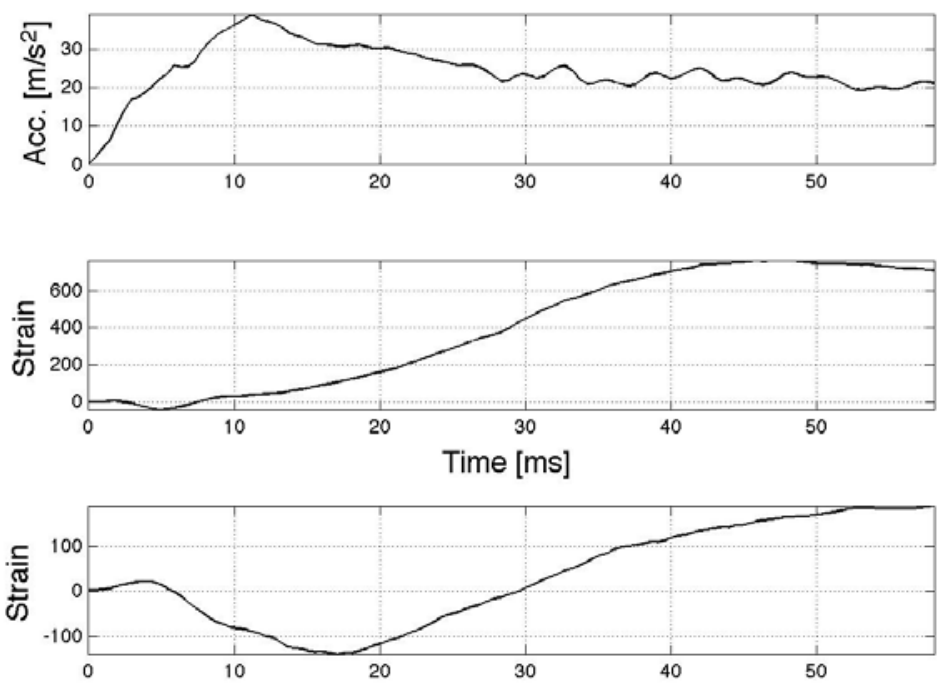

Figure 3.6: Experimental recorded acceleration and strains. Aluminium panel (A2), $\beta=35^{\circ}, V_{0}=2.7 \mathrm{~m} / \mathrm{s}$. Note that the acceleration (top) is smooth and the two strains (center and bottom) have the same shape and phase. The higher strain is recorded by the strain gauge close to the wedge tip (center).

Wedges of different stiffness to area mass ratio show different behavior in terms of deformations over time. Figure 3.6 shows the results of an aluminium wedge (A2) with deadrise angle of $35^{\circ}$ entering the water at $2.7 \mathrm{~m} / \mathrm{s}$; the signals of the two strain gauges show smooth shape and their trend is similar, suggesting that the first mode of vibration dominates the structural deformation. A different behavior is recorded in the case of a composite wedge (W2) with deadrise angle of $20^{\circ}$ impacting at $3 \mathrm{~m} / \mathrm{s}$ (Figure 3.7), where the deformation recorded by the strain gauges located at the center of the plate follows the overall trend recorded by the first strain gauge but marked oscillations appears, suggesting that more than one 

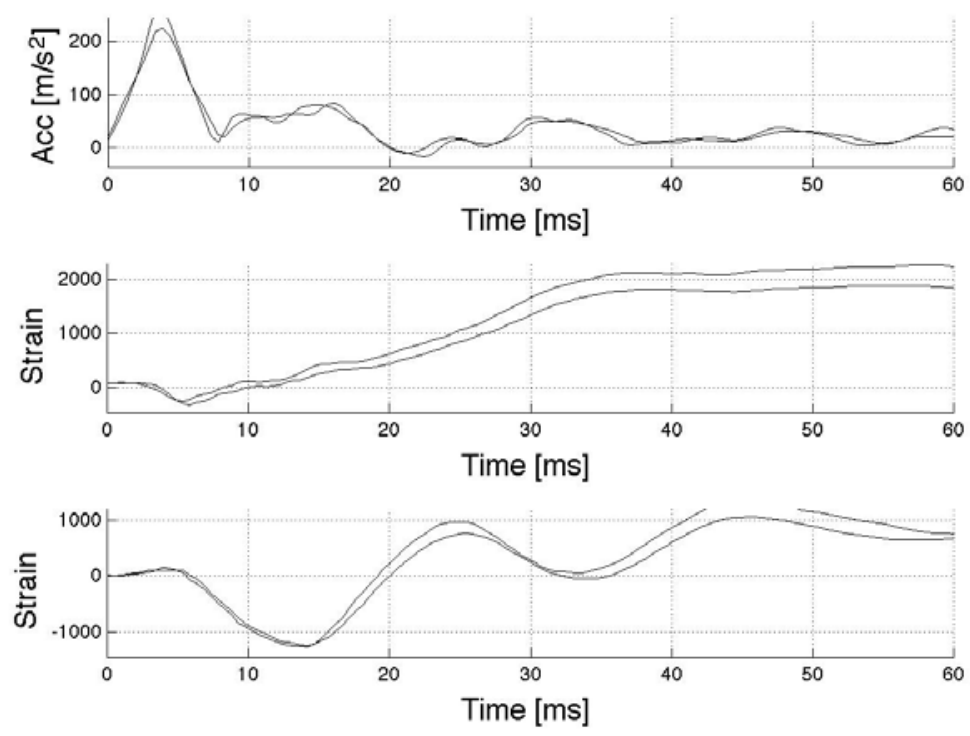

Figure 3.7: Experimental recorded acceleration and strains. Composite panel (W2), $\beta=20^{\circ}, V_{0}=3 \mathrm{~m} / \mathrm{s}$. In this case the acceleration (top) show high oscillations (compared to Von Karman solution, dashed line) and the strains (center and bottom) do not present the same behavior and have very different amplitude.

mode shape is excited. Furthermore, it was observed that the maximum strain is not always recorded by the strain gauge located at $25 \mathrm{~mm}$ from the wedge tip, but for the most severe impacts (higher velocity and lower deadrise angle) the maximum value is recorded by the strain gauge located at $120 \mathrm{~mm}$ from the wedge tip.

The effect of hydroelasticity can be better appreciated in the next graphs: Figures 3.8 and 3.11 show the recorded strains for a composite wedges (V2 and W2) with given deadrise angle presented as function of the drop height, while Figure 3.10 shows the recorded strains for an aluminium wedge $2 \mathrm{~mm}$ thick presented as function of the deadrise angle for a given impact velocity. The Figures show the transition from a single-mode dominated deformation in case of high deadrise angle (sharp wedge) and low impact velocity, to a multiple-mode dominated deformation when the structure flattens and the impact velocity increases. In fact, the overall strain presents a smooth (almost sinusoidal) shape in case of large deadrise angles 

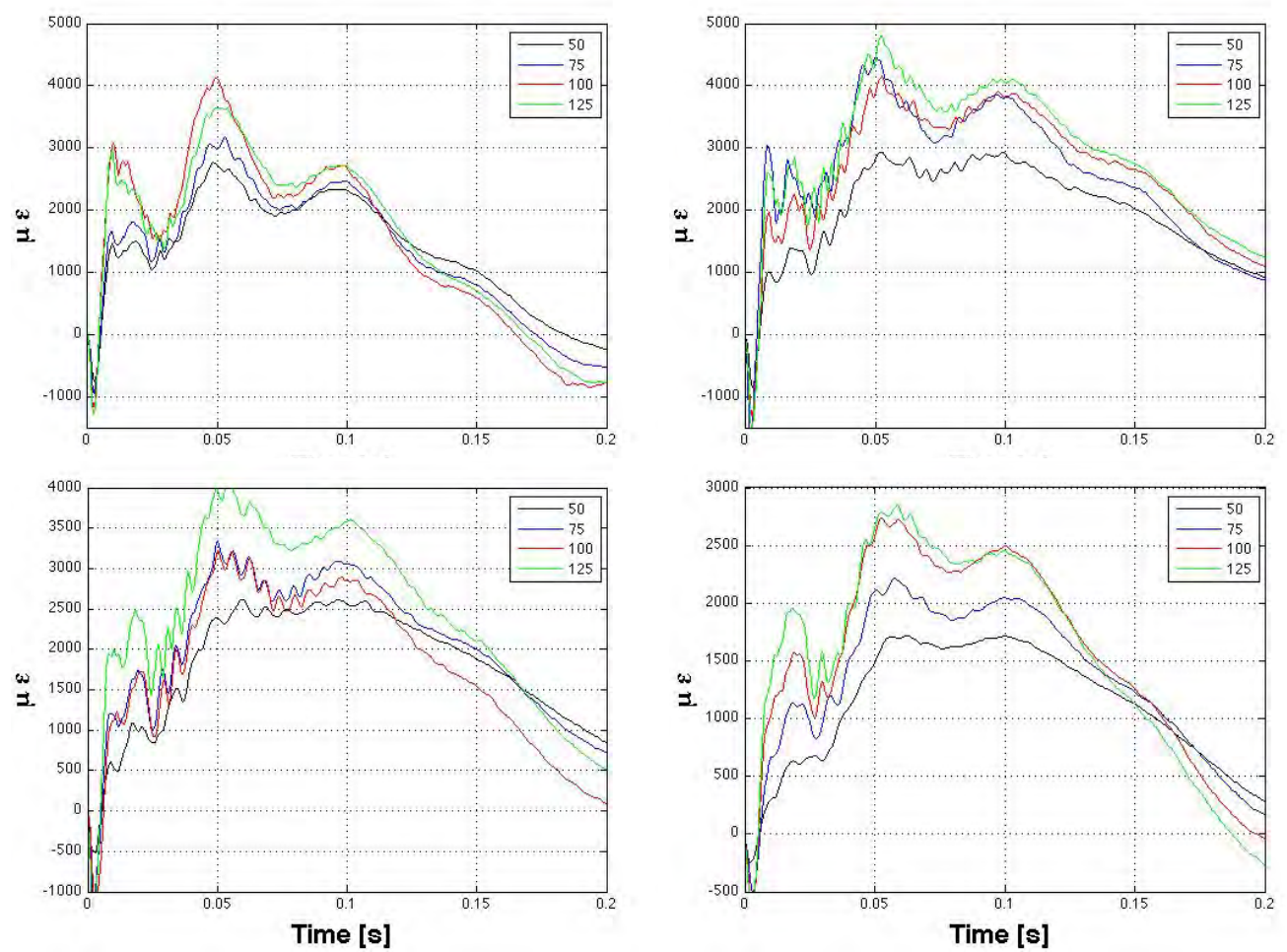

Figure 3.8: Experimental recorded strains for variable drop heights. Composite panel (V2), $2 \mathrm{~mm}$ thick. $\beta=10^{\circ}$ (top, left), $\beta=15^{\circ}$ (top, right), $\beta=20^{\circ}$ (bottom, left), $\beta=25^{\circ} \mathrm{m} / \mathrm{s}$ (bottom, right).
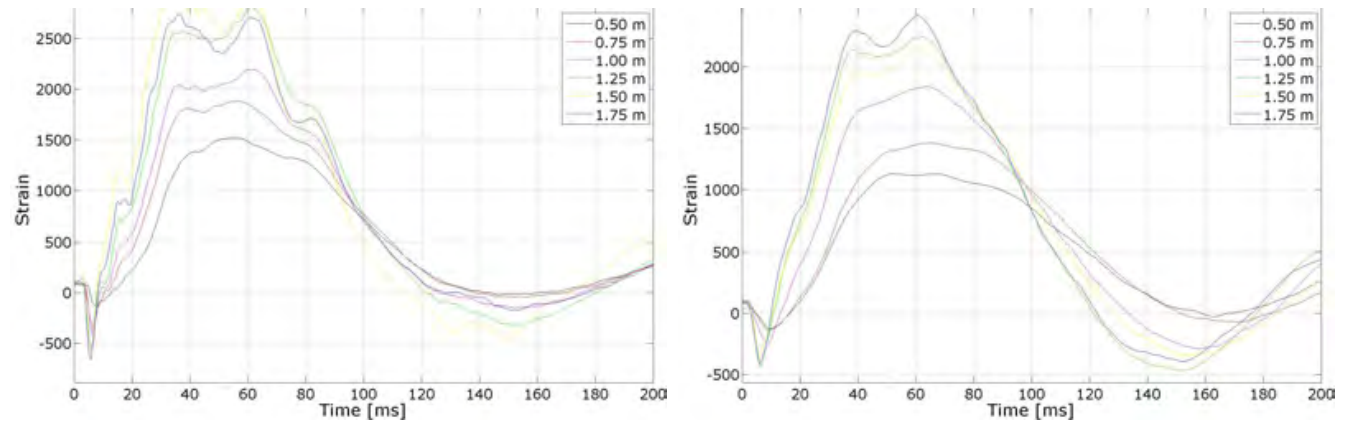

Figure 3.9: Experimental recorded strains for variable drop heights. Composite panel (V2), $2 \mathrm{~mm}$ thick. $\beta=20^{\circ}$ (left), $\beta=30^{\circ}$ (right).

and low impact velocities, while oscillations appear increasing the impact velocity and reducing the deadrise angle.

During all the impact tests, the structural deformation initially assumes neg- 

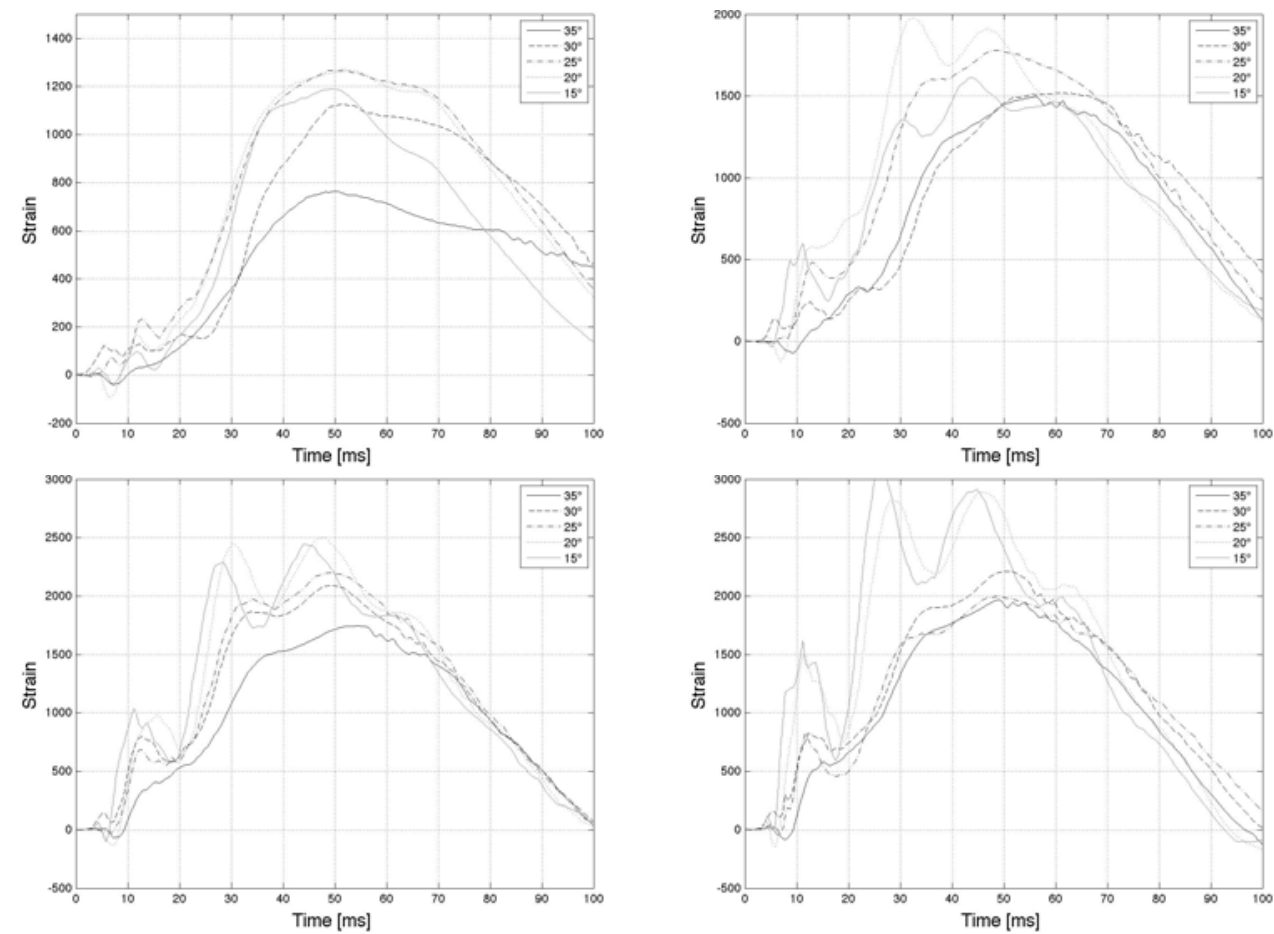

Figure 3.10: Experimental recorded strains for variable deadrise angle. Auminium Panel (A2), $2 \mathrm{~mm}$ thick. $V_{0}=3 \mathrm{~m} / \mathrm{s}$ (top, left), $V_{0}=4.2 \mathrm{~m} / \mathrm{s}$ (top, right), $V_{0}=5.2$ $\mathrm{m} / \mathrm{s}$ (bottom, left), $V_{0}=6 \mathrm{~m} / \mathrm{s}$ (bottom, right).
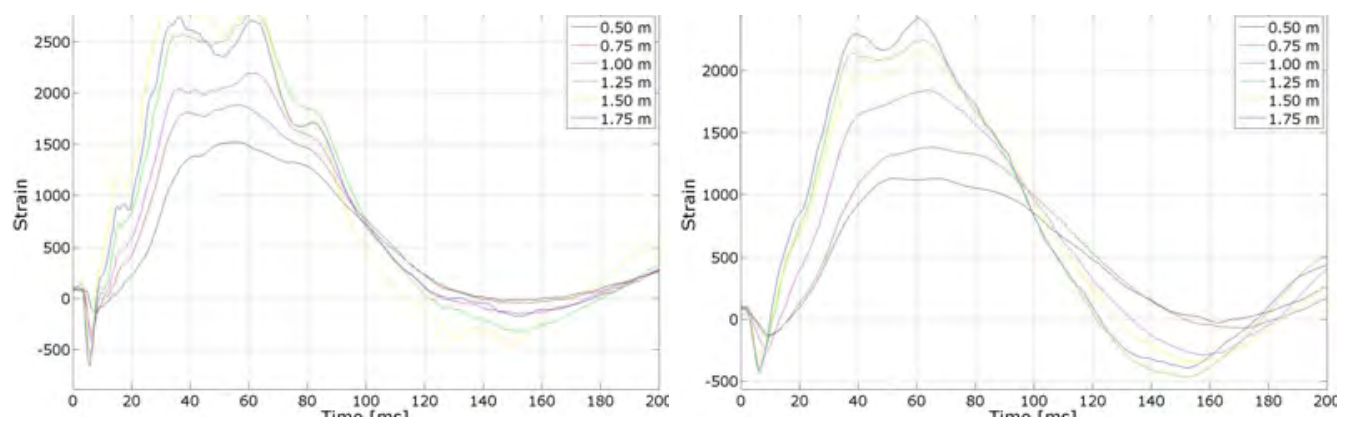

Figure 3.11: Experimental recorded strains for variable drop heights. Composite panel (W2), $2 \mathrm{~mm}$ thick. $\beta=20^{\circ}$ (left), $\beta=30^{\circ}$ (right)

ative values. This negative deformation is opposite to the one generated by the impact pressure and is due to the inertia of the panels that are being decelerated during the impact. The higher accelerations are reached close to the beginning of the impact and rapidly decrease. Thus, as the wedge enters the water, the defor- 
mation due to the hydrodynamic pressure exceeds the deformation due to inertia, leading the strains to assume positive values.

It was shown by Faltinsen [57] that hydroelasticity for the local slamminginduced stresses increases with decreasing deadrise angle $\beta$ and increasing the impact velocity $V$. Following a similar approach, it was defined a parameter $R$ as:

$$
R=\frac{\tan (\beta)}{\gamma V_{0}} \frac{h}{L^{2}} \sqrt{\frac{E M}{\rho}},
$$

which is similar to the one proposed by Faltinsen but it shows also the effect of the length $L$, thickness $h$, density of the material $\rho$, modulus of elasticity $E$ and total mass $M$ of the wedg $\Phi^{1}$

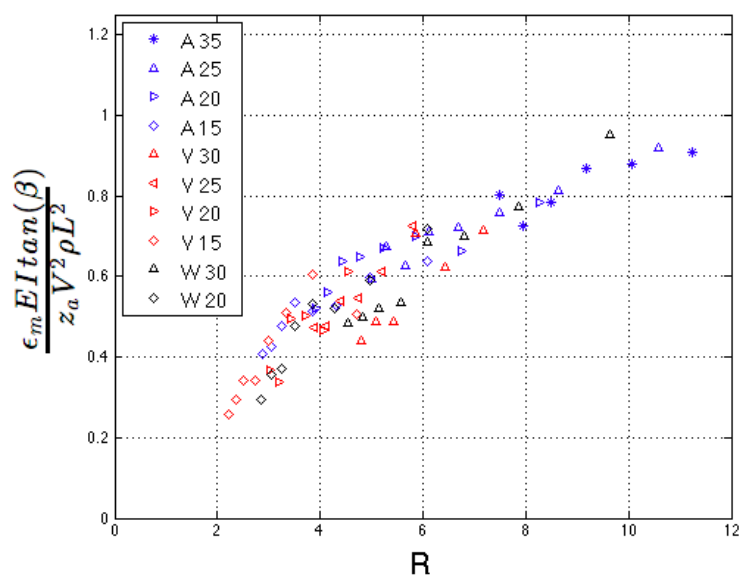

Figure 3.12: Nondimensional recorded maximum strain $\epsilon_{m}$, presented as a function of a parameter $R$. Where EI is the bending stiffness, $z_{a}$ is the thickness and $L$ is the panel length.

Figure 3.12 shows the nondimensional recorded maximum strain $\frac{\epsilon_{m} E \operatorname{Itan}(\beta)}{z_{a} V^{2} \rho L^{2}}$, as suggested in [57], as function of the parameter $R$. Results of various wedges are presented for variable impact velocity, deadrise angle and material (blue marks: aluminium, red marks: composite (V4) 4mm thick, black marks: composite (W2) $2 \mathrm{~mm}$ thick). It was found that hydroelastic effects (for the particular geometry studied) become important when the parameter $R$ is lower than 10 . In fact, in the

\footnotetext{
${ }^{1}$ The total mass of the wedge is an important parameter to consider since the mass of the sledge is higher than the panel's mass.
} 
range of $0<R<10$ the maximum strain is not proportional to $V^{2}$, as in quasisteady-pressure loading, but decreases as the parameter $\mathrm{R}$ decreases. These results are similar to the one found by Faltinsen [28, whose model however bases on the assumption of constant impact velocity and was not supported by experimental results. 


\section{Smoothed Particle Hydrodynamics (SPH)}

A coupled FEM and SPH formulation available in the commercial FE code LSDyna was used to model the water entry of elastic wedges. In the following it is shown how the fluid is modeled and the validation of the SPH method to correctly study water entry problems. First, the SPH model is validated and optimized by comparison with analytical and numerical examples of simple problems. Then, the optimized model is used to study water impacts of elastic structures, comparing the numerical results with experiments. Simulations were carried out with the commercial explicit nonlinear code LS-Dyna.

\subsection{Equation of state}

To model the fluid, an equation of state (EOS) needs to be defined in LS-Dyna. In the literature the most used EOS is the Gruneisen model [58 60], which follows the formula:

$$
p=\frac{\rho C^{2} \mu\left[1+\left(1-\frac{\gamma_{0}}{2}\right) \mu-\frac{a}{2} \mu^{2}\right]}{\left[1-\left(S_{1}-1\right) \mu-S_{2} \frac{\mu^{2}}{\mu+1}-S_{3} \frac{\mu^{3}}{(\mu+1)^{2}}\right]^{2}}+\left(\gamma_{0}+a \mu\right) E
$$

Where $\mu=\eta-1$ ( $\eta$ is the ratio between initial an final density), $C$ is the bulk speed of sound, $\rho$ is the density of the fluid. There are many combinations for the constant that satisfy the water behavior. In this work we used the values presented in table 4.1. values are taken from the literature [60].

By lowering the value of $C$ it is possible to reduce the bulk speed of sound. A reduction in the pressure waves speed leads to an increase of the minimum timestep 
Table 4.1: Gruneisen model constants for water.

\begin{tabular}{|c|c|c|c|c|c|c|c|}
\hline $\mathbf{C}[\mathrm{m} / \mathrm{s}]$ & $S_{1}$ & $S_{2}$ & $S_{3}$ & $\rho\left[\mathrm{kg} / \mathrm{m}^{3}\right]$ & $\gamma$ & $a$ & $E$ \\
\hline 1480 & 2.56 & 1.986 & 1.2268 & 1000 & 0.5 & 0 & 0 \\
\hline
\end{tabular}

needed for the solution and the consequent reduction of the computational time. Furthermore the travelling pressure waves take longer to reach the boundaries and get back to the impactor, it is consequently possible to build a model where there are no reflected pressure waves along the entire solution time. A common value used in the literature for the waves speed is $80 \mathrm{~m} / \mathrm{s}$. The main disadvantage of this trick is that, in case of slamming event, the quality of the impact dynamics get worse in terms of smoothness of acceleration and of the pressure distribution at the fluid/structure interface. As example, Figure 4.1 shows the the acceleration of a wedge entering the water at $4 \mathrm{~m} / \mathrm{s}$ varying the bulk speed of sound $(1480 \mathrm{~m} / \mathrm{s}$, $1000 \mathrm{~m} / \mathrm{s}$ and $80 \mathrm{~m} / \mathrm{s}$ ).

Figure 4.1: Acceleration response of a wedge entering the water varying the bulk speed of sound.

To avoid this loss of quality it is necessary to increment the number of elements, increasing the computational time. For these reasons we preferred to use the real pressure wave speed of $1480 \mathrm{~m} / \mathrm{s}$.

\subsection{Validation of the numerical model}

The so called Dam-break problem is often used in the literature as benchmark test to evaluate SPH accuracy. It consists in a two dimensional simulation of a water tank where a boundary is removed instantaneously to let the water to cover a larger tank ([48, 61 64]). Figure 4.2 shows the geometry, where $W=5.4 \mathrm{~m}$, $L=2 \mathrm{~m}$ and $H=1 \mathrm{~m}$. The fluid is modeled by 180000 particles and only the gravitational force is applied. Figure 4.3 shows the position of the front wave during time. Results about the water shape and the position of the surge front are in good agreement with those presented in the literature [48, 61,64]. However, while SPH seems to give accurate results for particles velocity and water flow, it seems not to 


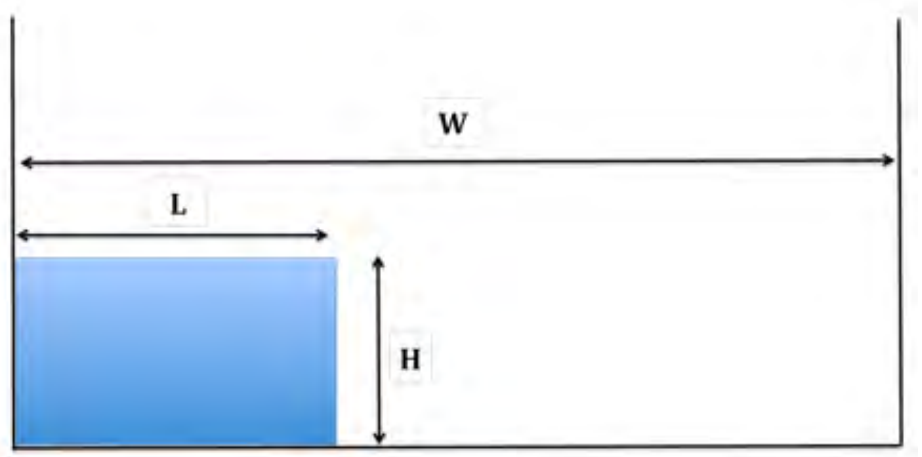

Figure 4.2: Dam-break geometry. The blue region is the fluid, initially at rest, whose right boundary is suddently removed to let the water occupy a larger tank. $H=$ initial water depth, $L=$ initial water length, $W=$ water tank length once the boundary is removed.

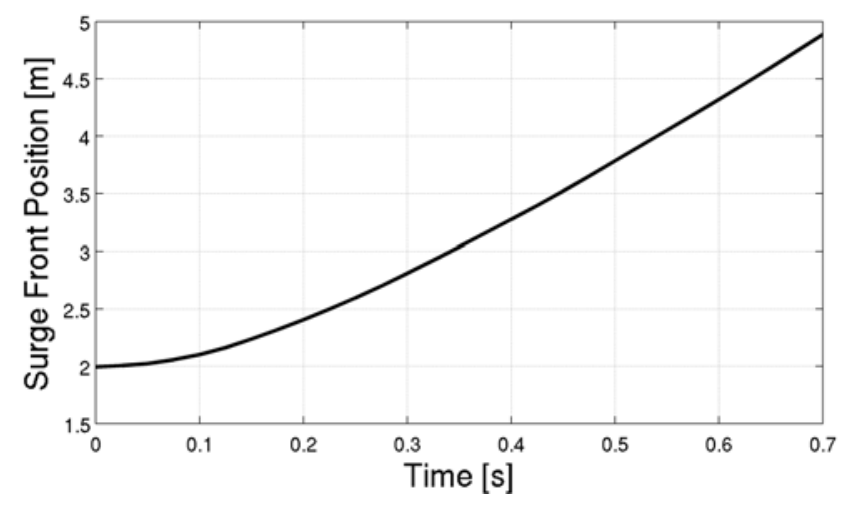

Figure 4.3: Numerical solution of the surge front position vs. time.

correctly account for the pressure field. In fact, as other numerical methods, SPH suffers noise in the pressure evaluation due to numerical fluctuations, leading to a poor definition of the pressure at the fluid/structure interface. This behavior is well known in the literature [65] and much effort is being spent on it. The most used technique to suppress these pressure fluctuations is the introduction of an artificial viscosity. Most of the work found in the literature focuses on the suppression of pressure oscillations in gases and solids $([66,68])$. To take into account the artificial viscosity [65, 69], an artificial viscous pressure term $q$ is added such that the 
pressure $p$ of the $i^{\text {th }}$ particle is computed as:

$$
p_{i}=p_{i}+q
$$

where

$$
q=\beta \cdot \rho \cdot h_{i} \cdot \dot{\epsilon}_{k k}^{2}-\alpha \cdot c_{0} \cdot \dot{\epsilon}_{k k}
$$

where $h_{i}$ is the minimum distance between the particles, $\alpha$ and $\beta$ are the linear and quadratic coefficients and $\dot{\epsilon}$ is the strain rate. For gases the linear and quadratic terms are usually in the range $\alpha=1.0 \div 4.0$ and $\beta=1.5 \div 2.0$, while for solids $\alpha=0.06$ and $\beta=1.5$. To study the influence of the artificial viscosity term for liquids, numerical results have been compared with an analytical solution.

The example considers a water column suddenly subjected to a uniform pressure load equal to $10 \mathrm{kPa}$ on the free surface. An analytical solution to this problem is found assuming that it is governed by the one dimensional wave equation. Boundaries are fixed. Figure 4.4 shows the Lagrange diagram, which is divided in five regions, namely 0, I, II, III and IV. In region 0 and IV the pressure is null, in region I and III the pressure equals the applied pulse and in region II the pressure is twice the applied pulse. The related stress history at the top, bottom and middle of the water column is presented in Figure 4.5. At the top, the pressure remains constant and obviously equals the applied pressure (black line). At the bottom (red line), pressure is zero until the first pressure wave reaches the boundary at time $1 / 2 t$, when the wave is entirely reflected and the pressure becomes twice the incident pulse. Once the reflected wave reaches the top, at the time $t$, a second pressure wave of intensity equal to the applied pressure, but negative, is generated. This second wave reaches the bottom at time $3 / 2 t$, it entirely reflects and the pressure at the bottom returns to zero. At the middle the pressure (blue line) turns from zero to the applied pressure at time $t / 4$, when the first wave pass through; the reflected wave arrives at time $3 t / 4$, switching the pressure to twice the applied pulse. The second (negative) wave arrives at $5 t / 4$, lowering the pressure again to the applied pressure, and the second reflected wave brings the pressure again to zero at time $7 t / 4$. In an ideal fluid this scheme continues infinitely with a period of $2 t$.

The travelling wave theoretically switches the pressure value instantaneously without transitions. This behavior is difficult to reproduce numerically, since there 

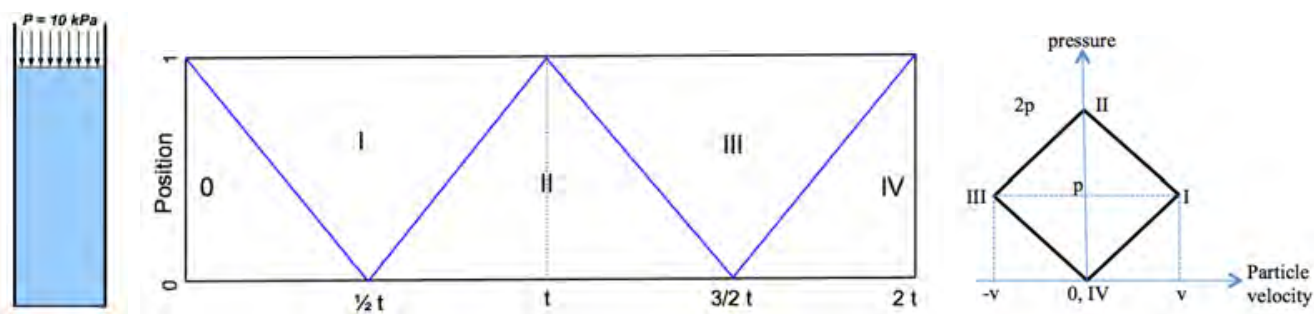

Figure 4.4: Left: sketch of the water column loaded at the free surface by a constant pressure. Center and right: Lagrange diagram. Analytical solution for the reflection of a pressure wave during time.

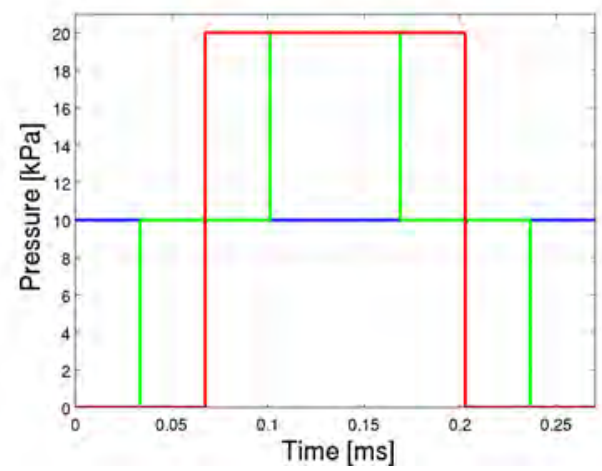

Figure 4.5: Analytical solution of the pressure due to a wave propagation at the top (blue line), middle (green line) and bottom (red line) of a water column.

is a transition between two different pressure regions which produces oscillations in the solution. This is known as Gibb's phenomenon and it occurs for most numerical methods unless some particular steps are taken to avoid it. These oscillations cannot be eliminated, but refining the particle size can reduce their duration and amplitude. Figure 4.6 shows the numerical results varying the linear bulk viscosity coefficient $\alpha$ of Eq. 4.2.2 (the quadratic term was found to have negligible effects) for a water column with particle spacing of $1 \mathrm{~mm}$. Artificial damping is effective for values as low as 0.2 , and numerical fluctuations are entirely smoothed out for values of $\alpha$ greater than 0.5 . On one hand we have seen that the introduction of the artificial viscosity term lowers the pressure oscillations, while on the other hand, in case of slamming problems, the impact dynamics is negatively affected: the higher the viscosity term, the higher the fluid resistance. Figure 4.7 shows 

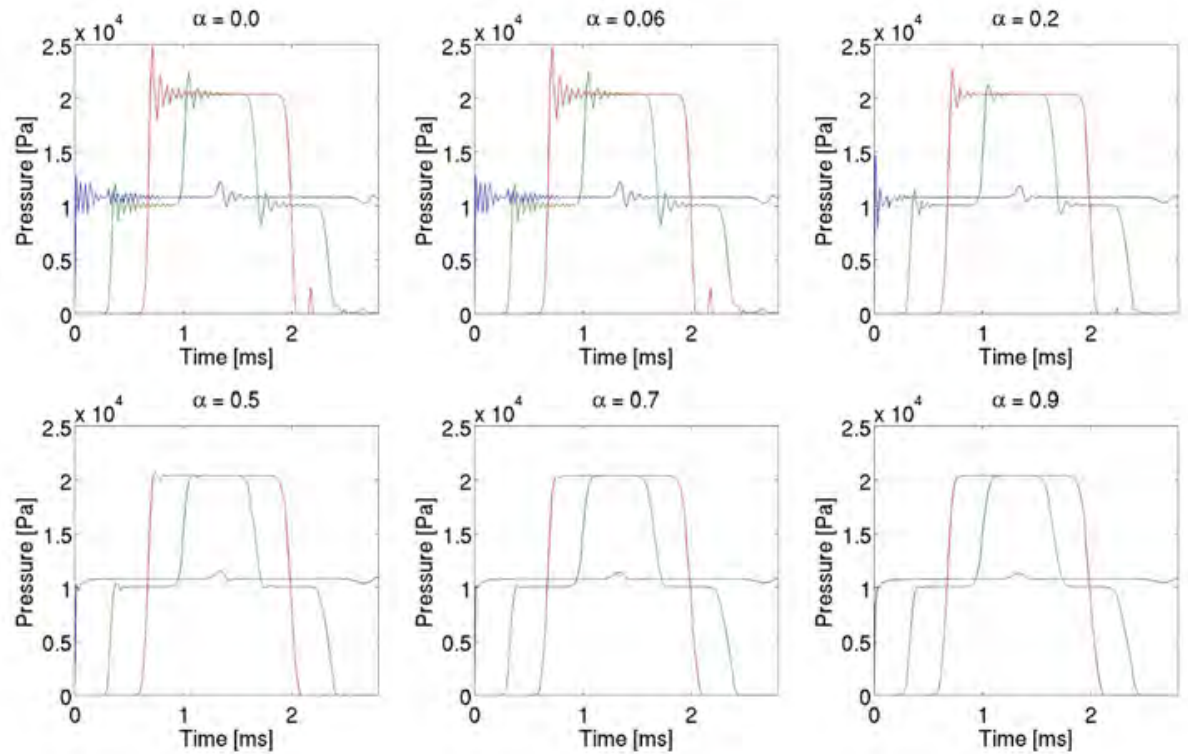

Figure 4.6: Numerical pressure fluctuation reduction varying the linear artificial viscosity coefficient. Blue line: Top, Green line: middle, Red line: bottom of the water column.
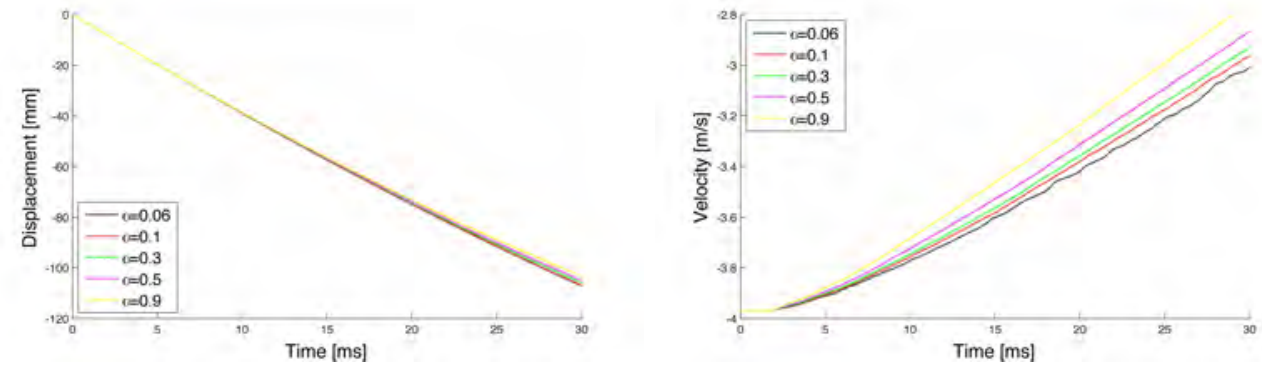

Figure 4.7: Displacement and velocity during slamming of a rigid wedge entering the water with an initial velocity of $4 \mathrm{~m} / \mathrm{s}$ varying the Bulk artificial viscosity term $\alpha$.

the displacement and velocity during a slamming event of a rigid wedge with a deadrise angle of $30^{\circ}$ entering the water with an initial velocity of $4 \mathrm{~m} / \mathrm{s}$ varying the bulk artificial viscosity term. The results show that the wedge decelerates more rapidly while the viscosity term increases, showing that $\alpha$ needs to be chosen as low as possible. For all the examples studied during this work $\alpha$ has been chosen 
to be lower than 0.2 .

\subsection{Non Reflecting Boundaries}

In case of impacts on wide water surfaces, these can be considered as infinite since there are no reflected pressure waves travelling back to the impacting body. On the contrary, numerical solutions are necessarily affected by these reflected pressure waves, since to reduce the computational time it is necessary to limit the fluid domain. One of the most used technique to suppress the reflected pressure waves is to lower the speed of sound in the fluid (usually it is lowered from 1480 $\mathrm{m} / \mathrm{s}$ to $80 \mathrm{~m} / \mathrm{s}$ ). As shown in section 4.1 , lowering the pressure waves speed permits to eliminate the reflected waves from the solution. However, since it is not always allowable to lower the sound speed, other techniques have to be used. In [70] Gong et al. proposed an improved boundary treatment capable to suppress the pressure waves reflection. They modelled the fluid with its real properties except for the last particles close to the boundary limits, whose sound speed has been reduced. This method presents the advantage of modeling the right fluid behavior together with the capability of entirely suppress the reflected pressure waves. Figure 4.8

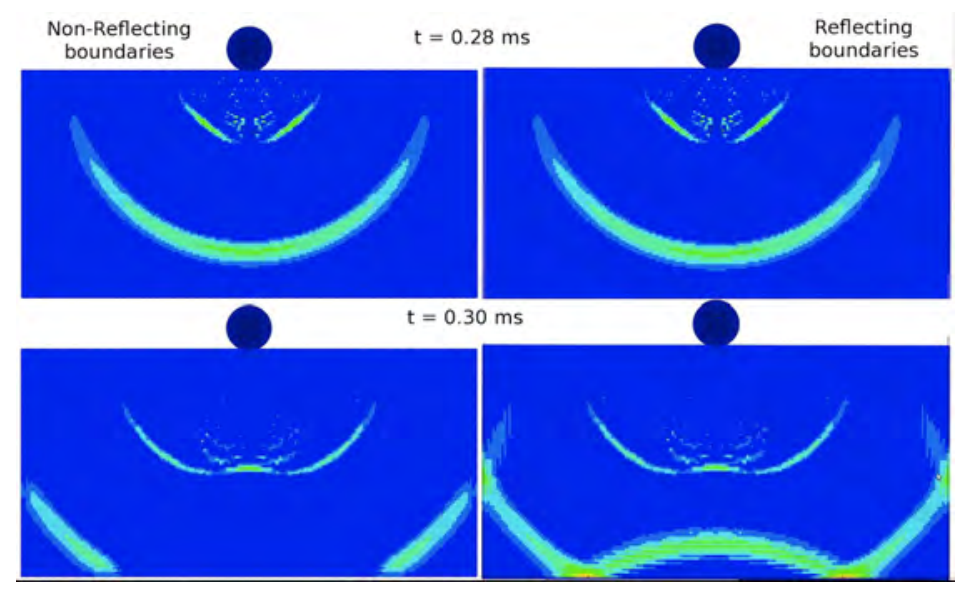

Figure 4.8: Position of a pressure wave generated by the water entry of a cylinder before and after it reaches the boundaries: Non-reflecting boundaries (left, the wave is absorbed) vs. rigid boundaries (right, the wave is reflected).

shows the effect of the non reflecting boundaries in the case of a wave generated 
by the water entry of a cylinder: the pictures on top show a cylindrical pressure wave moving from the top to the bottom that, after $2 \mathrm{~ms}$, is reflected in the case of rigid boundaries (on the right), while the non-reflecting boundaries (on the left) entirely absorbed it.

\subsection{Comparison with analytical models}

The optimized SPH model is now used to study the water entry of rigid wedges and its results will be compared with the analytical models presented in section 1.1. The numerical model bases on the following main assumptions:

1. the fluid free surface is initially at rest;

2. air is not included in the model. Air cushioning and air entrapment are consequently neglected;

3. the wedge is assumed infinite along the z-axis (3D boundary effects are not included);

4. the problem is symmetrical with respect to the zy plane (y is the gravity direction).

Figure 4.9 shows the SPH numerical results of the impact dynamics for rigid wedges of variable deadrise angle entering the water at $4 \mathrm{~m} / \mathrm{s}$. The numerical results show a good agreement with Von Karman's Solution (Figure 1.2) and Equations 1.1.2 1.1.6. The difference between the analytical an the numerical maximum impact force is always lower than $5 \%$ while the difference between the time the force peak is reached is lower than $15 \%$.

Figure 4.10 shows the comparison of the pressure along the wedge between Wagner's solution and the numerical results for a wedge entering the water at 4 $\mathrm{m} / \mathrm{s}$ with a deadrise angle of $30^{\circ}$ and a mass per unit width of $500 \mathrm{~kg} / \mathrm{m}$. SPH results were found to fit very well with Wagner's solution all over the time domain except for the very initial contact time, since there are too few elements in contact to show a smooth pressure distribution at the interface. The maximum pressure value is reached at the beginning of the impact, and is constant for a given entry velocity and deadrise angle, while mass is affecting only the impact dynamics. 

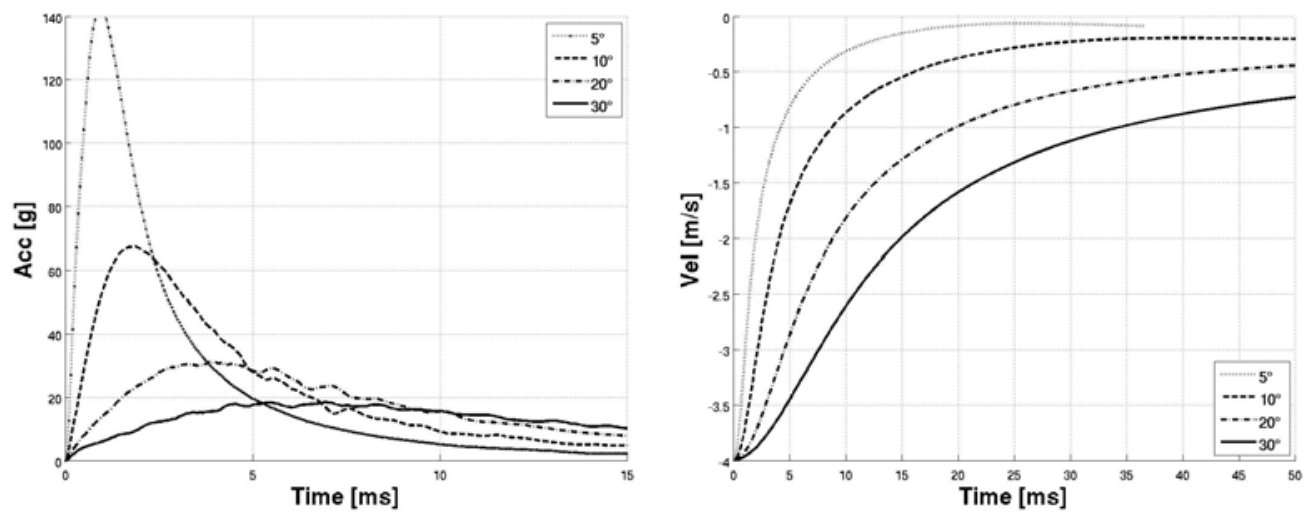

Figure 4.9: Acceleration and Velocity of a wedge varying the deadrise angle $\beta$. Total wedge mass: $20 \mathrm{~kg}$ per unit width. SPH simulations with rigid wedges.
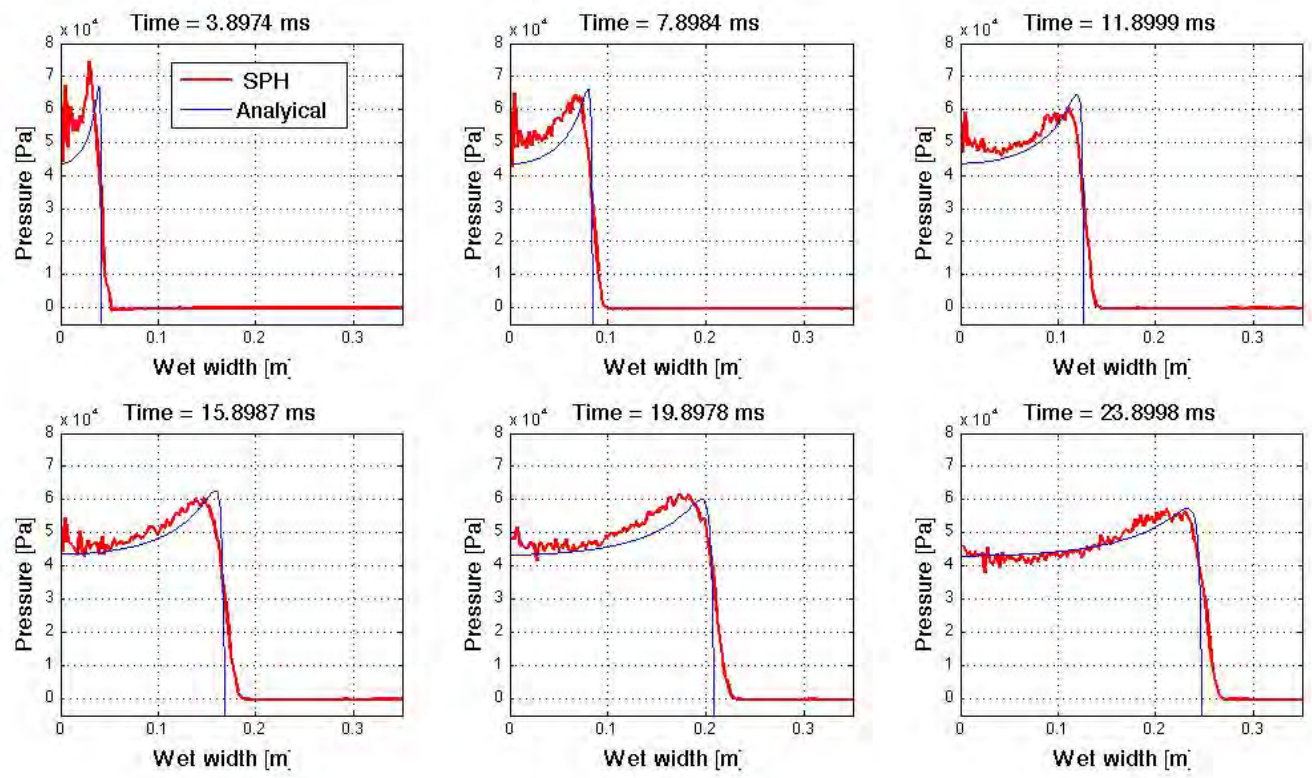

Figure 4.10: Pressure in time at the fluid/structure interface for a wedge of 500 $\mathrm{kg} / \mathrm{m}$, deadrise angle $30^{\circ}$ and initial velocity $V_{0}=4 \mathrm{~m} / \mathrm{s}$. Blue line: Wagner analytical solution. Red line: numerical results.

These results validate the SPH method and reveal that it is actually capable of predicting the impact dynamics and the pressure at the fluid/structure interface of rigid bodies entering the water. Thus, the SPH method will now be used for the 
analysis of water impacts of asymmetric structures and elastic structures, where analytical solutions are not available. 
Chapter 5

\section{Water entry of asymmetric wedges}

This chapter describes the effect of asymmetry on the impact dynamics and on the hydrodynamic pressure at the fluid/structure interface. Wedges are impacting with combined vertical and horizontal velocities and are not symmetric due to an initial tilt angle. As mentioned in the introduction, this kind of impacts might introduce ventilation in the fluid flow [7] due to fluid detachment at the wedge tip. A sketch of the problem is shown in Figure 5.1 a wedge with deadrise angle $\beta$ is impacting the water at the velocity $V_{0}$ and is rotated by a tilt angle $\beta_{t i l t}$ in respect to the water surface. The wedge is free to move horizontally and rotate during the

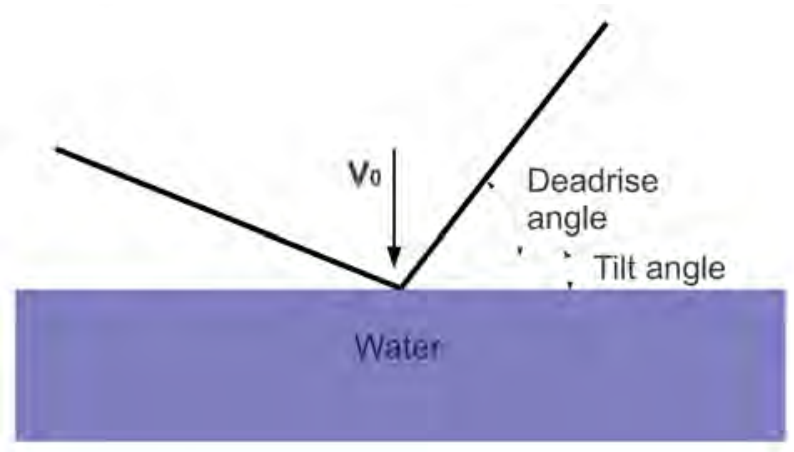

Figure 5.1: Sketch of the asymmetric wedge entering the water.

water entry. Both wedge's sides are $0.3 \mathrm{~m}$ long and the total mass equals $100 \mathrm{Kg}$ per unit width. In all the numerical solutions the fluid is modeled by 320000 particles equally spaced (with diameter of $0.25 \mathrm{~mm}$ ) covering a region $0.8 \mathrm{~m}$ wide and $0.2 \mathrm{~m}$ deep. The wedge is rigid and is composed by 100 elements per side, leading 
to an average of $4 S P H$ particles that get in contact with a single element in the wet region. The numerical results are recorded every $0.05 \mathrm{~ms}$, for a total solution time of $30 \mathrm{~ms}$.

\subsection{Asymmetric wedges with pure vertical velocity}

This section firstly proposes a simple adaption of Von Karman's formula to investigate the impact dynamics of asymmetric wedges. Later, the hydrodynamic pressure evaluated numerically will be compared with the Wagner's solution.

\subsubsection{Impact dynamics of asymmetric wedges}

The impact dynamics of the asymmetric wedge can be approximated by Von Karman's formula previous a correction of the added mass term: the flat disk approximation in case of asymmetric impact can be evaluated by:

$$
m=\rho \frac{\pi}{2}\left[\frac{1}{2}\left(\frac{\xi}{\tan \left(\beta_{0}+\beta_{t i l t}\right)}+\frac{\xi}{\tan \left(\beta_{0}-\beta_{t i l t}\right)}\right)\right]^{2} \gamma^{2} .
$$

This way, Von Karman's model for asymmetric impacts is given by equation 1.1.1. where the $\operatorname{term} \tan (\beta)$ is substituted by:

$$
\tan (\beta)=2 \frac{\tan \left(\beta_{0}+\beta_{t i l t}\right) \cdot \tan \left(\beta_{0}-\beta_{\text {tilt }}\right)}{\tan \left(\beta_{0}+\beta_{\text {tilt }}\right)+\tan \left(\beta_{0}-\beta_{\text {tilt }}\right)}
$$

The introduction of this term is necessary to better predict the added mass in the asymmetric condition. The comparison between analytical and numerical results shows good match until the maximum acceleration is reached, to later assume a slightly different behavior, probably due to the tilt motion that is not accounted in the analytical model (the analytical solution tends to overestimate the acceleration after the maximum value is reached). As title of example, figures 5.2 to 5.5 show the comparison between the numerical results and the analytical solutions for wedges with various tilt angles and entry velocities.

In the next section it will be investigated if Wagner's method is capable to predict the hydrodynamic pressure also in case of asymmetric impacts. Although Von Karman's method is found to match pretty well with the numerical results (at least until the maximum impact force is reached), in the next section the 

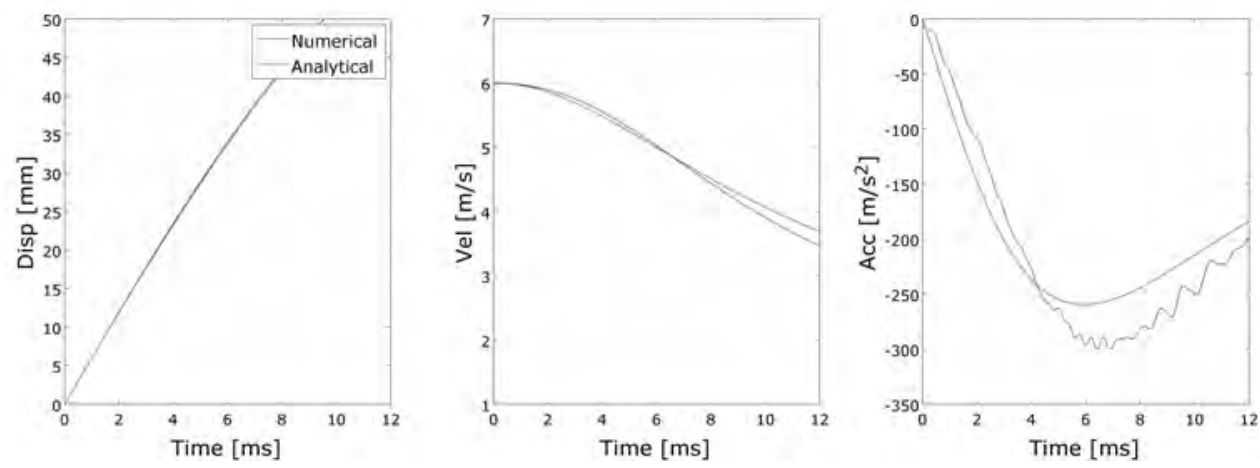

Figure 5.2: Impact dynamics of an asymmetric wedge entering the water at $6 \mathrm{~m} / \mathrm{s}$. Deadrise angle $\beta=25^{\circ}$, tilt angle $5^{\circ}$.
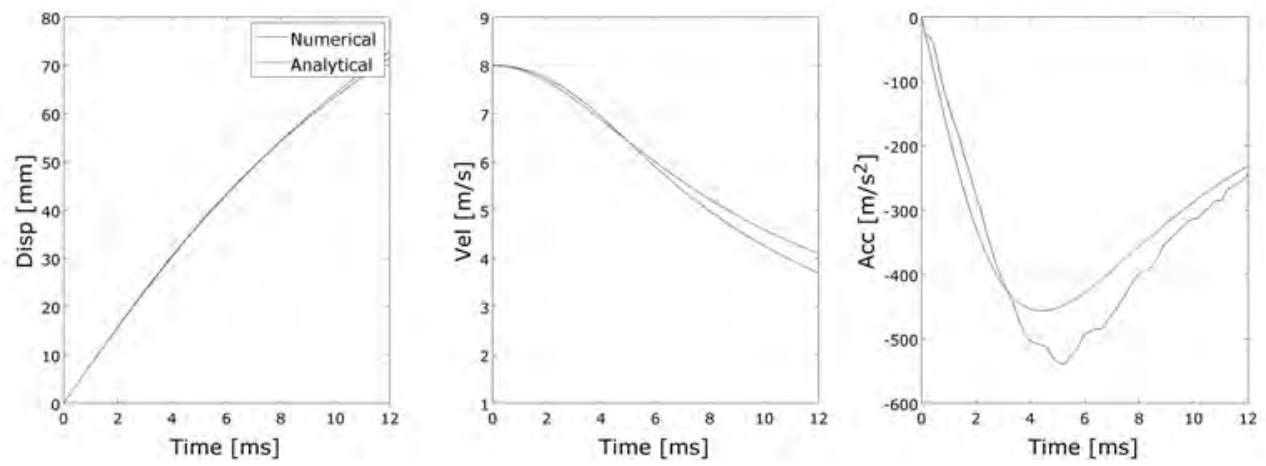

Figure 5.3: Impact dynamics of an asymmetric wedge entering the water at $8 \mathrm{~m} / \mathrm{s}$. Deadrise angle $\beta=25^{\circ}$, tilt angle $5^{\circ}$.
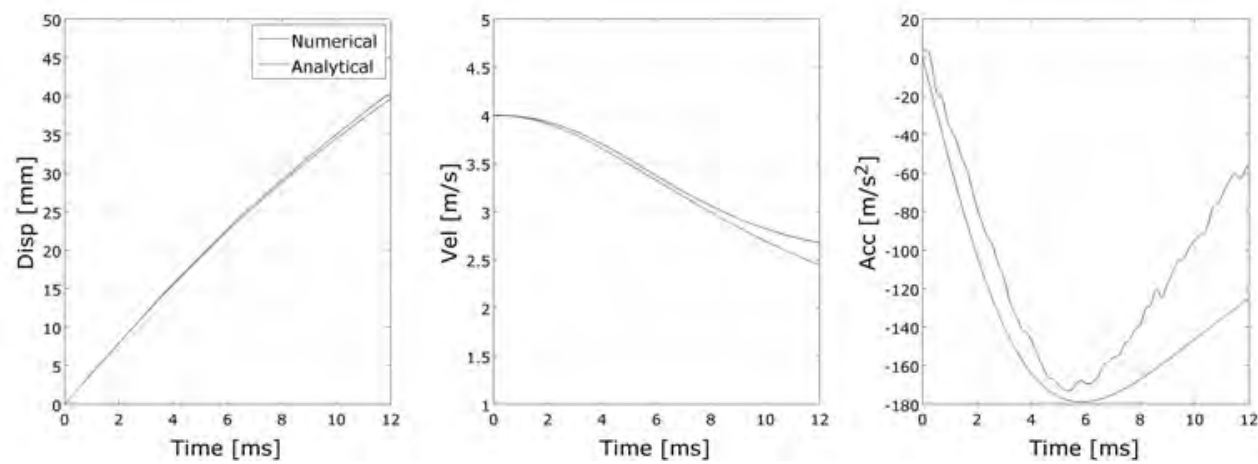

Figure 5.4: Impact dynamics of an asymmetric wedge entering the water at $4 \mathrm{~m} / \mathrm{s}$. Deadrise angle $\beta=25^{\circ}$, tilt angle $15^{\circ}$. 

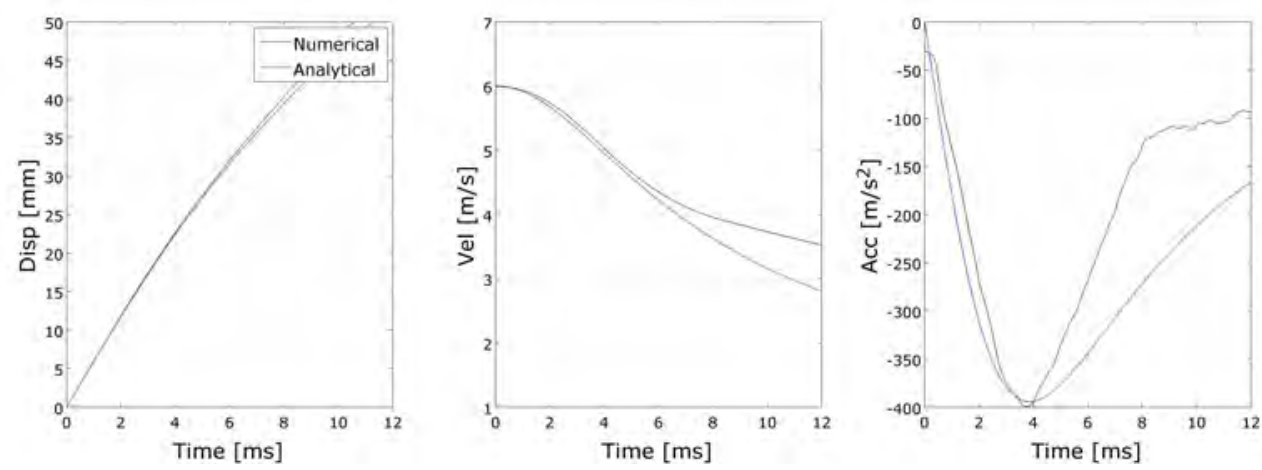

Figure 5.5: Impact dynamics of an asymmetric wedge entering the water at $6 \mathrm{~m} / \mathrm{s}$. Deadrise angle $\beta=25^{\circ}$, tilt angle $15^{\circ}$.

numerically evaluated impact dynamics will be used for the solution of Wagner's formula.

\subsubsection{Hydrodynamic pressure}

Wagner's method is now used to evaluate the pressure at the interface in the case of asymmetric impacts. The analytical formulation considers the wedge to have no tilt motion and pure vertical velocity; the impact time histories (displacement, velocity and acceleration) are taken from the numerical solution and are evaluated at the wedge tip. The wedge is considered to have constant deadrise angle equal to $\beta_{0}-\beta_{\text {tilt }}$ on the left side and $\beta_{0}+\beta_{\text {tilt }}$ on the right side.

Figures 5.6 and 5.7 show the pressure at the fluid/structure interface of a wedge with deadrise angle $\beta=25^{\circ}$ entering the water with a tilt angle of $5^{\circ}$ and initial velocity of $6 \mathrm{~m} / \mathrm{s}$ and $8 \mathrm{~m} / \mathrm{s}$.

Figures 5.8 to 5.10 show the pressure at the fluid/structure interface of a wedge with deadrise angle $\beta=25^{\circ}$ entering the water with a tilt angle of $15^{\circ}$ and initial velocity of $2 \mathrm{~m} / \mathrm{s}, 4 \mathrm{~m} / \mathrm{s}$ and $6 \mathrm{~m} / \mathrm{s}$. In all cases the hydrodynamic pressure on the side with lower deadrise angle compares well with Wagner's method both in terms of maximum impact pressure and overall pressure distribution on the wedge. On the face with higher deadrise angle the numerical results present slightly higher values than the one predicted by Wagner's method. It is possible that the hydrodynamic load is increased on this side due to the tilt motion during 

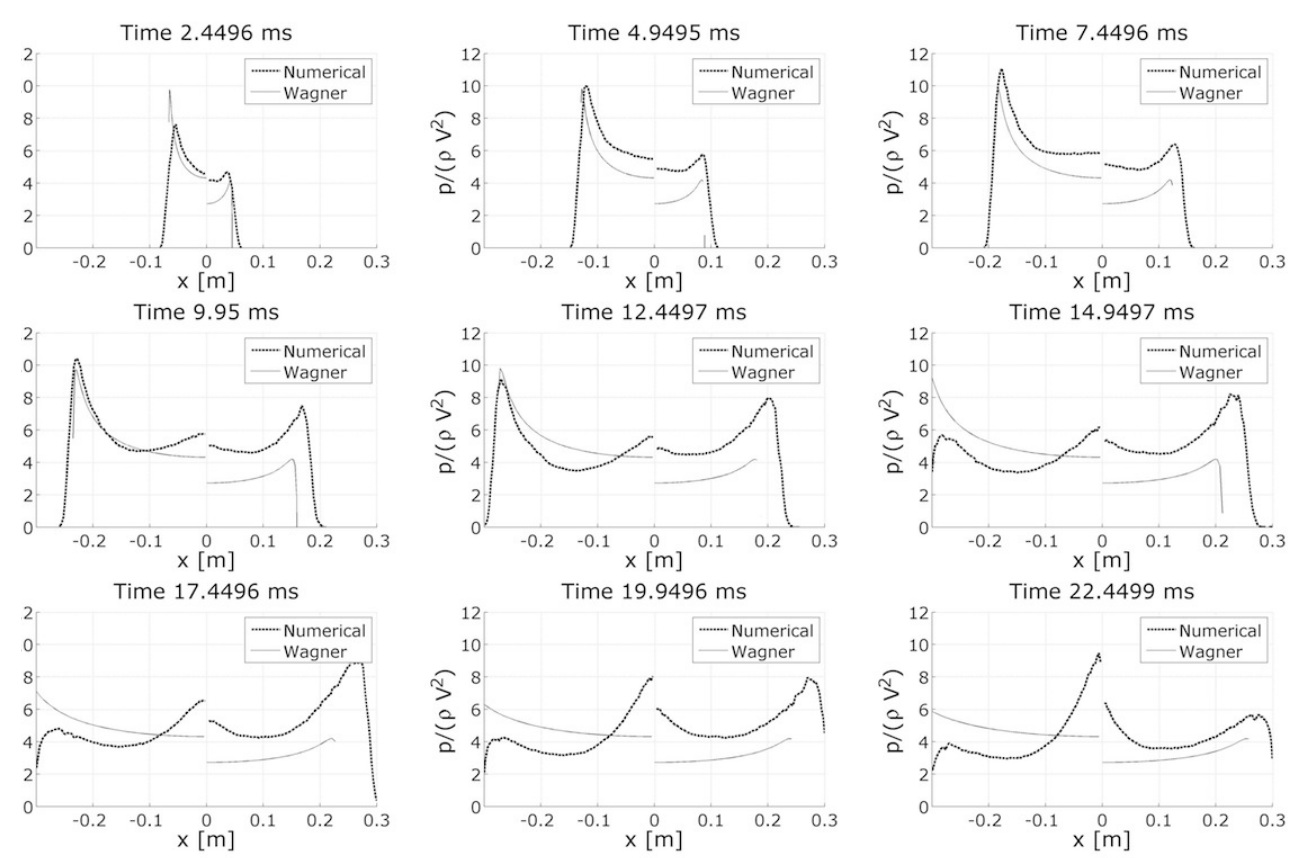

Figure 5.6: Asymmetric wedge entering the water at $6 \mathrm{~m} / \mathrm{s}$. Deadrise angle $\beta=25^{\circ}$, tilt angle $5^{\circ}$.

the impact. However, the magnitude of the pressure is always lower than on the other side. Thus, the face supporting the higher hydrodynamic load is always the one with lower deadrise angle. The difference between the numerically and the analytically evaluated pressure increases during the impact and is caused by the variation of the deadrise angle due to the tilt motion (e.g. see figures 5.8 to 5.10 . However, due to the inertia of the wedge, the maximum impact pressure has been reached when the tilt motion of the wedge is still negligible.

Once one face is completely wet (e.g at $\approx 15 \mathrm{~ms}$ in figure 5.6 and $\approx 11 \mathrm{~ms}$ in figure 5.7 the pressure distribution does not follows its classical shape any more: the maximum pressure is now located at the keel (on the left side), while the right face of the wedge is now carrying a higher hydrodynamic load, which, however, is lower than the maximum load experienced by the left side.

These results show that an eventual asymmetry during the water impact does not have remarkable effect on the impact dynamics, on the maximum impact force, or on the overall hydrodynamic pressure. This means that the experimental results 

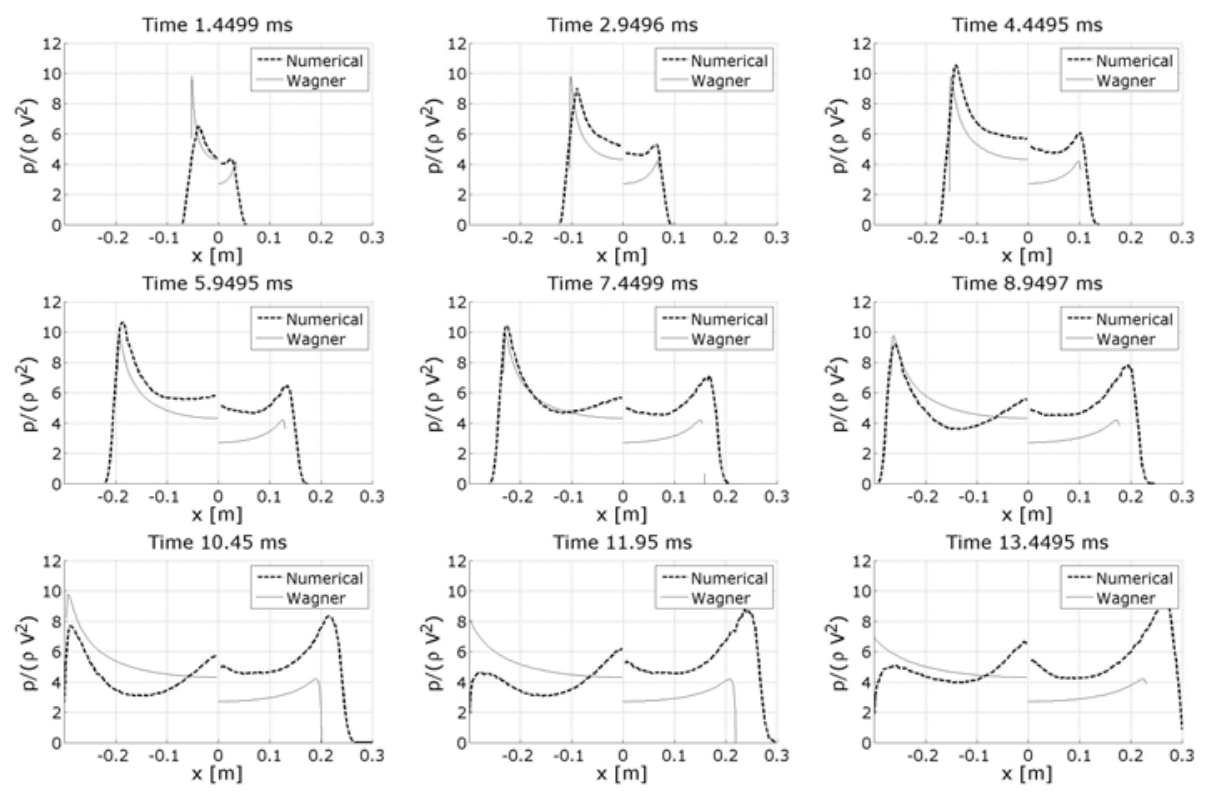

Figure 5.7: Asymmetric wedge entering the water at $8 \mathrm{~m} / \mathrm{s}$. Deadrise angle $\beta=25^{\circ}$, tilt angle $5^{\circ}$.

obtained for the water entry of symmetric wedges can be generalized to the water entry of asymmetric wedges as well.

The next section presents some numerical solutions for asymmetric wedges entering the water with combined vertical and horizontal velocity to investigate if there is an influence of the horizontal component on the hydrodynamic pressure. 

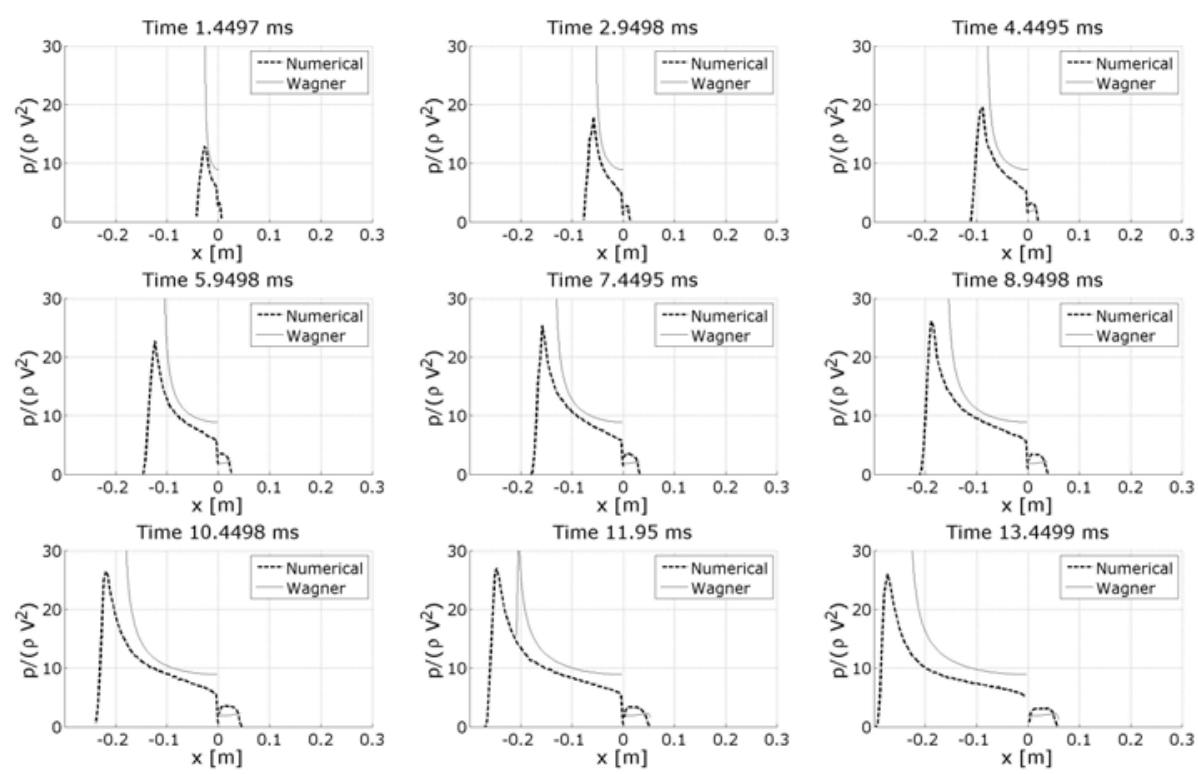

Figure 5.8: Asymmetric wedge entering the water at $2 \mathrm{~m} / \mathrm{s}$. Deadrise angle $\beta=25^{\circ}$, tilt angle $15^{\circ}$.
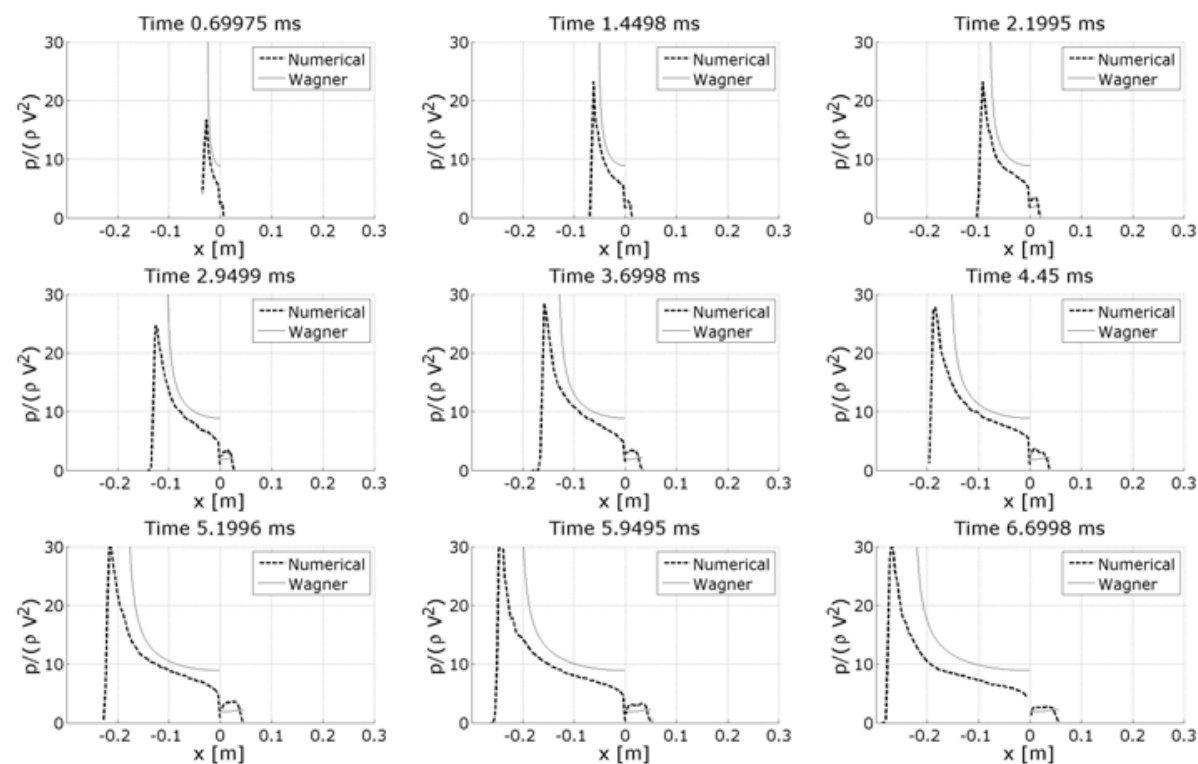

Figure 5.9: Asymmetric wedge entering the water at $4 \mathrm{~m} / \mathrm{s}$. Deadrise angle $\beta=25^{\circ}$, tilt angle $15^{\circ}$. 

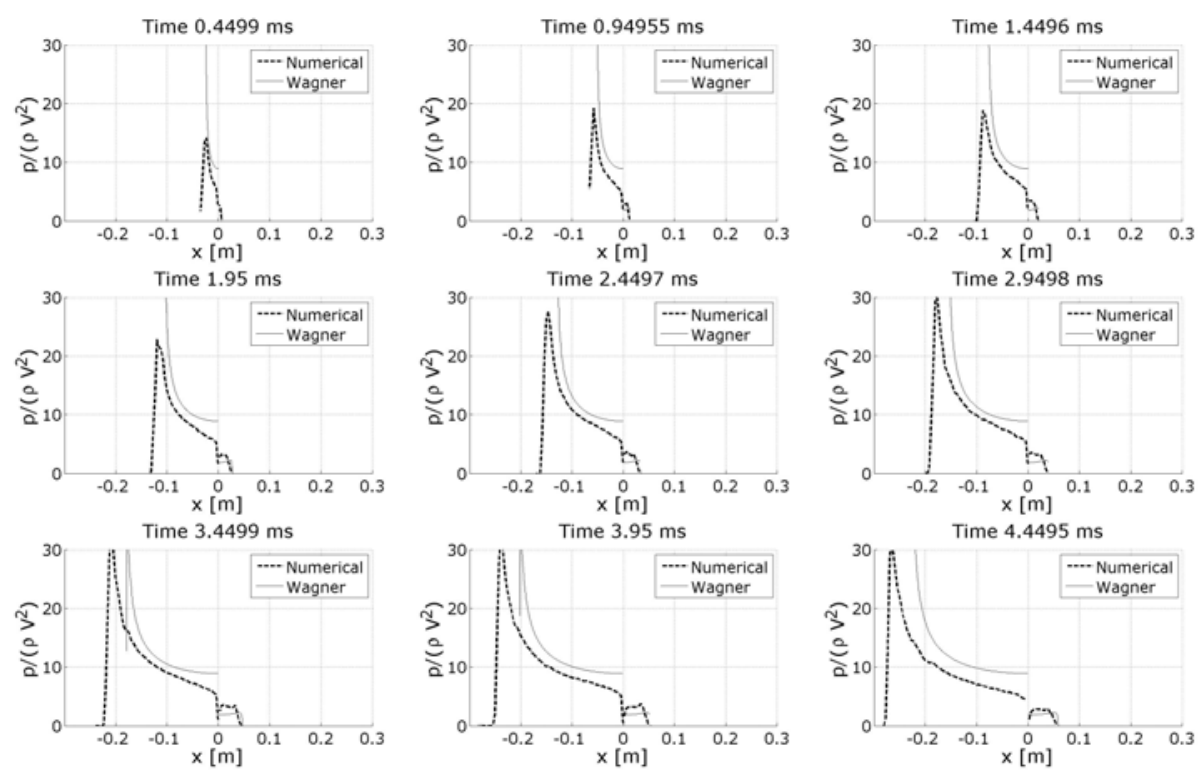

Figure 5.10: Asymmetric wedge entering the water at $6 \mathrm{~m} / \mathrm{s}$. Deadrise angle $\beta=25^{\circ}$, tilt angle $15^{\circ}$. 


\subsection{Asymmetric wedges with horizontal velocity component}

In this section, asymmetric wedges with combined vertical and horizontal impact velocity are presented. The objective is to evaluate the effect of the horizontal component on the hydrodynamic pressure. The problem is the same one presented in figure 5.1 but an horizontal component of the velocity is added. The horizontal velocity is in the same direction of the tilt angle (left direction in figure 5.1). As done in the previous analysis, in the analytical model the wedge is not tilting during the impact. The penetration is evaluated as the vertical displacement of the wedge tip, while different instantaneous velocities need to be be considered for the left and the right faces: the vertical impact velocity must be scaled by the parameters $\cos \left(\arctan \frac{V_{x}}{V_{y}}\right)$ on the right side (opposite to the direction of the horizontal velocity component) and $\frac{1}{\cos \left(\arctan \frac{V_{x}}{V_{y}}\right)}$ on the left side.

Figure 5.11 shows the comparison of the numerical and analytical results of a wedge with deadrise angle of $25^{\circ}$ and tilt angle of $15^{\circ}$ entering the water with vertical velocity $v_{y}=4 \mathrm{~m} / \mathrm{s}$ and horizontal velocity $v_{x}=2 \mathrm{~m} / \mathrm{s}$.
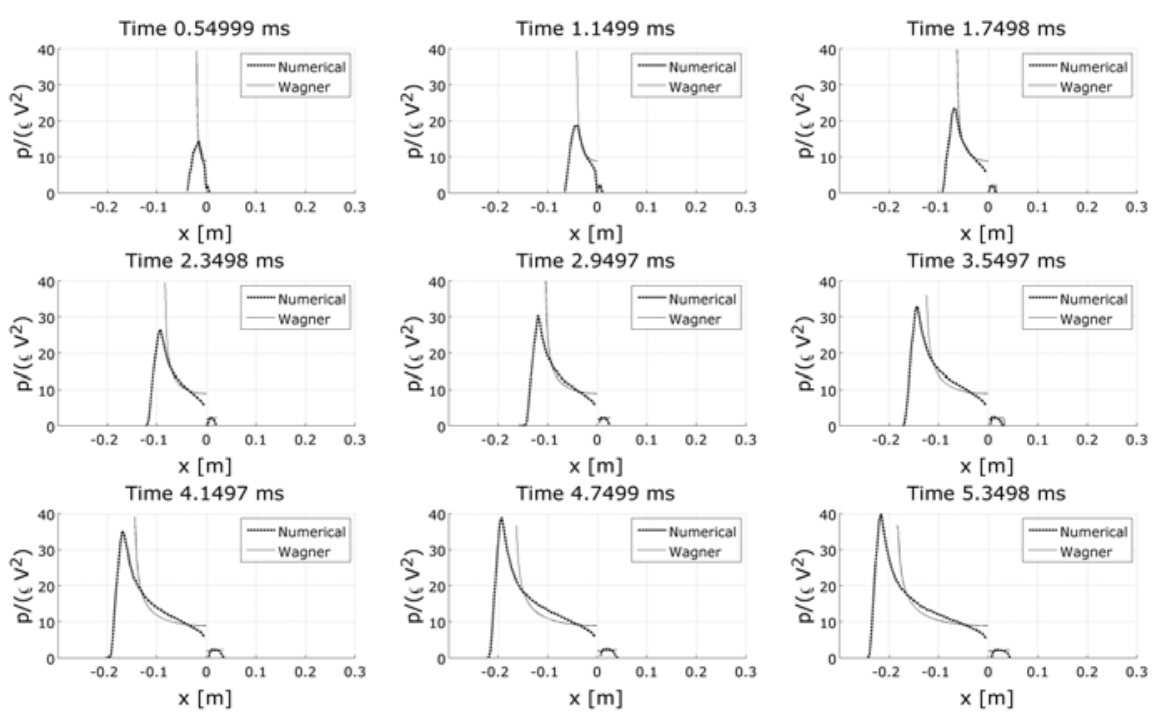

Figure 5.11: Asymmetric wedge entering the water at $4 \mathrm{~m} / \mathrm{s}(\mathrm{y})+2 \mathrm{~m} / \mathrm{s}(\mathrm{x})$. Deadrise angle $\beta=25^{\circ}$, tilt angle $15^{\circ}$.

Figure 5.12 shows a wedge with deadrise angle of $25^{\circ}$ and tilt angle of $5^{\circ}$ 
entering the water with vertical velocity $v_{y}=6 \mathrm{~m} / \mathrm{s}$ and horizontal velocity $v_{x}=$ $1 \mathrm{~m} / \mathrm{s}$.
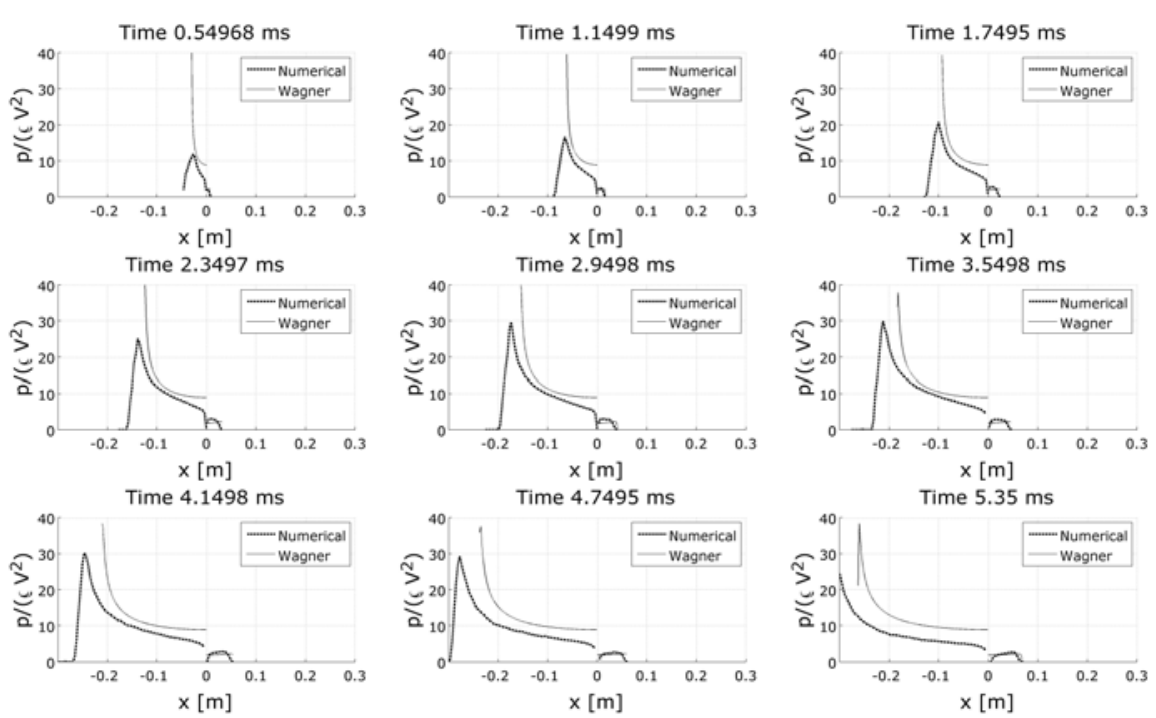

Figure 5.12: Asymmetric wedge entering the water at $6 \mathrm{~m} / \mathrm{s}(\mathrm{y})+1 \mathrm{~m} / \mathrm{s}(\mathrm{x})$. Deadrise angle $\beta=25^{\circ}$, tilt angle $15^{\circ}$.

Figure 5.13 shows a wedge with deadrise angle of $25^{\circ}$ and tilt angle of $5^{\circ}$ entering the water with vertical velocity $v_{y}=4 \mathrm{~m} / \mathrm{s}$ and horizontal velocity $v_{x}=$ $4 \mathrm{~m} / \mathrm{s}$. In the case shown in figure 5.13 , due to the pretty high horizontal velocity component, the fluid detached from wedge tip, as visible in Figure 5.14. Since air is not considered in the numerical model, the numerical solution might not represent the real behavior of the fluid. Although, results show that even if there is a region where the pressure drops to zero, the maximum pressure compares well with Wagner's model, even if the overall shape changed: the maximum pressure on the right face is now located where the fluid reattaches to the wedge rather than in the fluid jet. 

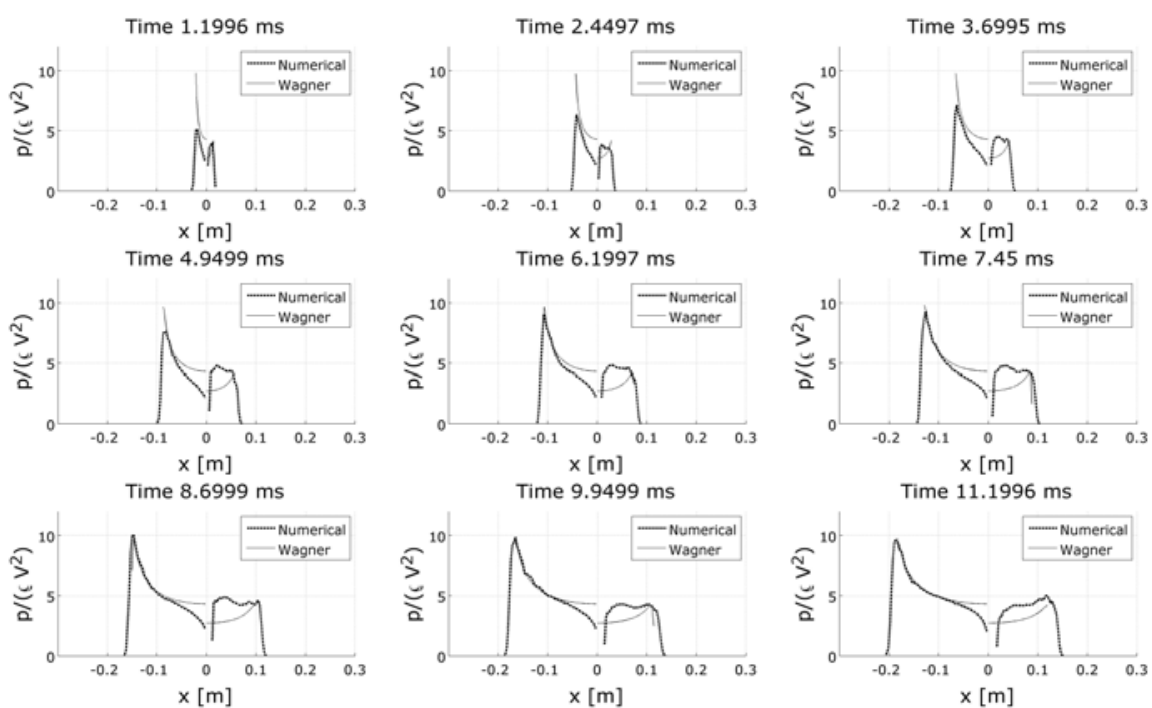

Figure 5.13: Asymmetric wedge entering the water at $4 \mathrm{~m} / \mathrm{s}(\mathrm{y})+4 \mathrm{~m} / \mathrm{s}(\mathrm{x})$. Deadrise angle $\beta=25^{\circ}$, tilt angle $5^{\circ}$.

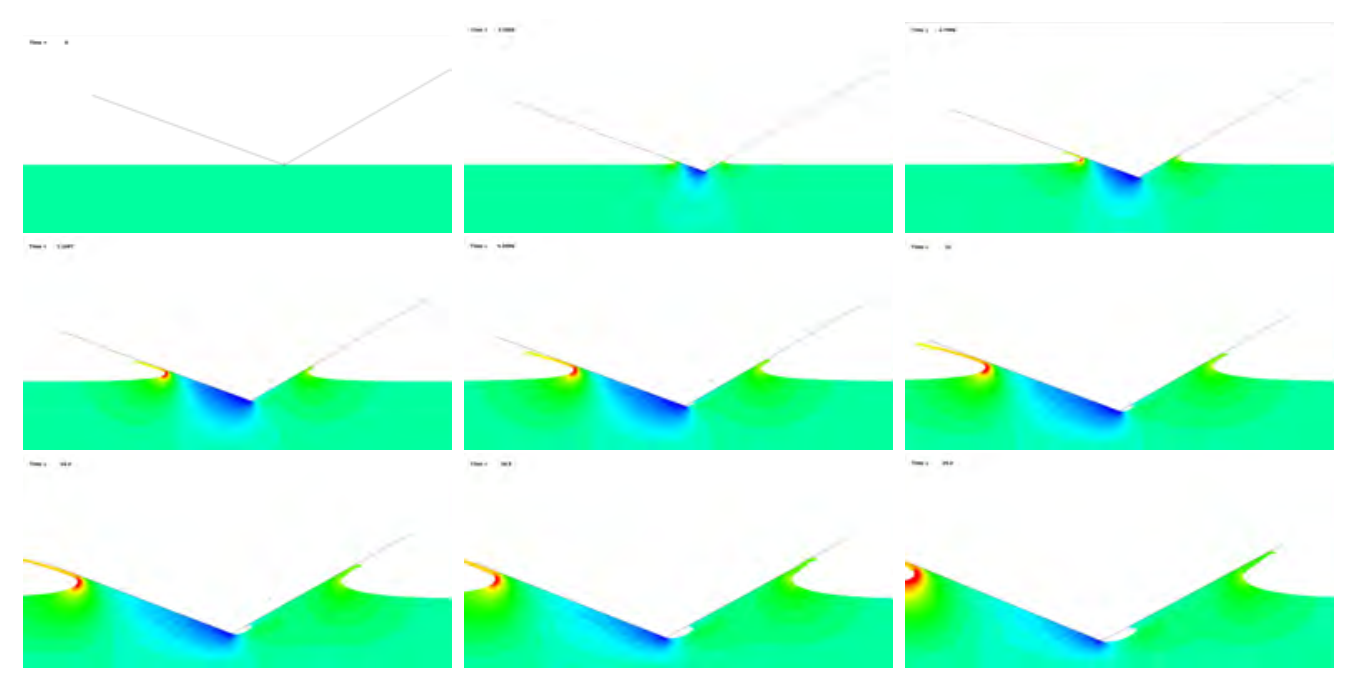

Figure 5.14: Asymmetric wedge entering the water with combined horizontal $(4 \mathrm{~m} / \mathrm{s})$ and vertical $(4 \mathrm{~m} / \mathrm{s})$ velocity. Deadrise angle $\beta=25^{\circ}$, tilt angle $5^{\circ}$. The horizontal component of the velocity is on the left direction. 


\subsection{Notes on the water entry of rigid bodies}

It has been shown in the last two chapters that the SPH method is capable of predicting the hydrodynamic pressure during the water entry of rigid bodies, as shown by the comparison with the analytical solutions. An eventual asymmetry (in terms of initial tilt angle or horizontal velocity component) is not affecting the maximum hydrodynamic load and the impact dynamics can still be predicted by analytical formulations with good approximation. An eventual detachment of the fluid at the wedge tip was found to have negligible effects on the maximum hydrodynamic load, even if it might variate the overall pressure shape. The maximum load is always carried by the side with lower deadrise angle and the impact loads can be easily referred to a symmetric impact case. Thus, in the following, the effect of hydroelasticity on the impact dynamics will be studied only on symmetric impacts. 
CHAPTER 6

\section{Numerical simulations of deformable wedges}

In the previous chapters it was found that $\mathrm{SPH}$ is capable of modeling the impact dynamic and the pressure at the fluid/structure interface during the water entry of rigid wedges. In the following sections elastic structures are considered. In these cases the structural deformation might change the fluid motion introducing the so-called hydroelastic effects, leading the impact dynamics to differ from the analytical solution.

This section presents a parametric analysis of hydroelastic impacts of elastic wedges entering the water varying wedge flexural stiffness, impact velocity, deadrise angle and SPH particles size. Wedges are modeled as an ideally elastic aluminium ( $\mathrm{E}=80 \mathrm{GPa}, \nu=0.3, \rho=2700 \mathrm{~kg} / \mathrm{m}^{3}$ ), or as an ideally elastic fibreglass mat composite $\left(E_{1}=E_{2}=20 \mathrm{GPa}, \nu=0.3, \rho=2050 \mathrm{~kg} / \mathrm{m}^{3}\right)$. To compare wedges of different thickness, an added mass is applied to the tip of the wedge to reach a total mass of $20 \mathrm{~kg}$ per unit width in all analysis, which, following Faltinsen [28], is not affecting the hydroelastic behavior. Faltinsen demonstrated that hydroelastic effects are important when

$$
\tan (\beta)<0.25 V \sqrt{\frac{\rho L^{3}}{E I}}
$$

showing that the occurrence of hydroelastic effects depends on: impact velocity, deadrise angle and structural stiffness to area mass ratio. In particular, the higher the impact velocity $V$, the lower the deadrise angle $\beta$ and the higher the structure natural period $T_{1}$ is, the more important the hydroelastic effects are. To investigate the effect of hydroelasticity on the impact dynamics, wedges of different thickness were implemented: $2 \mathrm{~mm}$ and $4 \mathrm{~mm}$, both for aluminium and fibreglass composite 
wedges. This way different bending stiffness to area mass ratios are considered. The effect of impact velocity has been also investigated.

In all the numerical simulations only one half of the wedge and the fluid is modeled due to symmetry. Constraints are applied to the wedge tip: only the vertical translation is released. The wedge's side is $0.3 \mathrm{~m}$ long and the total mass equals $20 \mathrm{Kg}$ per unit width. The fluid is modeled by 160000 particles equally spaced (with diameter of $0.25 \mathrm{~mm}$ ) covering a region $0.4 \mathrm{~m}$ wide and $0.2 \mathrm{~m}$ deep. The wedge is composed by 100 elements per side, leading to an average of $4 \mathrm{SPH}$ particles that get in contact with a single element in the wet region. The numerical results are recorded every $0.05 \mathrm{~ms}$, for a total solution time of $60 \mathrm{~ms}$.

\subsection{Hydroelasticity}

Figures 6.1 and 6.2 show two examples of the water entry of elastic wedges. Initially (up to $2.5 \mathrm{~ms}$ in these cases) the deformation of the wedge is low, so that it behaves like a rigid wedge. Then, the deformation of the wedge becomes important $(\approx 5 \mathrm{~ms})$ resulting into a mutual interaction between the fluid motion and the structural deformation. In this initial time of the impact the wedge is deforming downward due to its inertia. The wedge eventually reaches its maximum deformation $(\approx 7.5 \mathrm{~ms})$ and starts bending in the other direction (at $\approx 10 \mathrm{~ms}$ the wedge is in its neutral position). At this point, three events could happen:

1. The entire wet part of the wedge (the part already touched by the water) stays in contact with the water, and no air is entrapped in between the solid and the fluid. The fluid/structure interaction continues and the vibrations are damped by the fluid.

2. Along the wet part of the wedge the fluid tends to move away from the wedge, then pressure becomes negative and cavitation occurs, as shown in Figure 6.1.

3. The wedge detaches from the fluid and some air enters from the side. The air is eventually trapped in between the wedge and the fluid and an air cushion is generated, as shown in Figure 6.2. In this case the interaction between the air flow and the fluid flow has to be taken into account. 

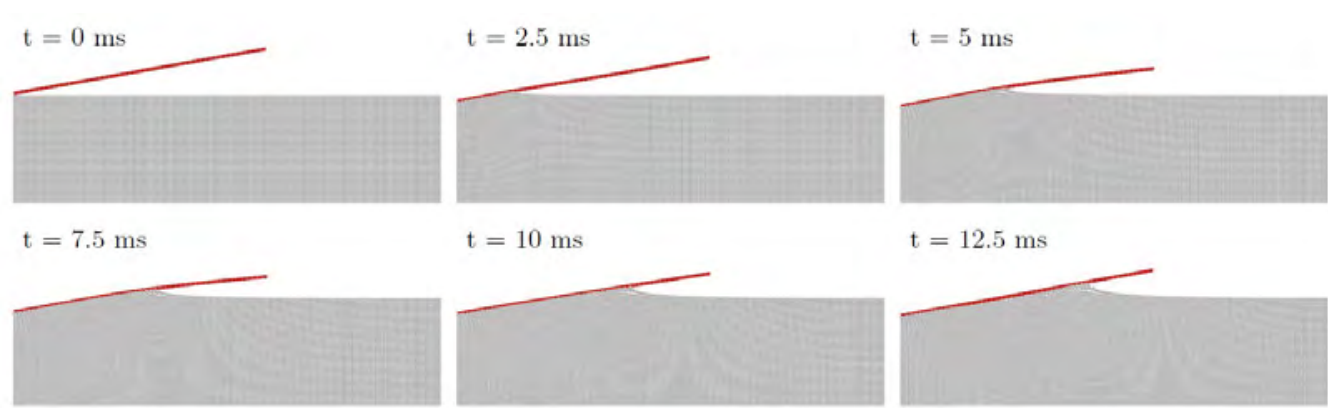

$\mathrm{t}=10 \mathrm{~ms}$

$\mathrm{t}=12.5 \mathrm{~ms}$

$\mathrm{t}=15 \mathrm{~ms}$
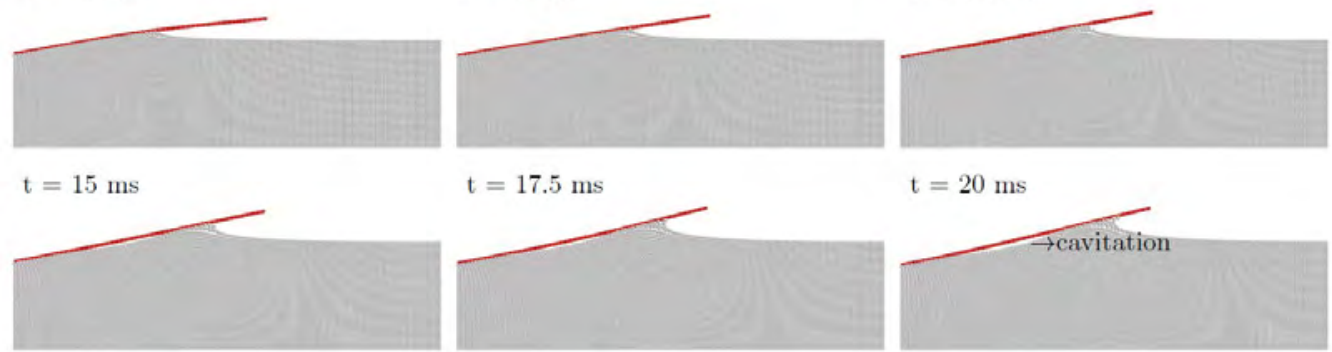

Figure 6.1: Wedge deformation over time. $10^{\circ}$ deadrise angle, $4 \mathrm{~mm}$ thick, $4 \mathrm{~m} / \mathrm{s}$ initial velocity.
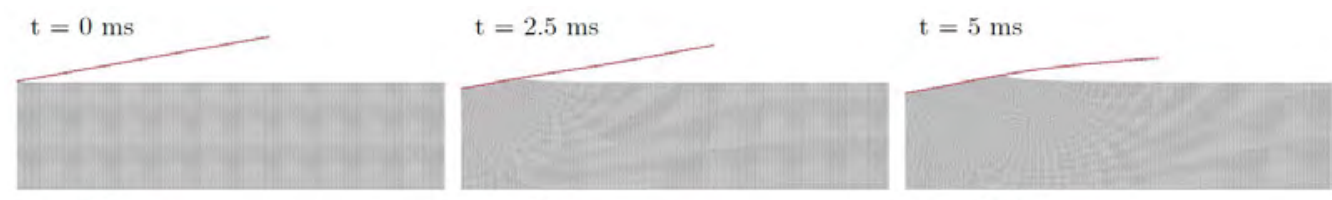

$\mathrm{t}=7.5 \mathrm{~ms}$

$\mathrm{t}=10 \mathrm{~ms}$

$\mathrm{t}=12.5 \mathrm{~ms}$
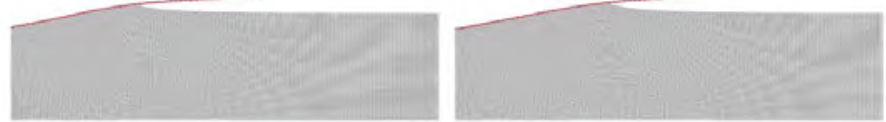

$\mathrm{t}=15 \mathrm{~ms}$

$\mathrm{t}=17.5 \mathrm{~ms} \quad \digamma$ Air can enter

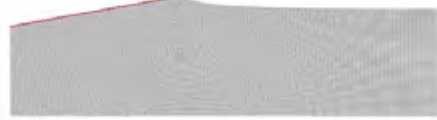

$\mathrm{t}=20 \mathrm{~ms}$
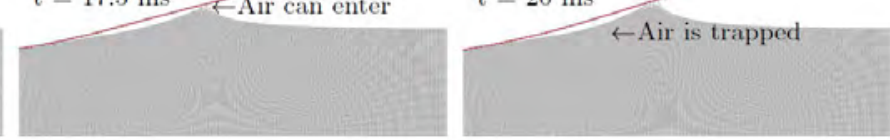

Figure 6.2: Wedge deformation over time. $10^{\circ}$ deadrise angle, $2 \mathrm{~mm}$ thick, $4 \mathrm{~m} / \mathrm{s}$ initial velocity.

\subsection{Influence of the structural deformation on the hydrodynamic pressure}

As shown, the structural deformation might change the fluid motion. As a consequence, the pressure at the interface will differ from the rigid case. An example of the effect of the structural deformation on the impact pressure in the case no fluid detaches from the wedge and no air is trapped in the fluid during the impact is presented in Figure 6.3. The plots show the comparison of the pressures over time 

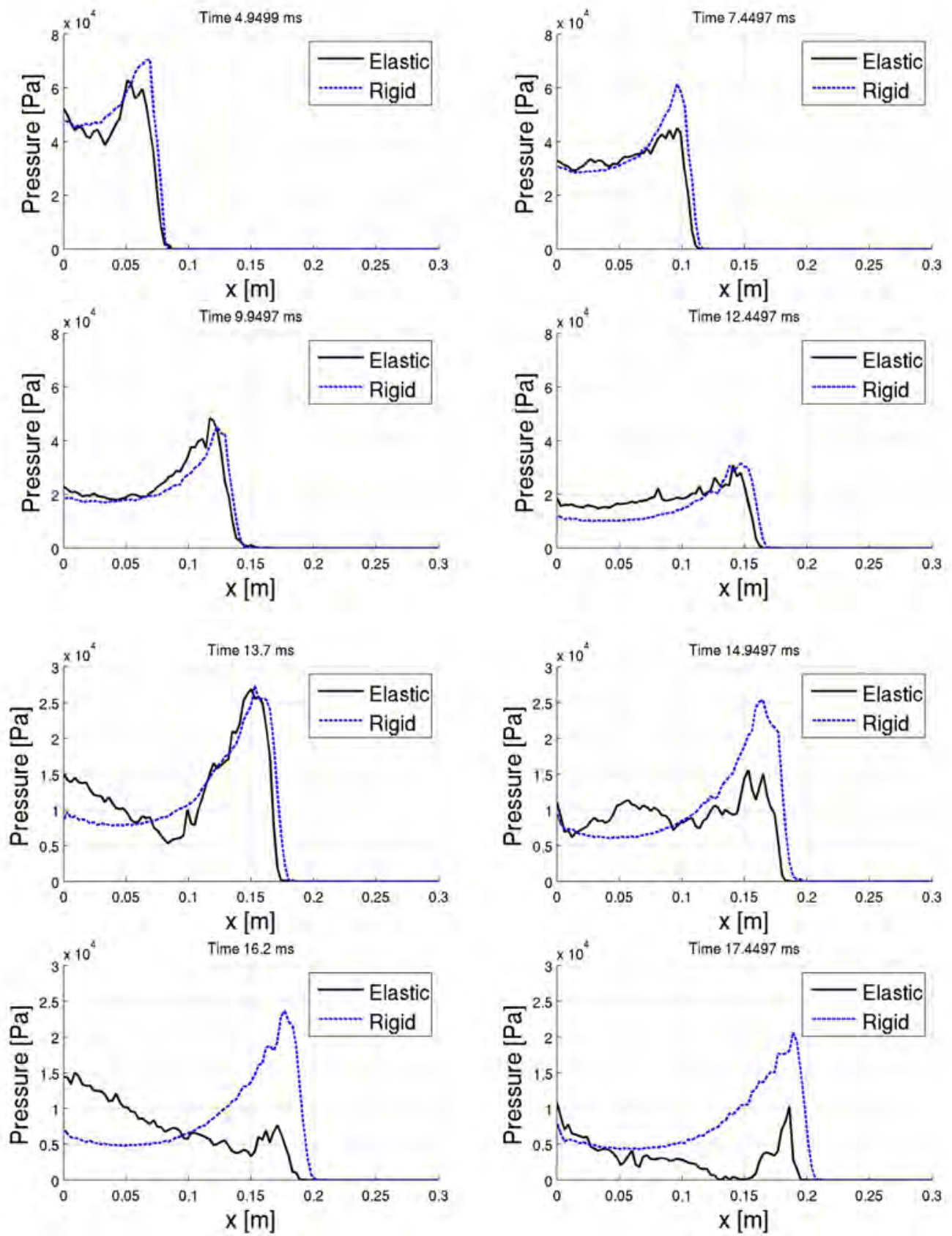

Figure 6.3: Impact pressure along the wedge over time. Deadrise angle $30^{\circ}$, mass $20 \mathrm{Kg} / \mathrm{m}$,. Comparison between rigid wedge (blue line) and elastic wedge (black line, Aluminium wedge $2 \mathrm{~mm}$ thick). results are similar at the beginning of the impact but diverges rapidly after $10 \mathrm{~ms}$. 
of a rigid wedge vs. an elastic wedge (aliminium $2 \mathrm{~mm}$ thick) with deadrise angle of $30^{\circ}$ and total mass of $20 \mathrm{~kg} / \mathrm{m}$ entering the water at $4 \mathrm{~m} / \mathrm{s}$. It is found that the two solutions show extremely similar results at the beginning of the impact (until about $15 \mathrm{~ms}$ ), when the impact pressure is higher. Pressures are similar until the panel has reached its maximum negative (leaded by the inertia) deformation. Once the wedge starts to deform in the opposite direction, the pressure eventually reduce to a lower value compared to the rigid case. Note that at this stage the impact force is already in its descending phase and the maximum impact force has already been reached. At the time the hydrodynamic pressure diverges, the
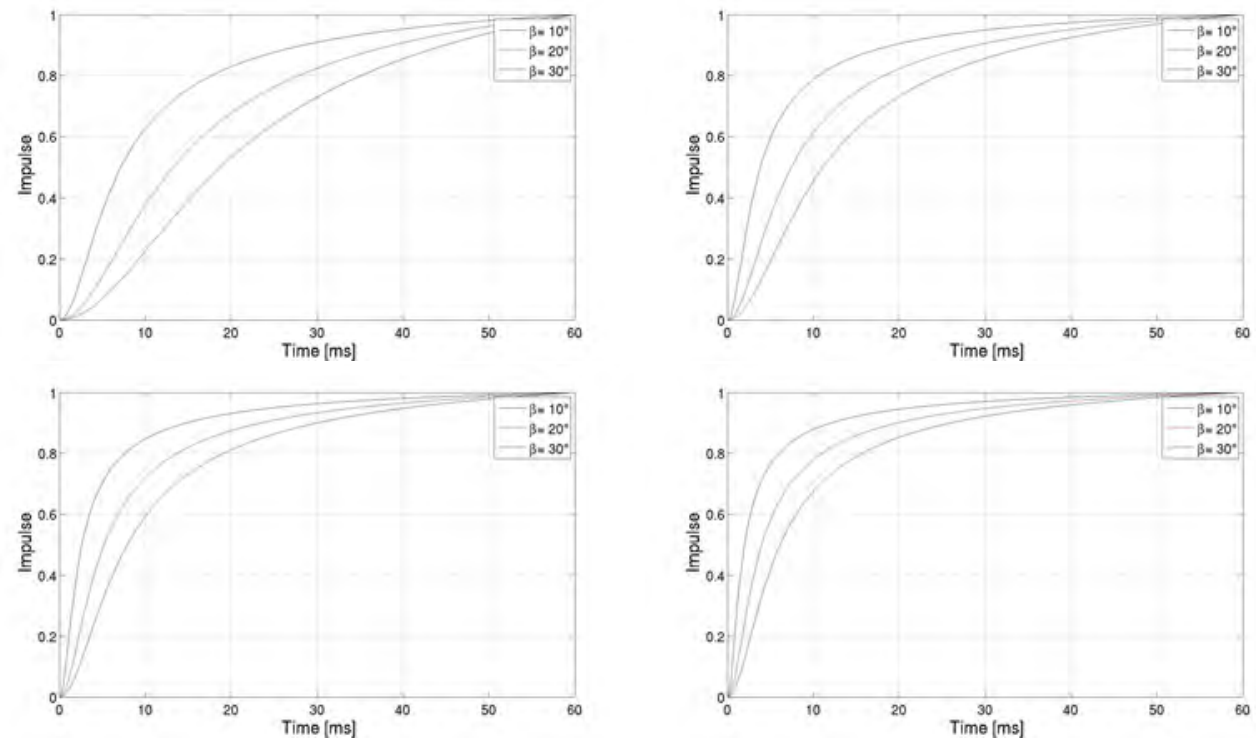

Figure 6.4: Adimensional impulse over time for various deadrise angles and impact velocities: 2, 4, 6 and $8 \mathrm{~m} / \mathrm{s}$ (left to right, top to bottom).

impulse applied to the wedge is more than the $50 \%$ of the maximum impulse that would apply to a rigid wedge during the water entry. Figure 6.4 shows the adimensionalized impulse over time for various deadrise angles and impact velocities. Note that for this case and for all the other cases that will be shown in the following, the impulse exchanged at this stage is in the order of $55-60 \%$ of its maximum.

Other examples are presented in the following. They all show similar behavior to the example presented above: Pressure follows Wagner's formula until the 50$60 \%$ of the impulse load, to later diverge due to fluid detachment. Figure 6.5 
shows the comparison of the impact pressure between a rigid wedge and deformable wedges with deadrise angle of $30^{\circ}$ entering the water at $4 \mathrm{~m} / \mathrm{s}$. Figure 6.6 shows the relative deformation of the wedges during the impact referred to the undeformed shape.
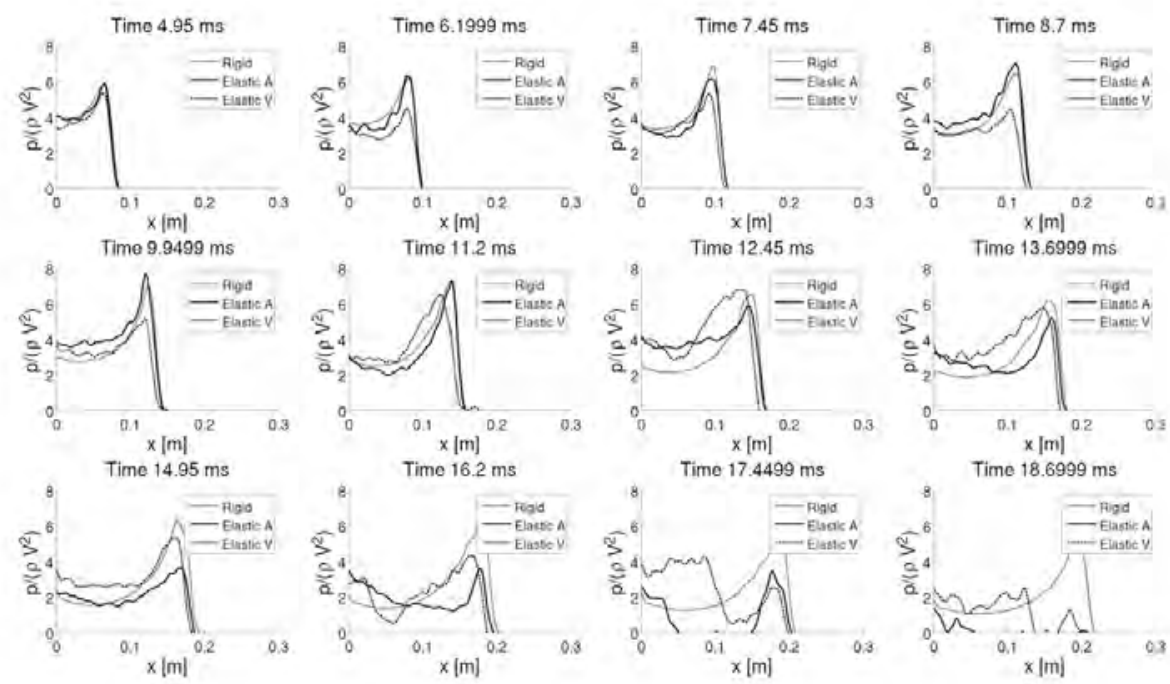

Figure 6.5: Pressure at the fluid/structure interface during the impact of a rigid wedge (blue line), a deformable aluminium wedge (red line) and a deformable composite wedge (black line) entering the water at $4 \mathrm{~m} / \mathrm{s}$. Deadrise angle $30^{\circ}$. 

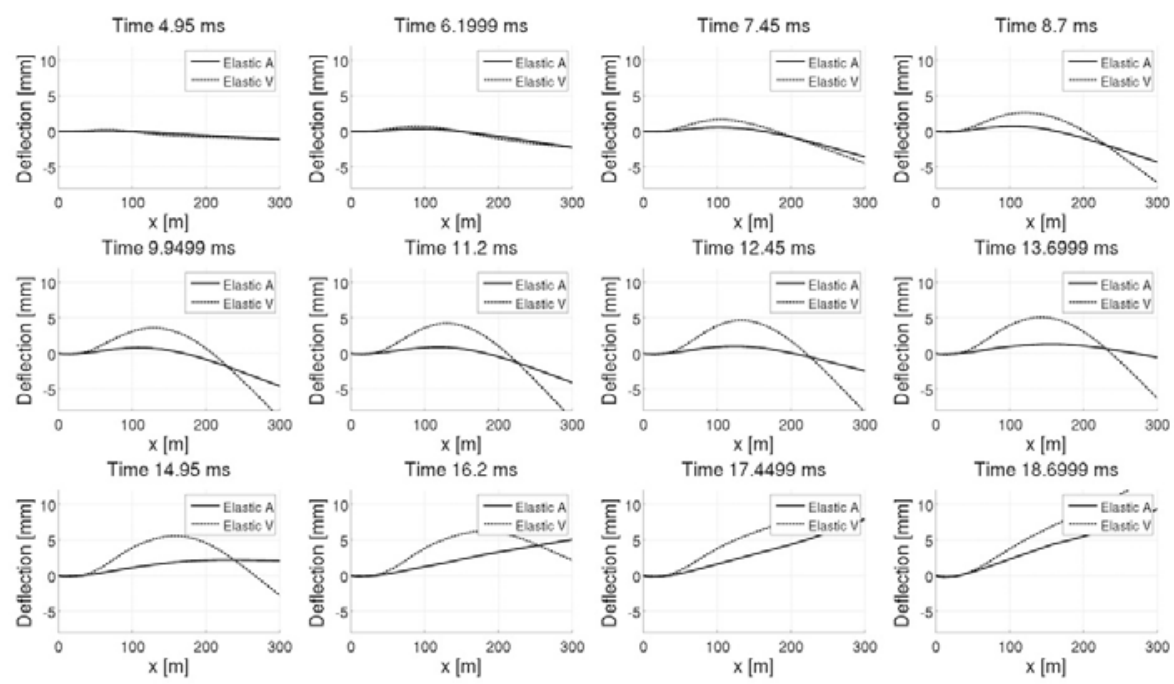

Figure 6.6: Deformation of the aluminium (A) and composite (V) wedge during the impact.

Figure 6.7 shows the comparison of the impact pressure of wedges with deadrise angle of $30^{\circ}$ entering the water at $2 \mathrm{~m} / \mathrm{s}$. Figure 6.8 shows the deformation of the wedges during the impact.
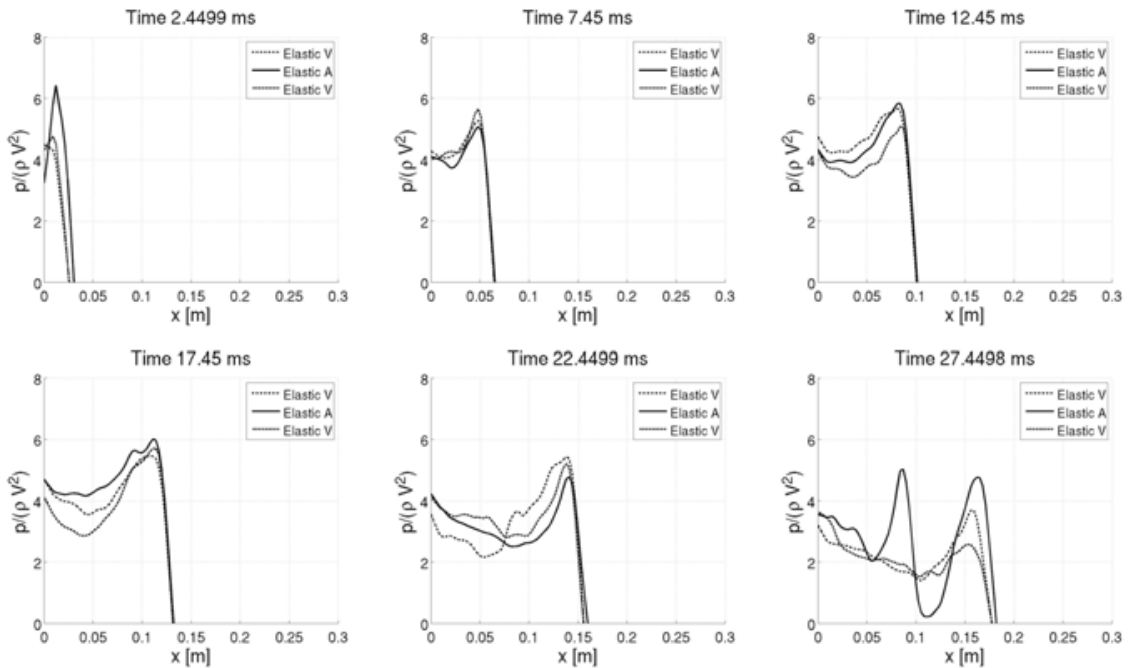

Figure 6.7: Pressure at the fluid/structure interface during the impact of wedges entering the water at $2 \mathrm{~m} / \mathrm{s}$. Deadrise angle $30^{\circ}$. 

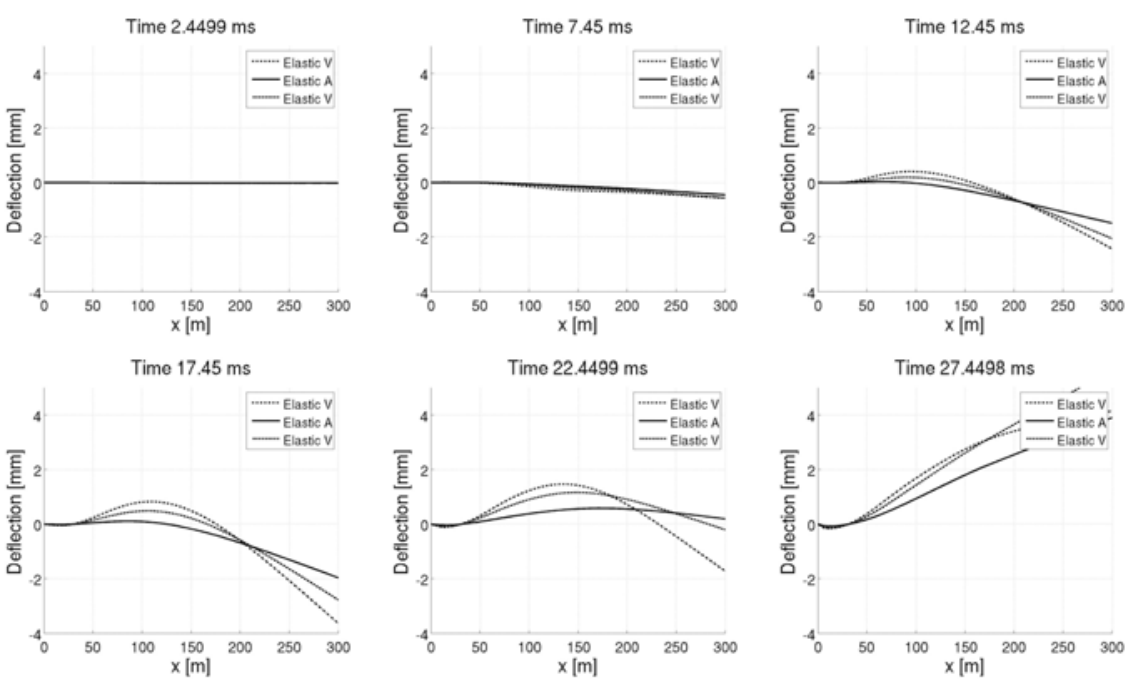

Figure 6.8: Deformation of the wedges during the impact. $V_{0}=2 \mathrm{~m} / \mathrm{s}, \beta=30^{\circ}$.

Figure 6.9 shows the comparison of the impact pressure of wedges with deadrise angle of $30^{\circ}$ entering the water at $6 \mathrm{~m} / \mathrm{s}$. Aluminium and composite wedges are shown. In all cases the impact pressure can be predicted with good approximation until $6.5 \mathrm{~ms}$ of impact. After this time, the wedge detaches from the fluid and the pressure at the interface assumes complicate shapes. Figure 6.10 shows the deformation of the wedges during the impact. 

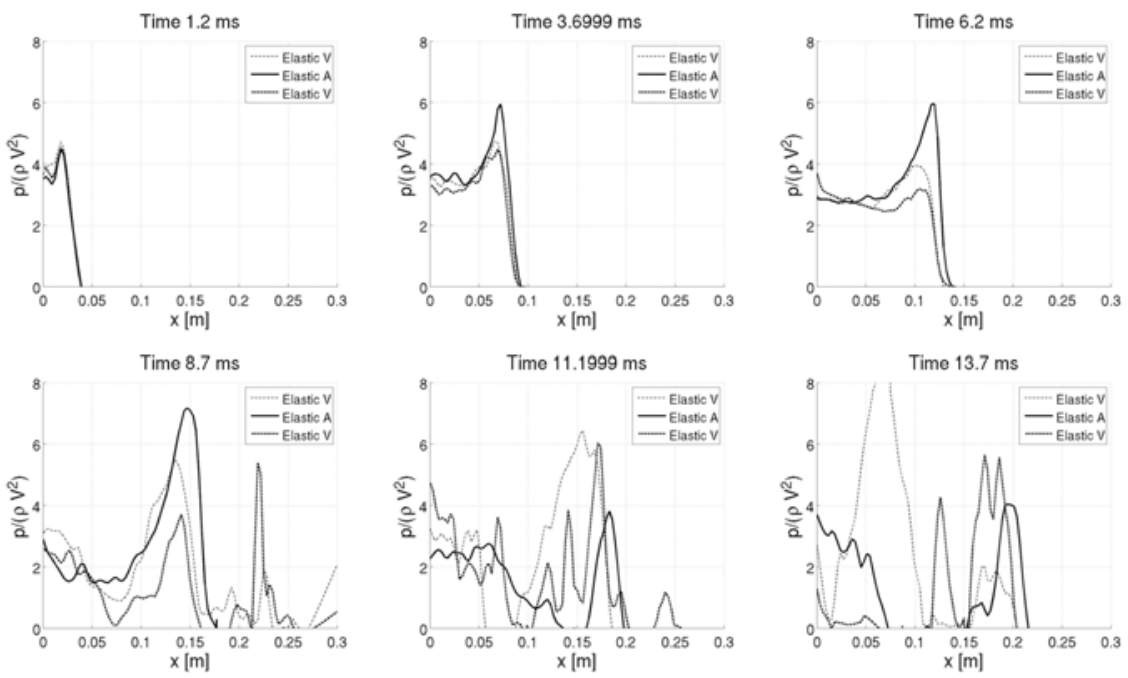

Figure 6.9: Pressure at the fluid/structure interface during the impact of a wedges entering the water at $6 \mathrm{~m} / \mathrm{s}$. Deadrise angle $30^{\circ}$.
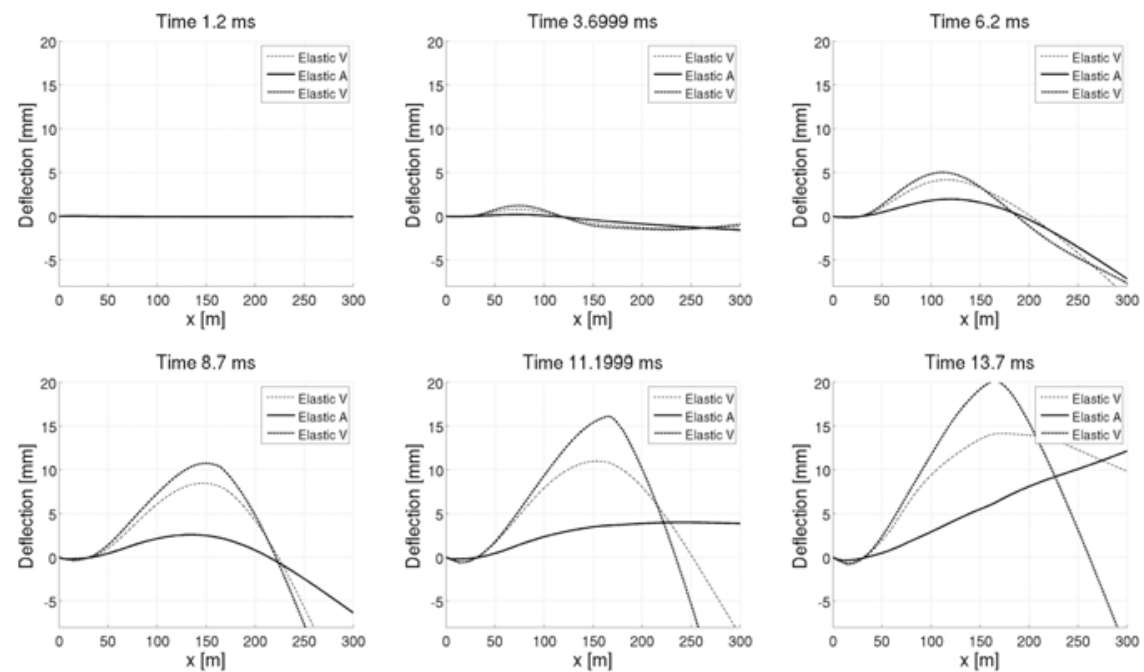

Figure 6.10: Deformation of the wedges during the impact. $V_{0}=6 \mathrm{~m} / \mathrm{s}, \beta=30^{\circ}$.

Figure 6.11 shows the comparison of the impact pressure of an aluminium wedge with deadrise angle of $20^{\circ}$ entering the water at $6 \mathrm{~m} / \mathrm{s}$.

Figure 6.12 shows the comparison of the impact pressure of an aluminium wedge with deadrise angle of $10^{\circ}$ entering the water at $3 \mathrm{~m} / \mathrm{s}$.

Figure 6.13 shows the comparison of the impact pressure of an aluminium 

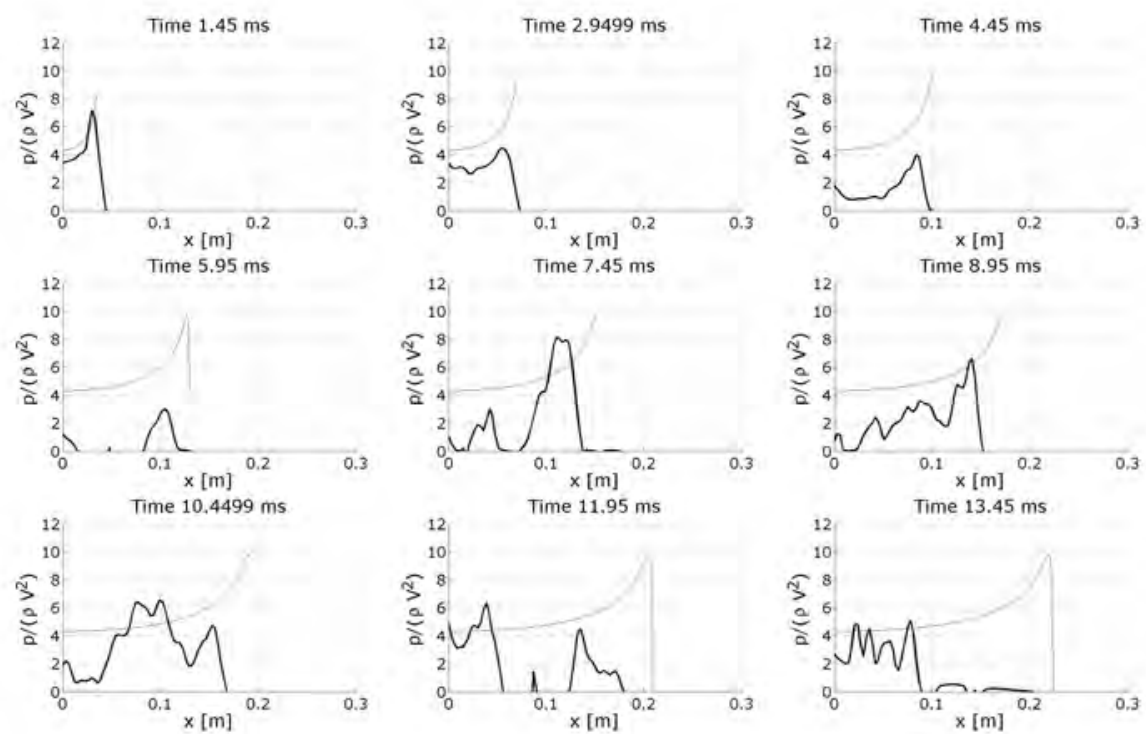

Figure 6.11: Pressure at the fluid/structure interface during the impact of an aluminium wedges entering the water at $6 \mathrm{~m} / \mathrm{s}$. Deadrise angle $20^{\circ}$.
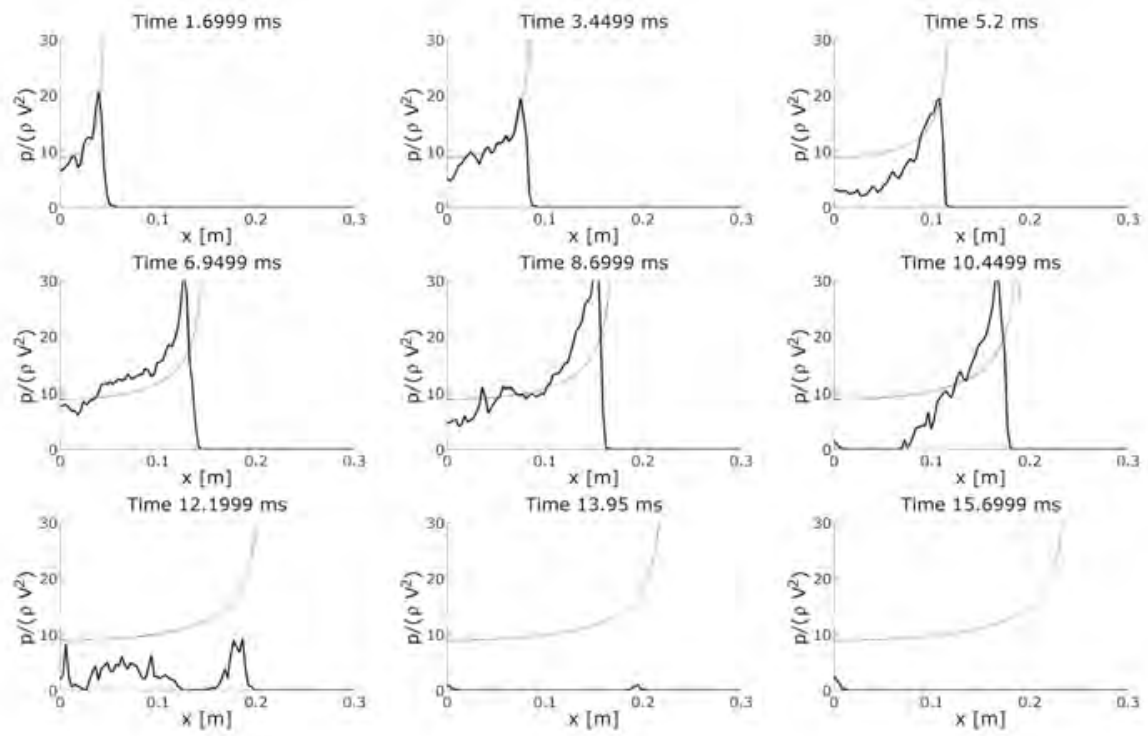

Figure 6.12: Pressure at the fluid/structure interface during the impact of an aluminium wedges entering the water at $3 \mathrm{~m} / \mathrm{s}$. Deadrise angle $10^{\circ}$. 
wedge with deadrise angle of $10^{\circ}$ entering the water at $4 \mathrm{~m} / \mathrm{s}$.
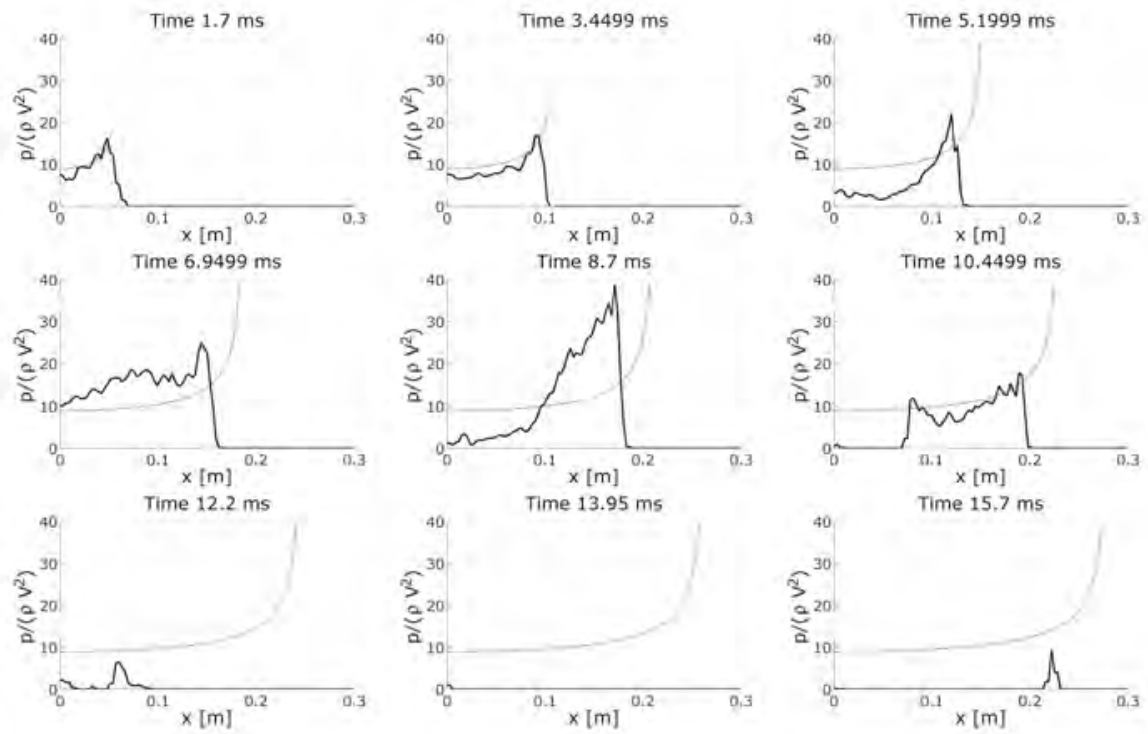

Figure 6.13: Pressure at the fluid/structure interface during the impact of an aluminium wedges entering the water at $4 \mathrm{~m} / \mathrm{s}$. Deadrise angle $10^{\circ}$.
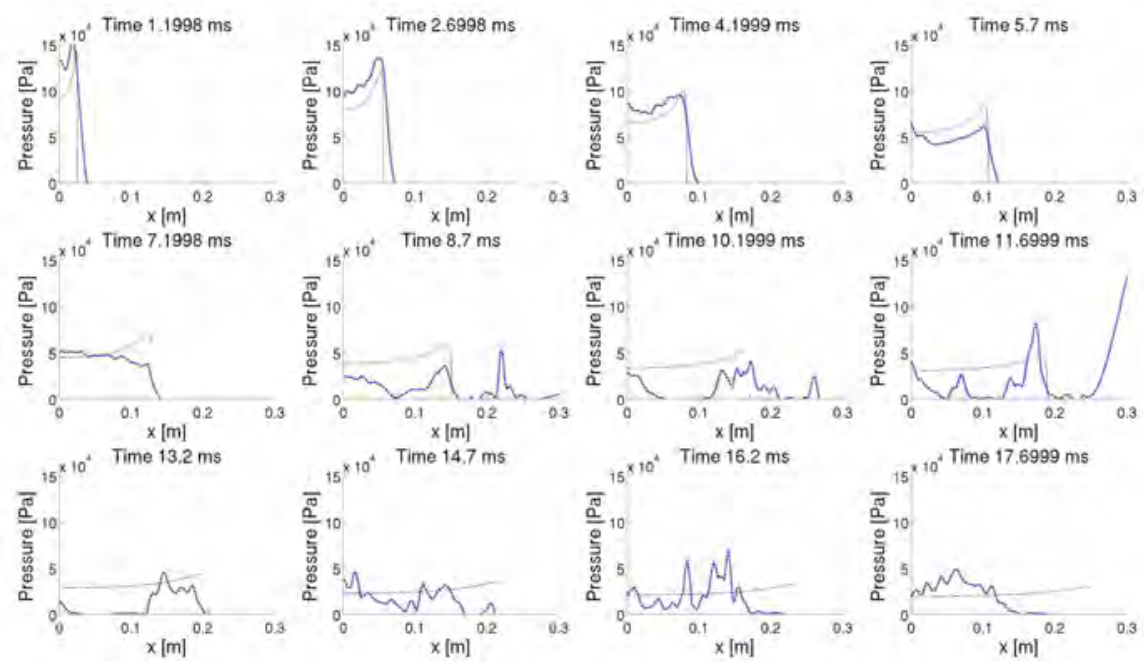

Figure 6.14: Pressure at the fluid/structure interface during the impact of a rigid wedge (blue line), a deformable aluminium wedge (red line) and a deformable composite (W2) wedge (black line) entering the water at $6 \mathrm{~m} / \mathrm{s}$. Deadrise angle $30^{\circ}$. 

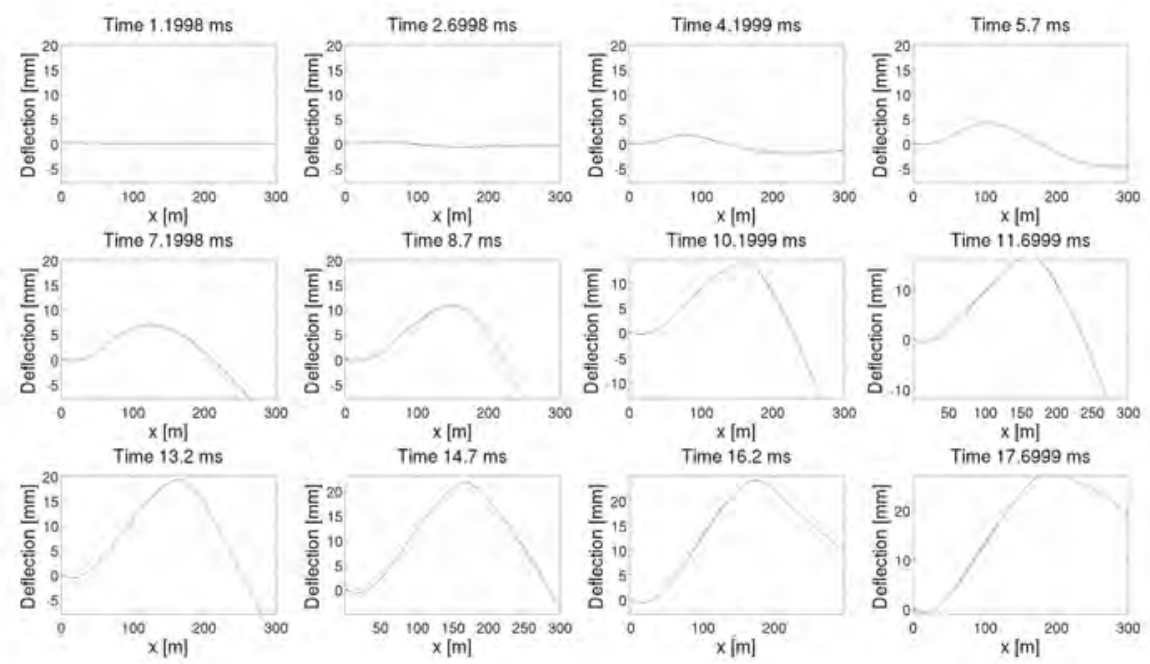

Figure 6.15: Deformation of the composite wedge (W2) impact ing at $6 \mathrm{~m} / \mathrm{s}$. Note that due to the severe impact the wedge is highly distorted.
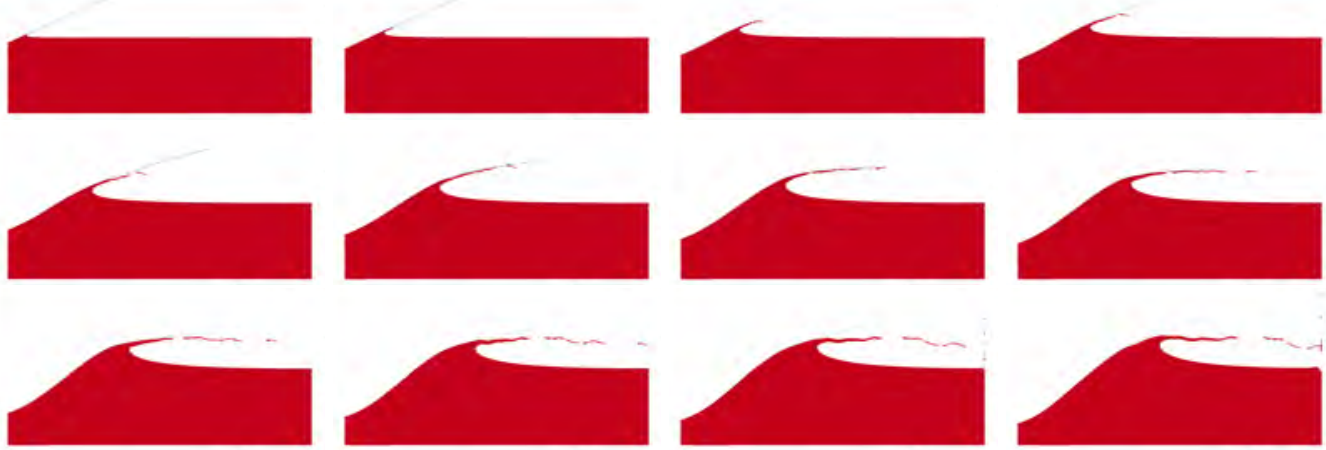

Figure 6.16: Deformation in time of a composite wedge (W2) entering the water at $6 \mathrm{~m} / \mathrm{s}$. The time step of the plots is the same one of figures 6.14 and 6.15. Note that, due to the high structural deformation, after $10 \mathrm{~ms}$ the wedge is wetted by the jet flow, leading to the high differences between the theoretical pressure for rigid wedges and the simulated one.

\subsection{Impact dynamics}

This section presents a parametric study on the influence of the hydroelastic effects on the impact dynamics. Figures 6.17, 6.18 and 6.19 show a parametric 
study varying the particle size of the numerical solutions of aluminium wedges 2 $m m$ thick with deadrise angle of $10^{\circ}, 20^{\circ}$, and $30^{\circ}$ respectively, entering the water at $4 \mathrm{~m} / \mathrm{s}$. Since only vertical impacts are considered, one half of the wedge and water are modeled splitting the structure on its symmetry axis. Wedges side length is $300 \mathrm{~mm}$ while the fluid domain has been modeled as a tank $800 \mathrm{~mm}$ width and $600 \mathrm{~mm}$ height. Three particles sizes have been chosen for the simulations: $1 \mathrm{~mm}$ (Fine model, 480,000 particles), $2.5 \mathrm{~mm}$ (Medium model, 192,000 particles) and $5 \mathrm{~mm}$ (Rough model, 48,000 particles). The computation takes about 12 hours to run in the case of fine model and only about 0.5 hour for the rough model. Results show that the particle size is only slightly affecting the impact dynamics (velocity and acceleration are evaluated at the wedge tip). While velocity and displacement are computed correctly, the acceleration presents fluctuations increasing with the particle size, especially in the early stage of the impact. These fluctuations increase with the deadrise angle. This behavior is due to the lower number of particles getting in contact with the wedge while rising the deadrise angle. As expected from Faltinsen's [28] observations, results show that the impact dynamics differ from the rigid case for all the deadrise angles investigated. Figures 6.17 to 6.19 show that the impact dynamics of the elastic wedges initially follows the rigid solution, to later show a response influenced by the first natural frequency of the structure, visible in the oscillations of acceleration and velocity.
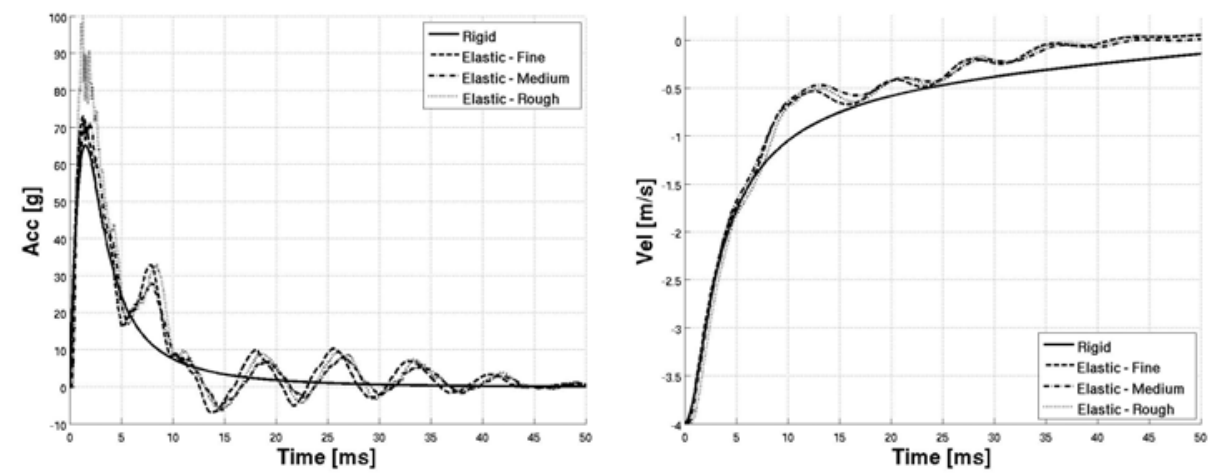

Figure 6.17: Acceleration and Velocity of a wedge varying the particle refinement. Total wedge mass: $20 \mathrm{~kg}$ per unit width. Deadrise angle $10^{\circ}$

Figure 6.20 shows the comparison of the impact dynamic of elastic and rigid 

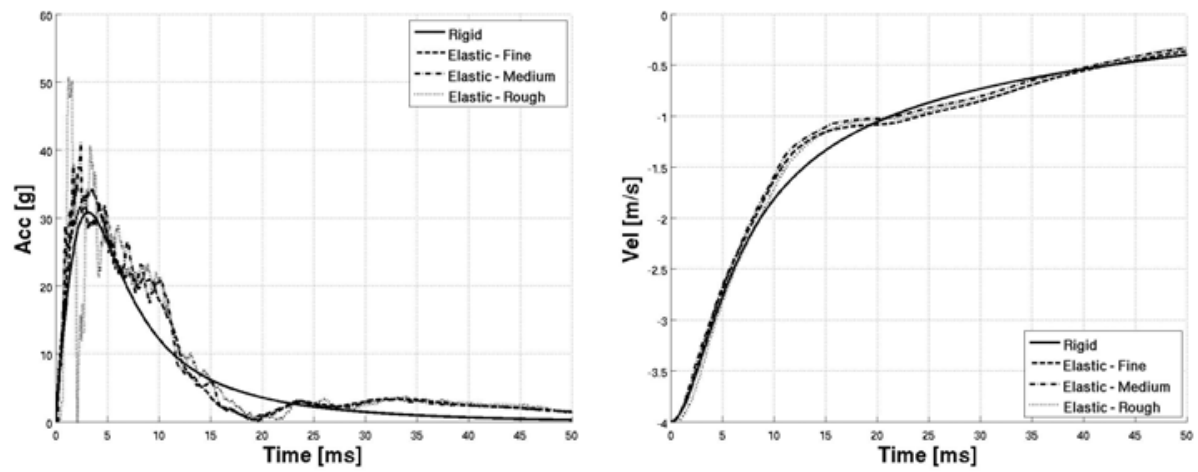

Figure 6.18: Acceleration and Velocity of a wedge varying the particle refinement. Total wedge mass: $20 \mathrm{~kg}$ per unit width. Deadrise angle $20^{\circ}$
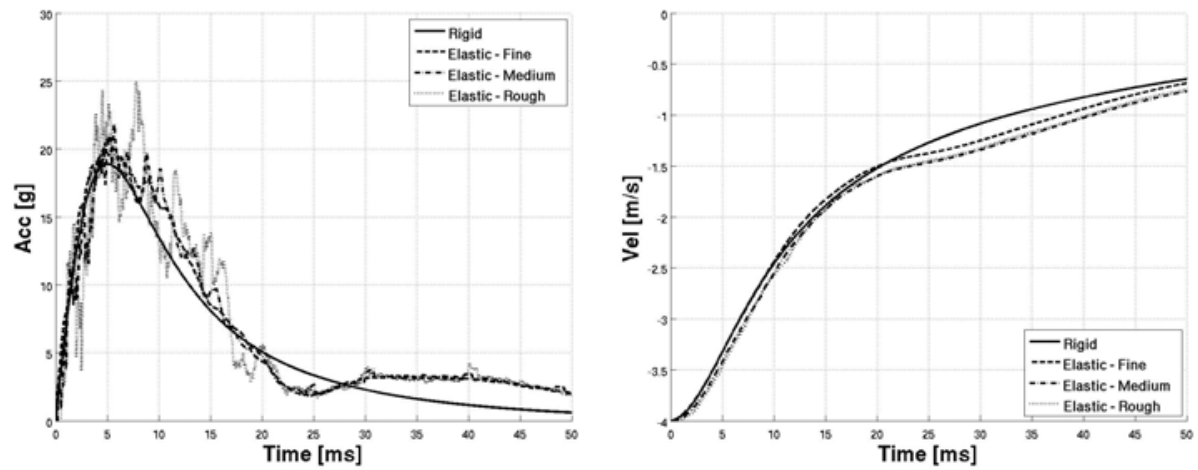

Figure 6.19: Acceleration and Velocity of a wedge varying the particle refinement. Total wedge mass: $20 \mathrm{~kg}$ per unit width. Deadrise angle $30^{\circ}$

$4 \mathrm{~mm}$ thick aluminium wedges with various deadrise angles entering the water at $4 \mathrm{~m} / \mathrm{s}$. As before, results are in accordance with Faltinsen's observations: hydroelasticity highly affects the impacts of wedges with deadrise angle from $5^{\circ}$ to $20^{\circ}$, while the $30^{\circ}$ behavior is close to the rigid case and very small hydroelastic effects appear. Figure 6.21 shows the same example but at an initial entry velocity of $2 \mathrm{~m} / \mathrm{s}$. As for the cases presented before it was found that in the cases of $20^{\circ}$ and $30^{\circ}$ deadrise angles hydroelasticity is very low affecting the dynamic response and behave like the rigid cases. Figures 6.22 and 6.23 shows the comparison for given deadrise angle and impact velocity varying the plate stiffness. The results are as expected: the hydroelastic effect lowers increasing deadrise angle and plate 
stiffness, while increases with the impact velocity. Further results about the importance of hydroelasticity on the structural deformation are presented in the next section, where a dependency of the structural response from the hydroelastic effect is shown.
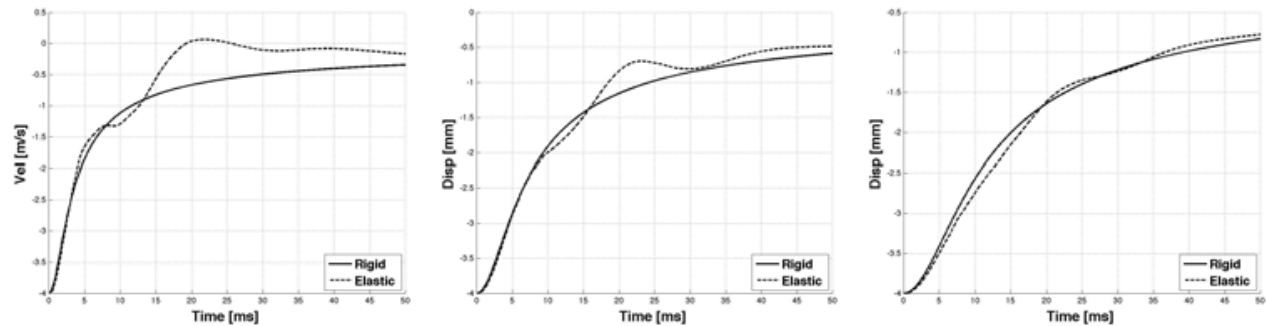

Figure 6.20: Hydroelasticity effect on the impact dynamics of aluminium wedges $4 \mathrm{~mm}$ thick of different deadrise angles entering the water at $4 \mathrm{~m} / \mathrm{s}$. From Left to right: $10^{\circ}, 20^{\circ}, 30^{\circ}$ deadrise angle.
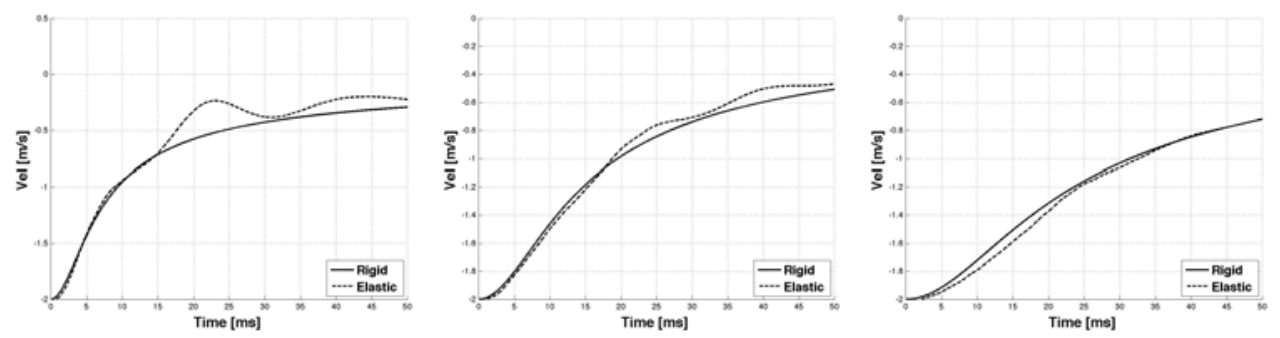

Figure 6.21: Hydroelasticity effect on the impact dynamics of aluminium wedges $4 \mathrm{~mm}$ thick of different deadrise angles entering the water at $2 \mathrm{~m} / \mathrm{s}$. From Left to right: $10^{\circ}, 20^{\circ}, 30^{\circ}$ deadrise angle.
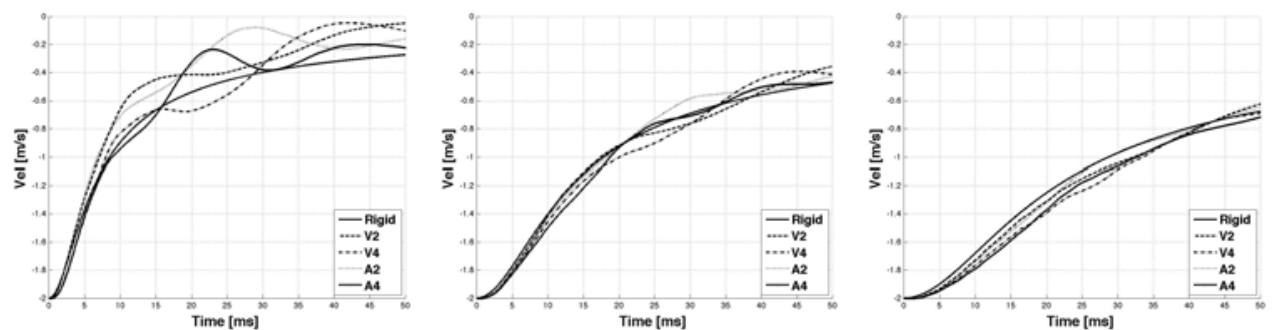

Figure 6.22: Impact dynamics varying plate stiffness, deadrise angle from left to right: $10^{\circ}, 20^{\circ}, 30^{\circ}, V_{0}=2 \mathrm{~m} / \mathrm{s}$. 

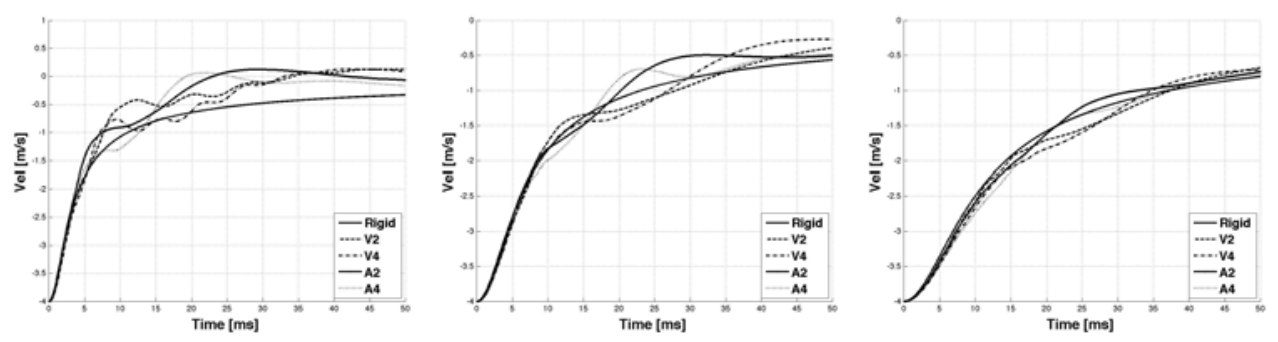

Figure 6.23: Impact dynamics varying plate stiffness, deadrise angle from left to right: $10^{\circ}, 20^{\circ}, 30^{\circ}, V_{0}=4 \mathrm{~m} / \mathrm{s}$.

\subsection{Stresses evaluation}

Figures 6.24 and 6.25 show the comparison of the stresses evolution in time at different distances from the wedge tip in case of fine and rough particles refinement models. Results are definitely in good agreement, especially considering that the difference in the computational time between the fine particles model and the rough particles model is about 12 hours vs. 0.5 hours. The cases of $30^{\circ}$ and $10^{\circ}$ deadrise angles are shown, since these represents respectively the minimum and maximum influence of hydroelastic effects on the impact loads. It is found that in the first case the wedge deformation is ruled by the first mode of vibration, while when high hydroelastic effects appear more modes of vibrations superpose. As mentioned before, the main disadvantage of increasing the particle size is that it becomes impossible to evaluate the pressure at the fluid/structure interface, however, the overall structural deformation is evaluated correctly, as evidenced by the stresses results.

Figure 6.26 shows a comparison of wedges with $30^{\circ}$ deadrise angle and different stiffness entering the water at $4 \mathrm{~m} / \mathrm{s}$. Results show that moving from a stiffer plate (on the left, Aluminium $4 \mathrm{~mm}$ thick plate) to a weaker plate (Fibreglass $2 \mathrm{~mm}$ thick, on the right), hydroelastic effects become more important and the deformations of the plate get more complicate since more vibrating modes superpose. 

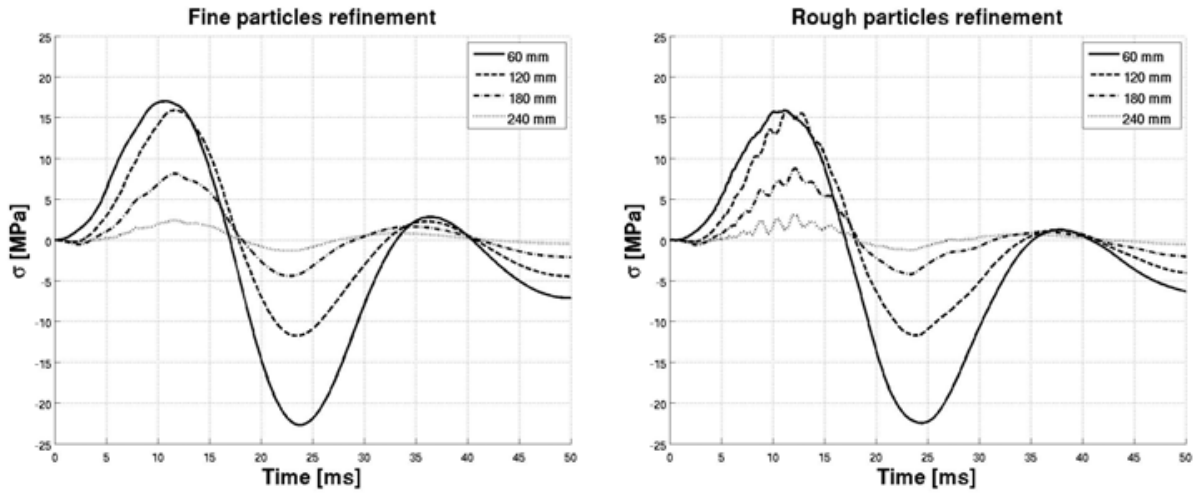

Figure 6.24: Stresses at different distances from the wedge tip for fine and rough particle refinement. $\beta=30^{\circ}, V_{0}=4 \mathrm{~m} / \mathrm{s}$
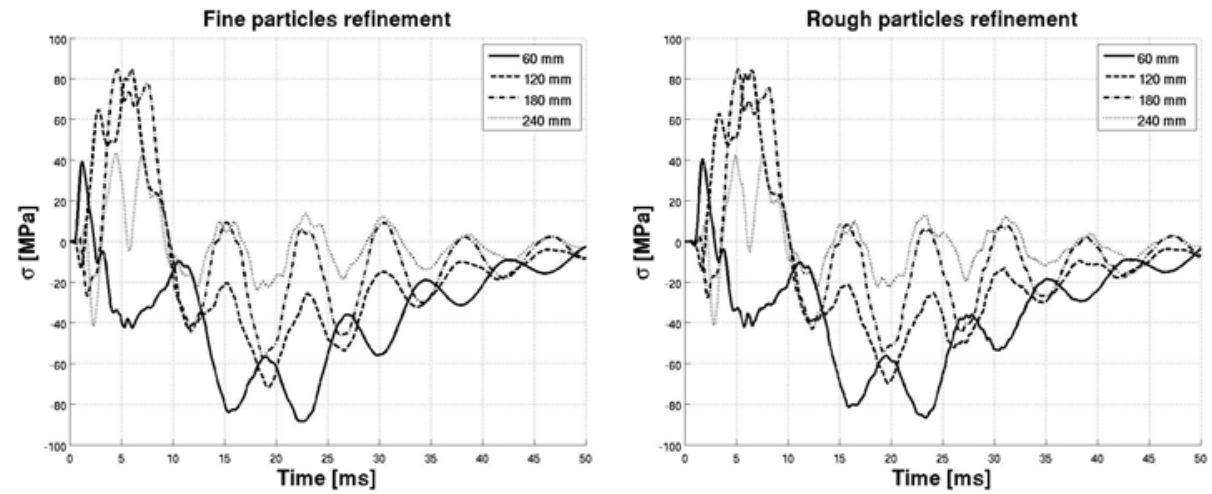

Figure 6.25: Stresses at different distances from the wedge tip for fine and rough particle refinement. $\beta=10^{\circ}, V_{0}=4 \mathrm{~m} / \mathrm{s}$
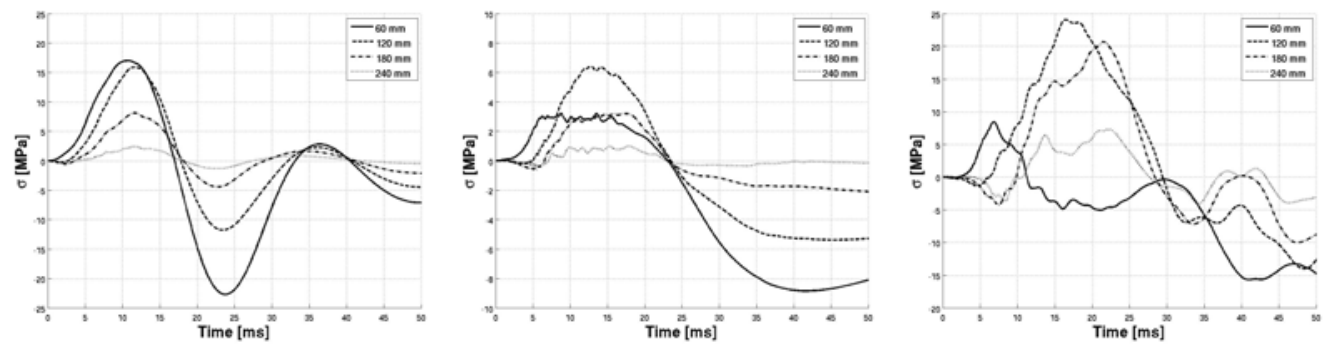

Figure 6.26: Stresses at different distances from the wedge tip increasing the hydroelastic effect. A4-4 (left), A2-4 (center), V2-4 (right). $\beta=30^{\circ}\left(V_{0}=4 \mathrm{~m} / \mathrm{s}\right)$ 


\subsection{Hydroelastic effect}

As suggested in [28], the loading can be considered as quasi static if the loading period is significantly larger than the first natural period of the structure, otherwise hydroelastic effects might appear. In Figure 6.27 it is shown the impact dynamics maximum variation in respect to Von Karman's results as function of the term $R$ given by the ratio between the wetting time calculated as $\frac{\tan (\beta) \cdot l}{v_{0}}$ and the first dry natural period of the structure calculated by the beam theory. Where $\beta$ is the deadrise angle, $v_{0}$ is the impact velocity and $l$ is the wedge side length. The numerical impact dynamics has been evaluated at the tip of the wedge. The calculation of the maximum variation between SPH and Von Karman results was calculated as:

$$
\begin{aligned}
\Delta a & =\max \left[a_{S P H}(t)-a_{t h}(t)\right] \\
\Delta v & =\max \left[v_{S P H}(t)-v_{t h}(t)\right] \\
\Delta w & =\max \left[w_{S P H}(t)-w_{t h}(t)\right]
\end{aligned}
$$
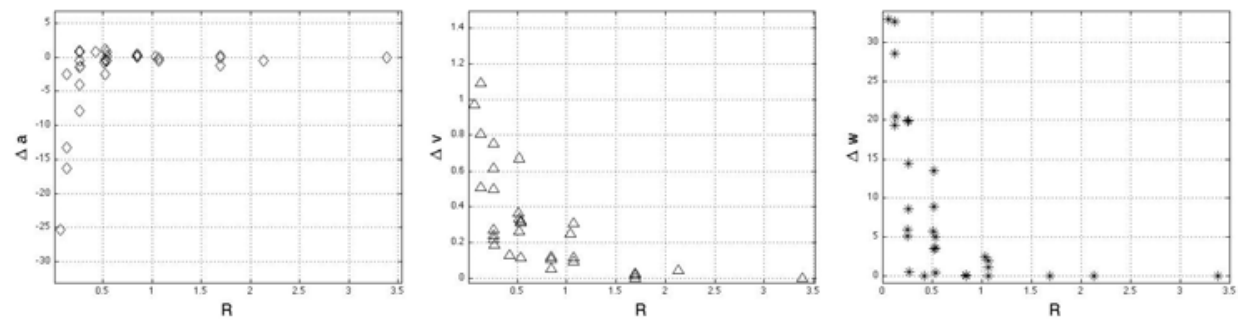

Figure 6.27: Maximum impact dynamics variation between SPH results and Von Karman results. Acceleration $a\left[\mathrm{~m} / \mathrm{s}^{2}\right]$ (left), Velocity $v[\mathrm{~m} / \mathrm{s}]$ (center) and Displacement $w[\mathrm{~mm}]$ (right).

Results show that the impact dynamics differ from the Von Karman's analytical solution for values of $\mathrm{R}$ lower than 1 , meaning that hydroelasticity needs to be taken into account when the wetting time is lower than the first structural dry natural period. 


\section{Comparison between experiments and numerical results}

Figures 7.1 to 7.4 show the comparison between experimental (blue lines) and numerical (red lines) results of the water-entry of elastic wedges. Figures 7.1 and 7.2 show the impact-induced stresses in an aluminium plate $2 \mathrm{~mm}$ thick with deadrise angle of $30^{\circ}$ entering the water at $3 \mathrm{~m} / \mathrm{s}$ and $4 \mathrm{~m} / \mathrm{s}$. The numerical solutions compare well with the experimental results: stresses in time are well replicated both in terms of maximum value and overall shape. This indicates that the simulations are correctly replicating the fluid/structure interaction in case of hydroelastic impacts. These results are particularly interesting considering that the panels are only $2 \mathrm{~mm}$ thick, deformations are consequently very high and the fluid motion is highly modified by the structure.

In Figure 7.2 the numerical solution slightly differ from the experimentally recorded values after $40 \mathrm{~ms}$ of impact. This difference has to be attributed to boundary effects: after $40 \mathrm{~ms}$ the entire wedge is wet and the water starts to overflow the panel from the side. To solve this problem the hydrodynamic loads acting on the free edge of the wedge have to be computed accurately. This can be done increasing the particle spatial resolution, with a consequent increase of the computational time. However, this problem is not on interest at this stage of the work.

Figures 7.3 and 7.4 show the comparison between numerical and experimental results of an aluminium wedge $2 \mathrm{~mm}$ thick with deadrise angle of $15^{\circ}$ entering the water at $4 \mathrm{~m} / \mathrm{s}$ and $5 \mathrm{~m} / \mathrm{s}$. In both cases the numerical solution fits with the 

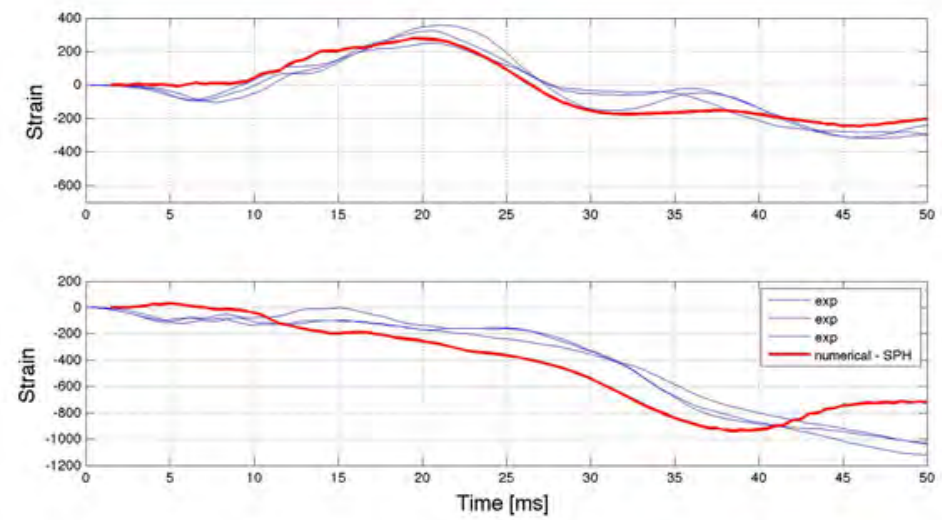

Figure 7.1: Recorded strains and numerical solution of an aluminium wedge $2 \mathrm{~mm}$ thick, deadrise angle $\beta=30^{\circ}$. Initial velocity $3 \mathrm{~m} / \mathrm{s}$
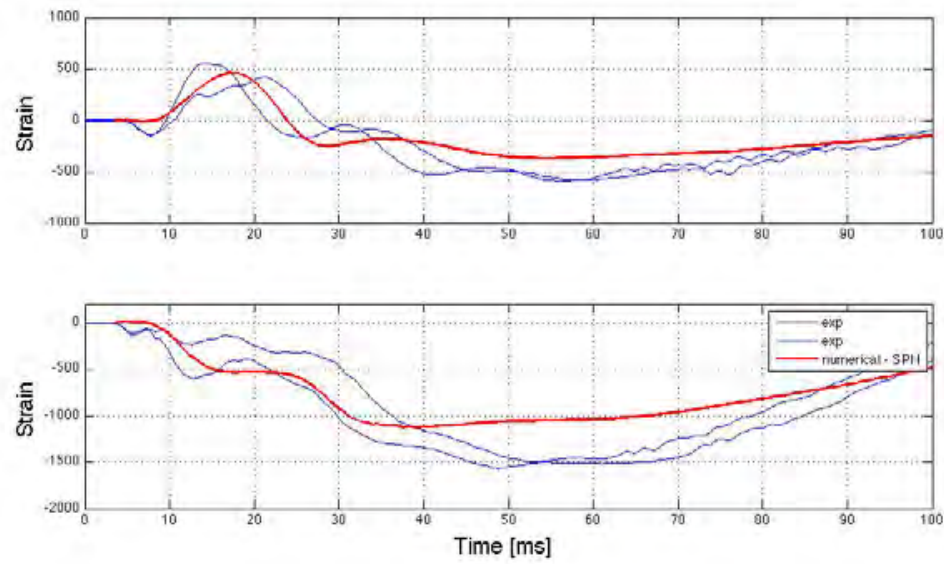

Figure 7.2: Recorded strains and numerical solution of an aluminium wedge $2 \mathrm{~mm}$ thick, deadrise angle $\beta=30^{\circ}$. Initial velocity $4 \mathrm{~m} / \mathrm{s}$

experiments only in the very first instants of the impact, approximately up to $20 \mathrm{~ms}$. The plates later vibrate at higher frequencies in the numerical solution than in reality. In these simulations in fact the wedge detaches from the fluid and vibrates like in vacuum. Figure 7.5 shows a sequence of the numerical simulation. In these cases the numerical simulation is not capable of correctly predicting the experimental results because of the approximations introduced in the model (see section (4). Better results can be achieved modifying the model to account for ventilation and cavitation since, if air is entrapped in between the fluid and the 

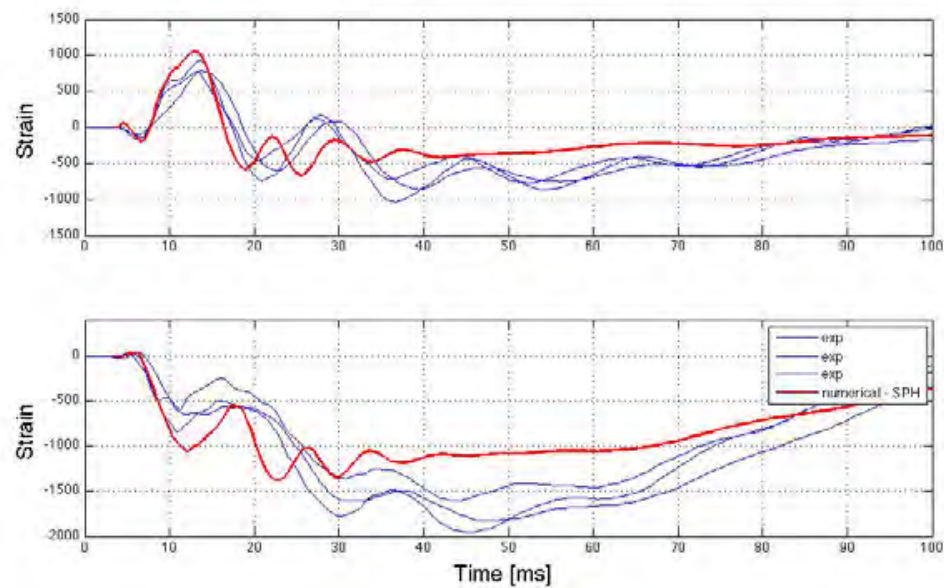

Figure 7.3: Recorded strains and numerical solution of an aluminium wedge $2 \mathrm{~mm}$ thick, deadrise angle $\beta=15^{\circ}$. Initial velocity $4 \mathrm{~m} / \mathrm{s}$. Note that after $20 \mathrm{~ms}$ the experimental recorded strain show longer period of vibration compared to the numerical results.
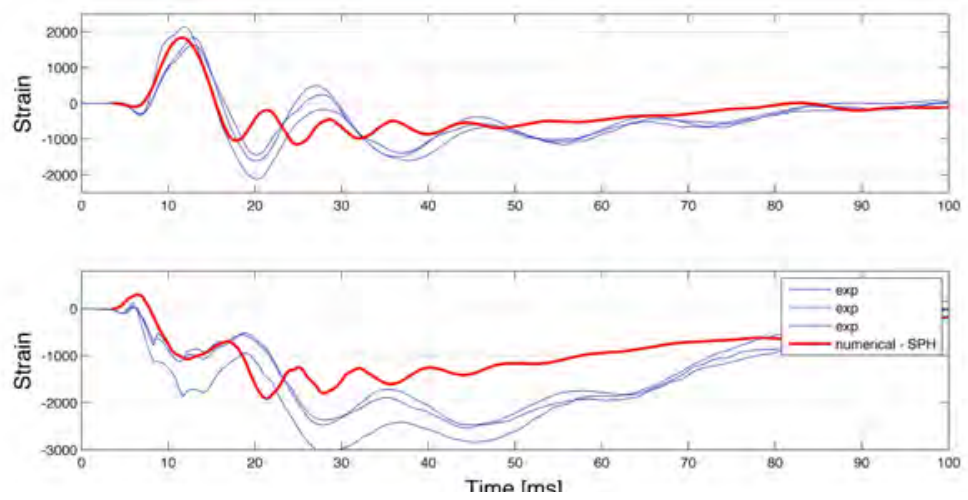

Figure 7.4: Recorded strains and numerical solution of an aluminium wedge $2 \mathrm{~mm}$ thick, deadrise angle $\beta=15^{\circ}$. Initial velocity $5 \mathrm{~m} / \mathrm{s}$. As in Figure 7.3 in the numerical solution the wedge vibrates at higher frequency beyond $20 \mathrm{~ms}$ of impact.

body, a small difference in the water shape may lead to high difference in the hydrodynamic pressure. 

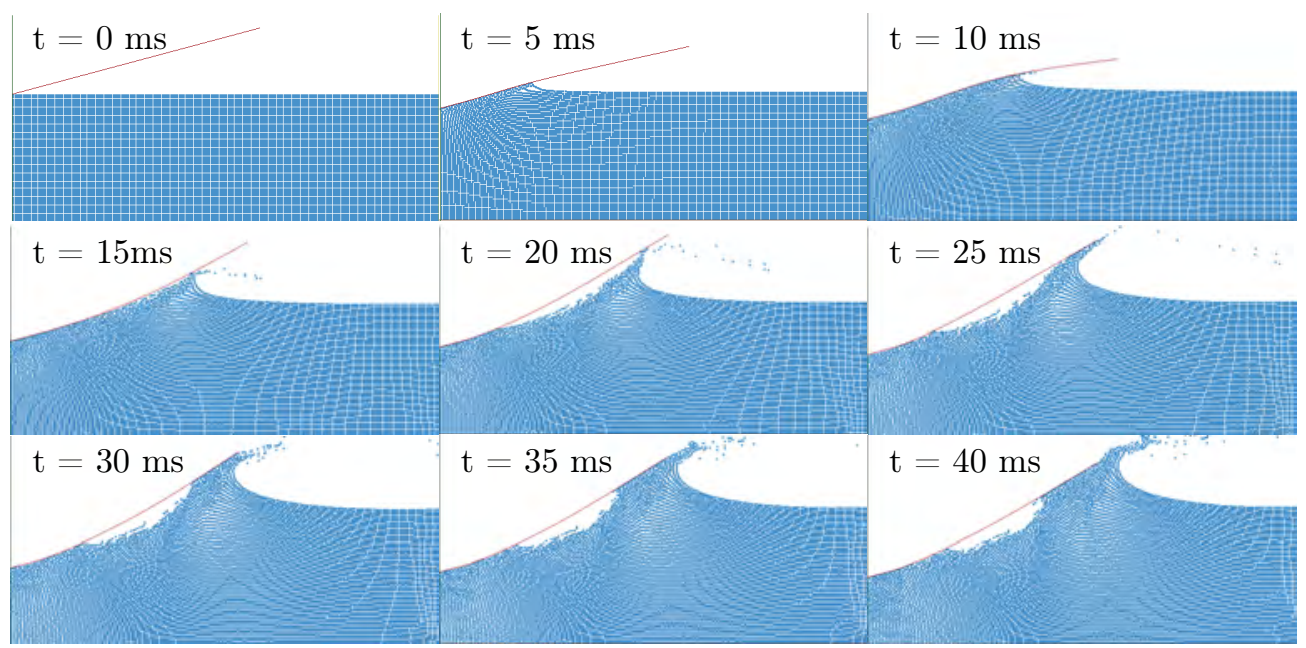

Figure 7.5: Aluminium wedge deformation over time. $15^{\circ}$ deadrise angle, $2 \mathrm{~mm}$ thick, $V_{0}=5 \mathrm{~m} / \mathrm{s}$. At about $20 \mathrm{~ms}$ of impact a void in the fluid is formed. Beyond this instant, since no air is implemented in the model, the numerical solution differs from the experimental results. 


\section{CHAPTER 8}

\section{Conclusions}

In this work, hydroelastic impacts of deformable wedges entering the water through free fall motion was studied numerically and experimentally. The water entry of deformable structures has been previously treated in the literature by other authors, however, on the contrary with their studies, this work investigates extremely flexible structures, introducing high hydroelastic effects. Furthermore, in opposition with what has been found in the literature, interest focused not only on the evaluation of the pressure at the fluid/structure interface but also on the overall structural deformation.

Hydroelastic effects were studied as function of different parameters like: deadrise angle, impact velocity and stiffness to area mass ratio. In particular, it was found that hydroelastic effects lowers increasing deadrise angle and plate stiffness, while increase with the impact velocity. The relative importance of hydroelasticity was found to be governed by the ratio $(\mathrm{R})$ between the wetting time and the natural period of the structure. For the particular geometry studied, hydroelasticity is important for values of $\mathrm{R}$ lower than 10 .

The experiments were replicated by a numerical method. A coupled SPH/FEM model was used for the simulations and, validating the solutions with the experimental results, it was found that this model is actually capable of correctly modeling the fluid behavior and of predicting hydroelastic impacts, although a range of validity applies.

The numerical model has been used to investigate the water entry of asymmetric wedges. It was found that the analytical models used for symmetric impacts 
can be easily adapted to asymmetric impacts. Both the impact dynamics and the hydrodynamic pressure are well predicted by the analytical methods: the hydrodynamic load follows Wagner's prediction previous correction of the impact dynamics due to the horizontal velocity component.

For the cases studied, it was found that the structural deformation is not affecting the hydrodynamic pressure at the fluid/structure interface during the first instants of the impact: difference in the pressure at the fluid/structure interface are noticeable only after the maximum impact force is reached and a half of the maximum impulse load has been applied to the wedge. The presented SPH model was found to be able to simulate hydroelastic impacts if no air is trapped between the structure and the fluid. In fact, if (due to the structural deformation) air bubbles are trapped into the fluid during the impact, air cannot be neglected in the numerical model. By the numerical simulations it was also possible to better understand the mechanisms causing cavitation and air entrapment between the structure and the fluid due to hydroelastic effects. 


\section{References}

[1] TH Von Karman. The impact on seaplane floats, during landing. NACA-TN321, 1929.

[2] Xiaoming Mei, Yuming Liu, and Dick K P Yue. On the water impact of general two-dimensional sections. Applied Ocean Research, 21:1-15, 1999.

[3] H. Wagner. Uber Stoss-und Gleitvorgange an der Oberflache von Flussigkeiten. Z. angew. Math. Mech., 12(4):193-215., 1932.

[4] J. C. Daidola and V Mishkevich. Hydrodynamic impact on displacement ship hulls: an assessment of the state of the art. Ship. Ship Structure Committee report SSC-385, NTIS PB96-129101,, 1995.

[5] A. Korobkin. Second-order Wagner theory of wave impact. Journal of Engineering Mathematics, 58(1-4):121-139, November 2006.

[6] E Yettou, a Desrochers, and Y Champoux. A new analytical model for pressure estimation of symmetrical water impact of a rigid wedge at variable velocities. Journal of Fluids and Structures, 23(3):501-522, April 2007.

[7] C. Judge, a. Troesch, and M. Perlin. Initial water impact of a wedge at vertical and oblique angles. Journal of Engineering Mathematics, 48(3/4):279-303, April 2004.

[8] A. A. Korobkin. Inclined entry of a blunt profile into an ideal fluid. Fluid Dynamics, 23(3):443-447, May 1988.

[9] Giorgio Riccardi and Alessandro Iafrati. Water impact of an asymmetric floating wedge. Journal of Engineering Mathematics, 49(1):19-39, May 2004. 
[10] G Xu, W Duan, and G Wu. Numerical simulation of oblique water entry of an asymmetrical wedge. Ocean Engineering, 35(16):1597-1603, November 2008.

[11] M S Seif, S M Mousaviraad, and S H Sadathosseini. ch Ar of Ar ch. Water, 17(2):205-212, 2004.

[12] R Algarín and O Tascón. Hydrodynamic Modeling of Planing Boats with Asymmetry and Steady Condition. In IX HSMV, volume 2, pages 1-9, Naples, 25-27 May 2011, 2011.

[13] Tam Truong, Nitin Repalle, Fabrizio Pistani, and Krish Thiagarajan. An experimental study of slamming impact during forced water entry. In 17th Australasian Fluid Mechanics Conference Auckland, New Zealand, number December.

[14] L Xu, A. W. TROESCH, and W. S. VORUS. Asymmetric vessel impact and planing hydrodynamics. Journal of ship research, 42(3):187-198.

[15] B Chekin. The entry of a wedge into an incompressible fluid. Journal of Applied Mathematics and Mechanics, 53(3):300-307, 1989.

[16] Z Qin and R.C. Batra. Local slamming impact of sandwich composite hulls. International Journal of Solids and Structures, 46(10):2011-2035, 2009.

[17] A. Korobkin. Unsteady hydroelasticity of floating plates. Journal of Fluids and Structures, 14:971-991, 2000.

[18] A. Korobkin, T.I. Khabakhpasheva, and G.X. Wu. Coupled hydrodynamic and structural analysis of compressible jet impact onto elastic panels. Journal of Fluids and Structures, 24(7):1021-1041, October 2008.

[19] A. Korobkin, R. Guéret, and Š. Malenica. Hydroelastic coupling of beam finite element model with Wagner theory of water impact. Journal of Fluids and Structures, 22(4):493-504, May 2006.

[20] A Iafrati and A. Korobkin. Hydrodynamic loads during early stage of flat plate impact onto water surface. Physics of Fluids, 20(8):082104, 2008. 
[21] G. Aertssen. Laboring of ship in rough seas with special emphasis on the fast ship. In SNAME Diamond Jubilee International Meeting, New york, NY: SNAME, pages 10.1-10.16, 1968.

[22] Paolo Manganelli, Ship Science, and Engineering Sciences. An experimental investigation of slamming on ocean racing yachts . Small, 1978.

[23] X Chen, Y Wu, W Cui, and J Jensen. Review of hydroelasticity theories for global response of marine structures. Ocean Engineering, 33(3-4):439-457, March 2006.

[24] Alexander Korobkin, Emilian Parau, and Jean-Marc VandenBroeck. The mathematical challenges and modelling of hydroelasticity. Philosophical transactions. Series A, Mathematical, physical, and engineering sciences, 369(1947):2803-12, July 2011.

[25] Sheng-Lun Chuang. Investigation of impact of rigid and elastic bodies with water. NSRDC report no. 3248, 1970.

[26] Antonio Carcaterra and Elena Ciappi. Prediction of the Compressible Stage Slamming Force on Rigid and Elastic Systems Impacting on the Water Surface. Nonlinear Dynamics, pages 193-220, 2000.

[27] M Arai and T Miyanchi. Numerical study of the impact of water on cylindrical shells, considering fluid structure interactions. Developments in Marine Technology, 11:59-68, 1998.

[28] Odd M. Faltinsen. Hydroelastic slamming. Journal of Marine Science and Technology, 5(2):49-65, January 2001.

[29] G K Kapsenberg. Slamming of ships: where are we now? Philosophical transactions. Series A, Mathematical, physical, and engineering sciences, 369(1947):2892-919, July 2011.

[30] O. M. Faltinsen. The effect of hydroelasticity on ship slamming. Philosophical Transactions of the Royal Society A: Mathematical, Physical and Engineering Sciences, 355(1724):575-591, March 1997. 
[31] A Bereznitski. Slamming: The role of hydroelasticity. International Shipbuilding Progress, 48(4):333-351, 2001.

[32] A Carcaterra. Hydrodynamic shock of elastic structures impacting on the water: theory and experiments. Journal of Sound and Vibration, 271(1-2):411439, March 2004.

[33] C.H Lu, Y.S HE, G.X Wu, and Torrington Place. Coupled analysis of nonlinear interaction between fluid and structure impact. Journal of Fluids and Structures, 14:127-146, 2000.

[34] B Peseux, L Gornet, and B Donguy. Hydrodynamic impact: Numerical and experimental investigations. Journal of Fluids and Structures, 21(3):277-303, November 2005.

[35] Y Scolan. Hydroelastic behaviour of a conical shell impacting on a quiescentfree surface of an incompressible liquid. Journal of Sound and Vibration, 277(1-2):163-203, October 2004.

[36] S. Charca, B. Shafiq, and F. Just. Repeated Slamming of Sandwich Composite Panels on Water. Journal of Sandwich Structures and Materials, 11(5):409424, June 2009.

[37] S. Charca and B. Shafiq. Damage Assessment Due to Single Slamming of Foam Core Sandwich Composites. Journal of Sandwich Structures and Materials, 12(1):97-112, June 2009.

[38] S E Hirdaris and P Temarel. Hydroelasticity of ships: recent advances and future trends. Proceedings of the Institution of Mechanical Engineers, Part M: Journal of Engineering for the Maritime Environment, 223(3):305-330, March 2009.

[39] G Wu. Numerical simulation and experimental study of water entry of a wedge in free fall motion. Journal of Fluids and Structures, 19(3):277-289, April 2004. 
[40] C Seddon and M Moatamedi. Review of water entry with applications to aerospace structures. International Journal of Impact Engineering, 32(7):1045-1067, July 2006.

[41] I. Stenius, a. Rosén, and J. Kuttenkeuler. Hydroelastic interaction in panelwater impacts of high-speed craft. Ocean Engineering, 38(2-3):371-381, February 2011.

[42] R A Dalrymple and B D Rogers. Numerical modeling of water waves with the SPH method. Coastal Engineering, 53(2-3):141-147, 2006.

[43] G Oger, M Doring, B Alessandrini, and P Ferrant. Two-dimensional SPH simulations of wedge water entries. Journal of Computational Physics, 213(2):803-822, 2006.

[44] A Khayyer, H Gotoh, and S Shao. Corrected Incompressible SPH method for accurate water-surface tracking in breaking waves. Coastal Engineering, $55(3): 236-250,2008$.

[45] Marco Anghileri, Luigi-Maria L. Castelletti, Edoardo Francesconi, Andrea Milanese, and Michele Pittofrati. Rigid body water impact: experimental tests and numerical simulations using the SPH method. International Journal of Impact Engineering, 38(4):141-151, April 2011.

[46] Songdong Shao. Incompressible SPH simulation of water entry of a free-falling object. Simulation, 59(April 2008):91-115, 2009.

[47] D. Battistin and A. Iafrati. A numerical model for the jet flow generated by water impact. Journal of Engineering Mathematics, 48(3/4):353-374, April 2004.

[48] A Colagrossi. Numerical simulation of interfacial flows by smoothed particle hydrodynamics. Journal of Computational Physics, 191(2):448-475, November 2003.

[49] D Molteni and A Colagrossi. A simple procedure to improve the pressure evaluation in hydrodynamic context using the SPH. Computer Physics Communications, 180(6):861-872, 2009. 
[50] M Geoffrey and P D Smith. Blast effects on buildings: design of buildings to optimize resistance to blast loading. 1995.

[51] A. Korobkin, a. S. Ellis, and F. T. Smith. Trapping of air in impact between a body and shallow water. Journal of Fluid Mechanics, 611:365-394, August 2008.

[52] Sheng-Lun Chuang and David T. Milne. Drop tests of cone to investigate the three-dimensional effect of slamming. NRDC report no. 3543, 1971.

[53] Sheng-Lun Chuang. Slamming of rigid wedge-shaped bodies with various deadrise angles. NSRDC report 2268, (October), 1966.

[54] A Engle. A comparison of hydrodynamic impacts prediction methods with two dimensional drop test data. Marine Structures, 16(2):175-182, April 2003.

[55] F.J. Huera-Huarte, D. Jeon, and M. Gharib. Experimental investigation of water slamming loads on panels. Ocean Engineering, 38(11-12):1347-1355, July 2011.

[56] Simon G Lewis, Dominic a Hudson, Stephen R Turnock, and Dominic J Taunton. Impact of a free-falling wedge with water: synchronized visualization, pressure and acceleration measurements. Fluid Dynamics Research, 42(3):035509, June 2010.

[57] O.M. Faltinsen. Water entry of a wedge by hydroelastic orthotropic plate theory. Journal of ship research, 43(3):180-193, 1999.

[58] G Yupu, Z Zhenhua, C Wei, and G Deping. Foreign Object Damage to Fan Rotor Blades of Aeroengine Part II: Numerical Simulation of Bird Impact. Chinese Journal of Aeronautics, 21(4):328-334, August 2008.

[59] John Brett. Numerical modeling of shock wave and pressure pulse generation by underwater explosion. Technical report, Department of Defence, 1998.

[60] M.B. Liu, G.R. Liu, and K.Y. Lam. Investigations into water mitigation using a meshless particle method. Shock Waves, 12(3):181-195, November 2002. 
[61] Daniel J Veen and Tim P Gourlay. SPH Study of High Speed Ship Slamming. In 3rd ERCOFTAC SPHERIC workshop on SPH applications June 4th-6th 2008, Lausanne, Switzerland.

[62] A Khayyer, Hitoshi Gotoh, and Songdong Shao. Enhanced predictions of wave impact pressure by improved incompressible SPH methods. Applied Ocean Research, 31(2):111-131, January 2009.

[63] Carla Antoci, Mario Gallati, and Stefano Sibilla. Numerical simulation of fluid-structure interaction by SPH. Computers $\mathcal{E}$ Structures, 85(11-14):879$890,2007$.

[64] S. Marrone, M. Antuono, a. Colagrossi, G. Colicchio, D. Le Touzé, and G. Graziani. $\delta$-SPH model for simulating violent impact flows. Computer Methods in Applied Mechanics and Engineering, 200(13-16):1526-1542, March 2011.

[65] Gordon R Johnson. Artificial viscosity effects for SPH impact computations. International Journal of Impact Engineering, 18(5):477-488, 1996.

[66] M. Nejad-Asghar, a. R. Khesali, and J. Soltani. Artificial viscosity in simulation of shock waves by smoothed particle hydrodynamics. Astrophysics and Space Science, 313(4):425-430, December 2007.

[67] Ali Mani, Johan Larsson, and Parviz Moin. Suitability of artificial bulk viscosity for large-eddy simulation of turbulent flows with shocks. Journal of Computational Physics, 228(19):7368-7374, October 2009.

[68] P. W. Randles and L. D. Libersky. Normalized SPH with stress points. International Journal for Numerical Methods in Engineering, 48(10):1445-1462, August 2000.

[69] Magnus Selhammar. Modified Artificial Viscosity in Smooth Particle Hydrodynamics. Observatory, (1989):1-7, 1996.

[70] Gong Kai, Liu Hua, and Wang Ben-long. Water entry of a wedge based on SPH model with an imporved boudary treatment. J Hydrodyn, 21(6):750-757, January 2009. 

APPENDIX I

\section{Experimental results}

For clarity, only a very reduced number of the experimental results have been presented in the main text. In the following are presented the remaining experimental results. For each configuration, only one repetition will be shown, due to the high repeatability encountered during the experiments.

\section{Abbreviations:}

- $\mathrm{A}=$ Aluminium plate.

- $\mathrm{V}=$ E-glass (mat) / Vynilester. Manufacturing technique: VARTM .

- $\mathrm{W}=$ E-glass(woven) / epoxy. Manufacturing technique: autoclave. 


\section{I.1 Aluminium wedges}
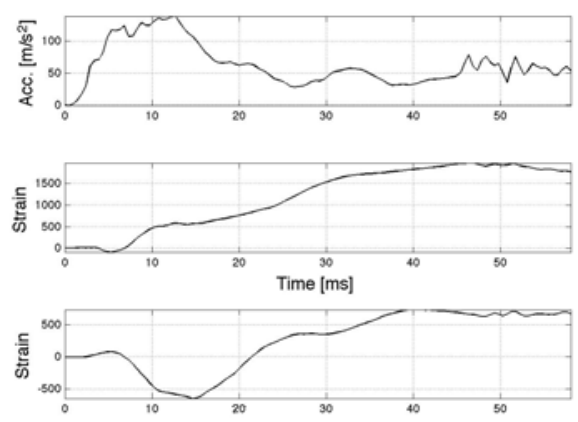

Figure I.1: $2 \beta 35^{\circ}$ impact height 225 $\mathrm{cm}$
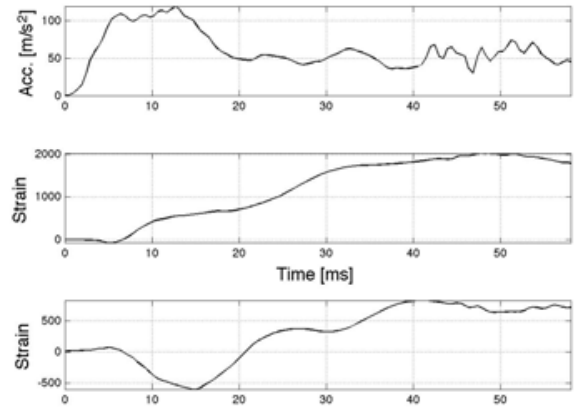

Figure I.2: A2 $\beta 35^{\circ}$ impact height 200 $\mathrm{cm}$
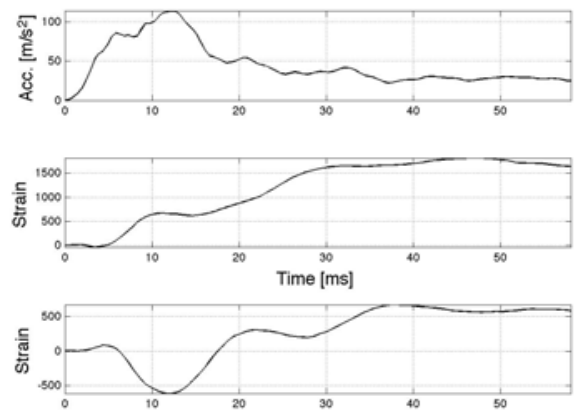

Figure I.3: A2 $\beta 35^{\circ}$ impact height 175 $\mathrm{cm}$
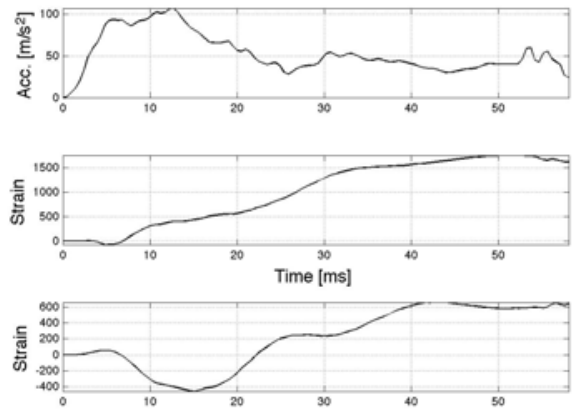

Figure I.4: A2 $\beta 35^{\circ}$ impact height 150 $\mathrm{cm}$
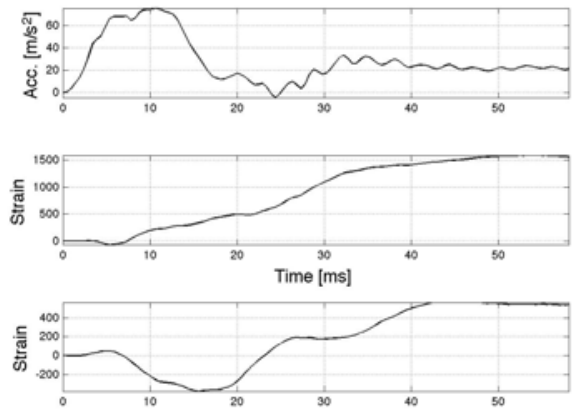

Figure I.5: A $\beta 35^{\circ}$ impact height 125 $\mathrm{cm}$
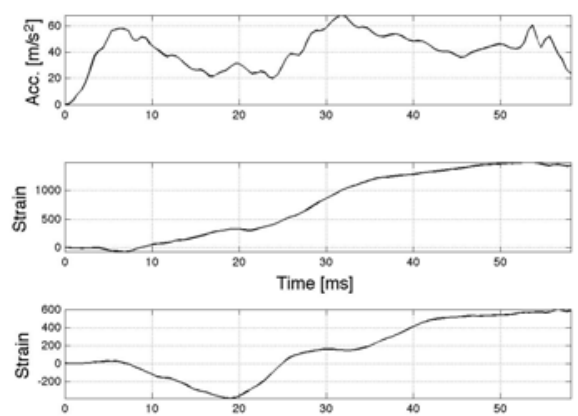

Figure I.6: A $\beta 35^{\circ}$ impact height 100 $\mathrm{cm}$ 

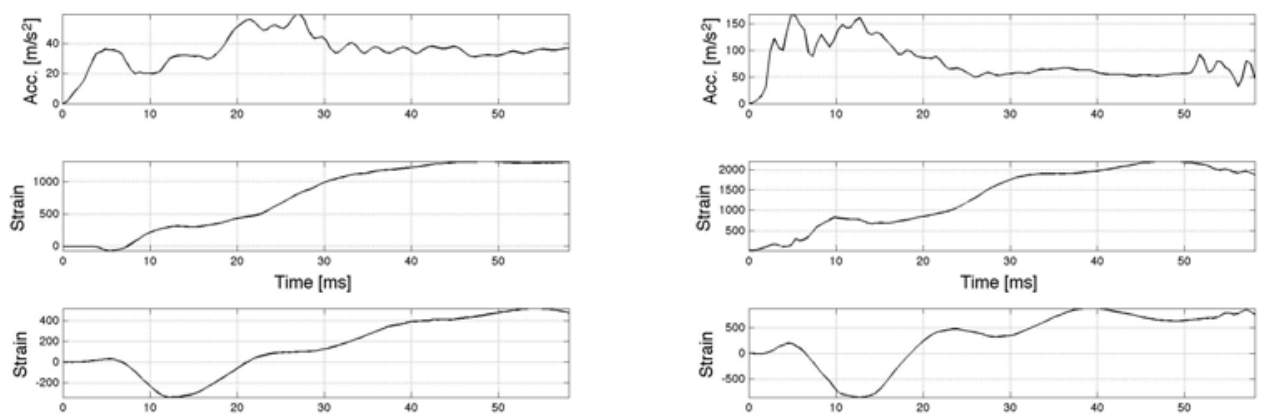

Figure I.7: A2 $\beta 35^{\circ}$ impact height 75 $\mathrm{cm}$

Figure I.10: A2 $\beta 30^{\circ}$ impact height 225 $\mathrm{cm}$
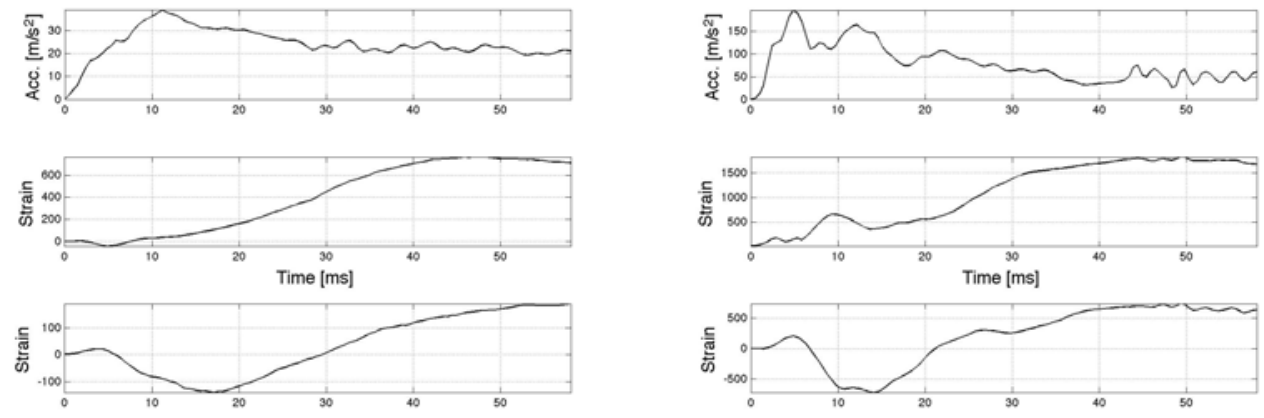

Figure I.8: A2 $\beta 35^{\circ}$ impact height 50 $\mathrm{cm}$

Figure I.11: A2 $\beta 30^{\circ}$ impact height 200 $\mathrm{cm}$
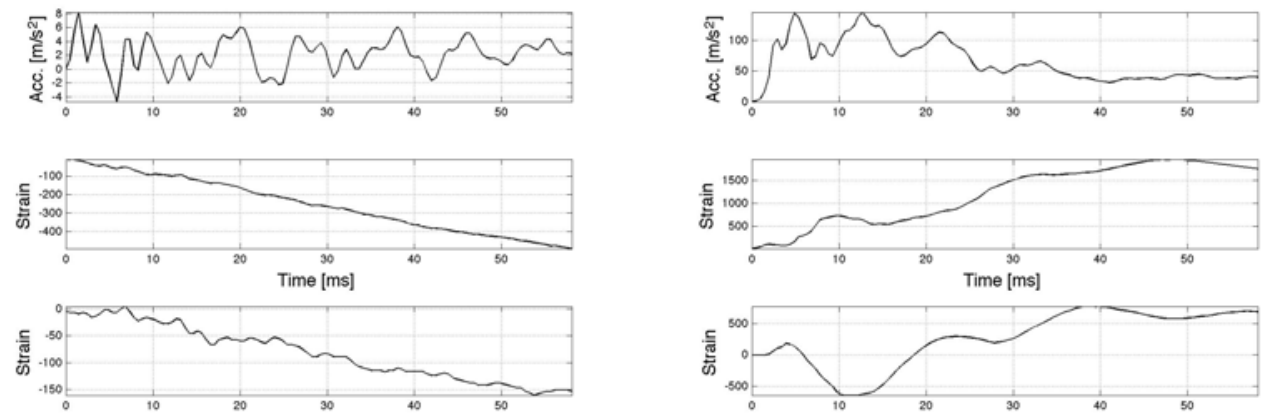

Figure I.9: A2 $\beta 35^{\circ}$ impact height 25 $\mathrm{cm}$

Figure I.12: A $2 \beta 30^{\circ}$ impact height 175 $\mathrm{cm}$ 

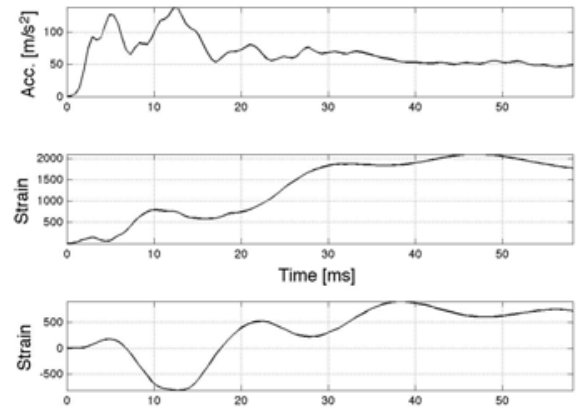

Figure I.13: A $2 \beta 30^{\circ}$ impact height 150 $\mathrm{cm}$
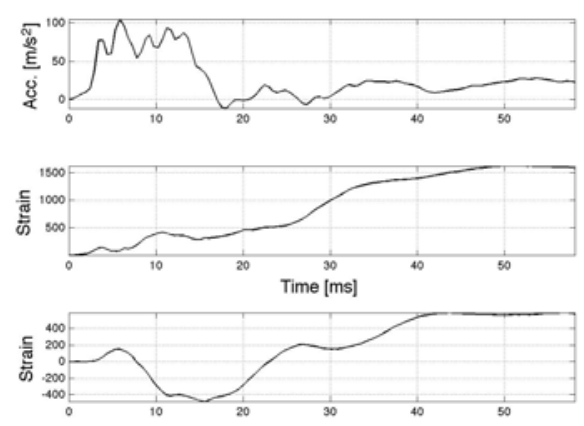

Figure I.14: A2 $\beta 30^{\circ}$ impact height 125 $\mathrm{cm}$
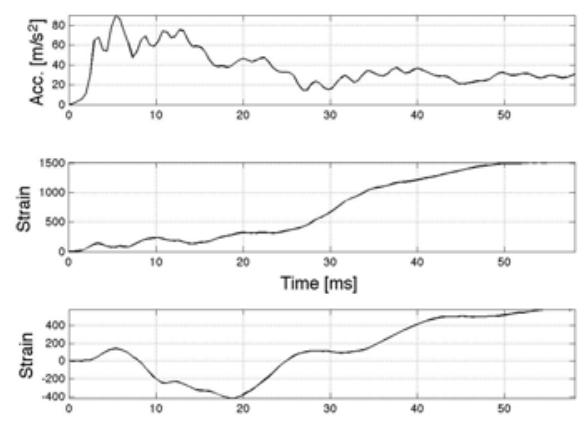

Figure I.15: A2 $\beta 30^{\circ}$ impact height 100 $\mathrm{cm}$
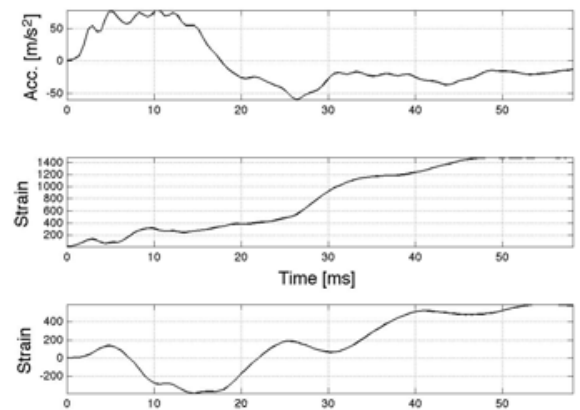

Figure I.16: A2 $\beta 30^{\circ}$ impact height 75 $\mathrm{cm}$
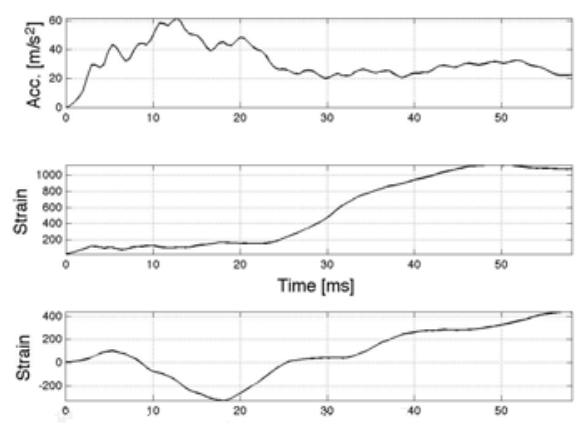

Figure I.17: A2 $\beta 30^{\circ}$ impact height 50 $\mathrm{cm}$
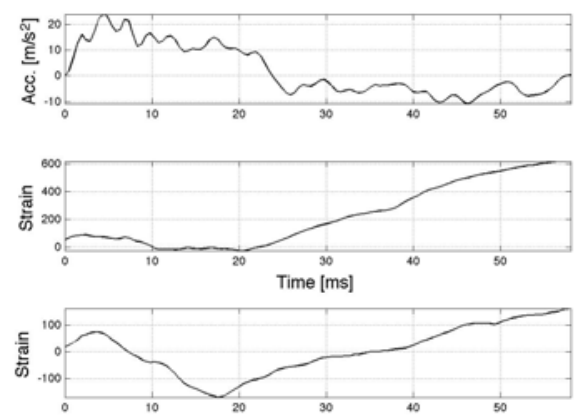

Figure I.18: A2 $\beta 30^{\circ}$ impact height 25 $\mathrm{cm}$ 

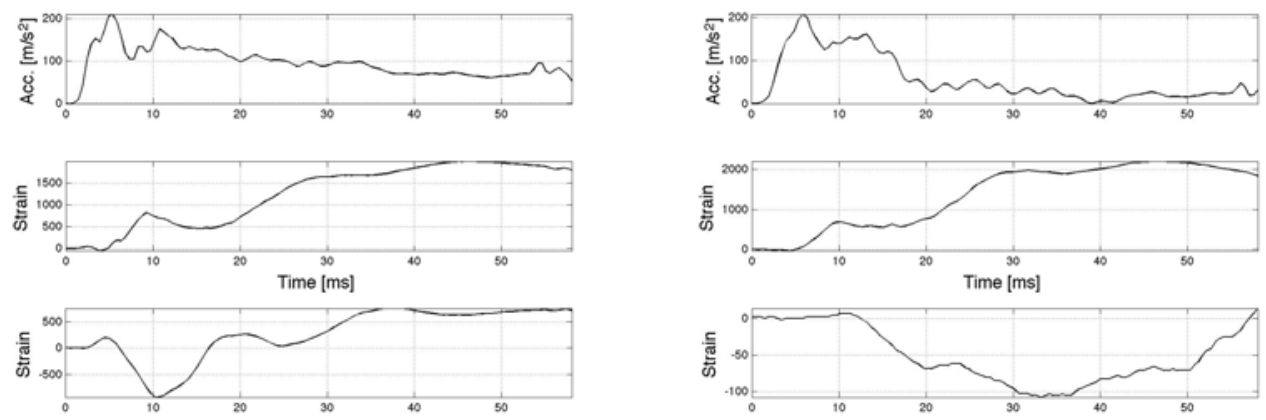

Figure I.19: A2 $\beta 25^{\circ}$ impact height 225 $\mathrm{cm}$

Figure I.22: A2 $\beta 25^{\circ}$ impact height 150 $\mathrm{cm}$
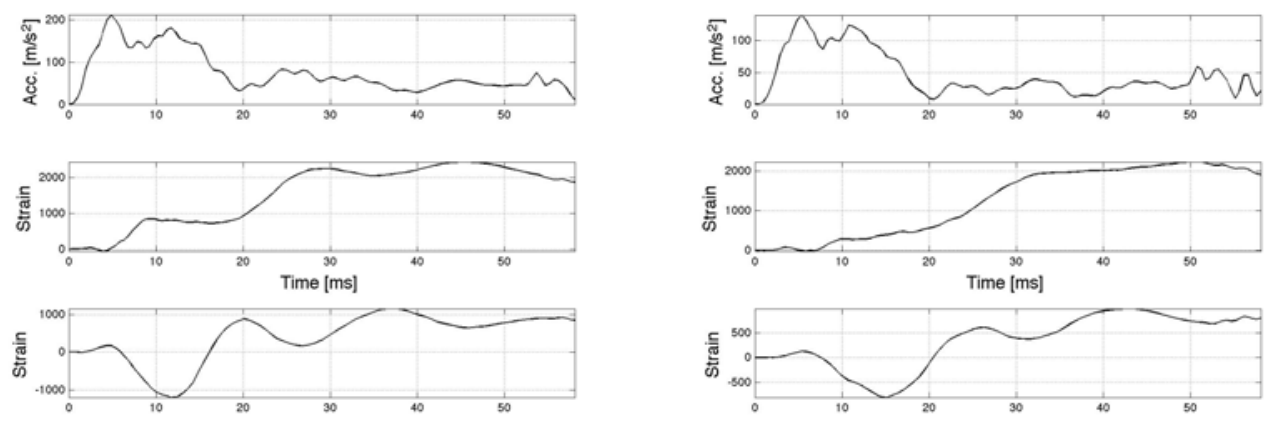

Figure I.20: A2 $\beta 25^{\circ}$ impact height 200 $\mathrm{cm}$

Figure I.23: A2 $\beta 25^{\circ}$ impact height 125 $\mathrm{cm}$
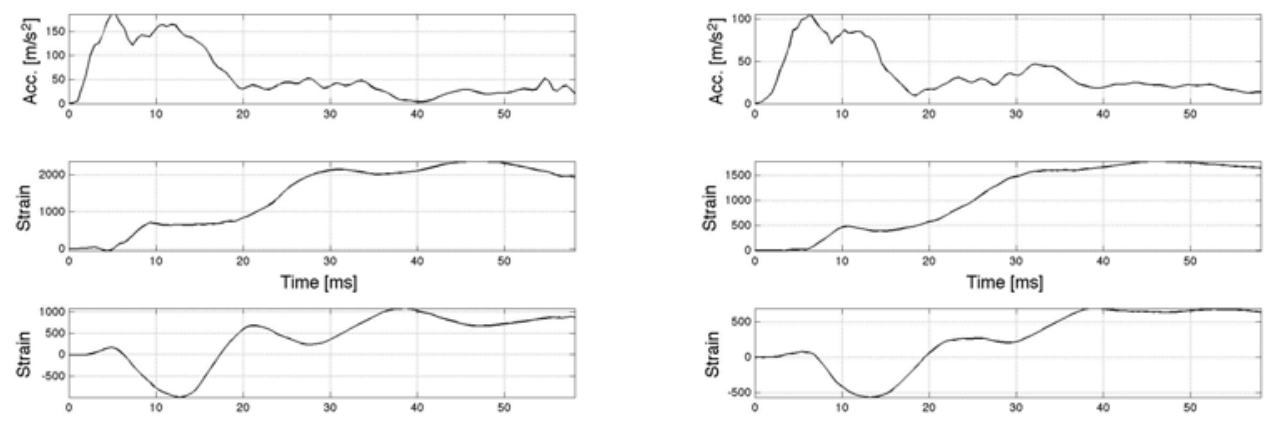

Figure I.21: A2 $\beta 25^{\circ}$ impact height 175 $\mathrm{cm}$

Figure I.24: A $\beta 25^{\circ}$ impact height 100 $\mathrm{cm}$ 

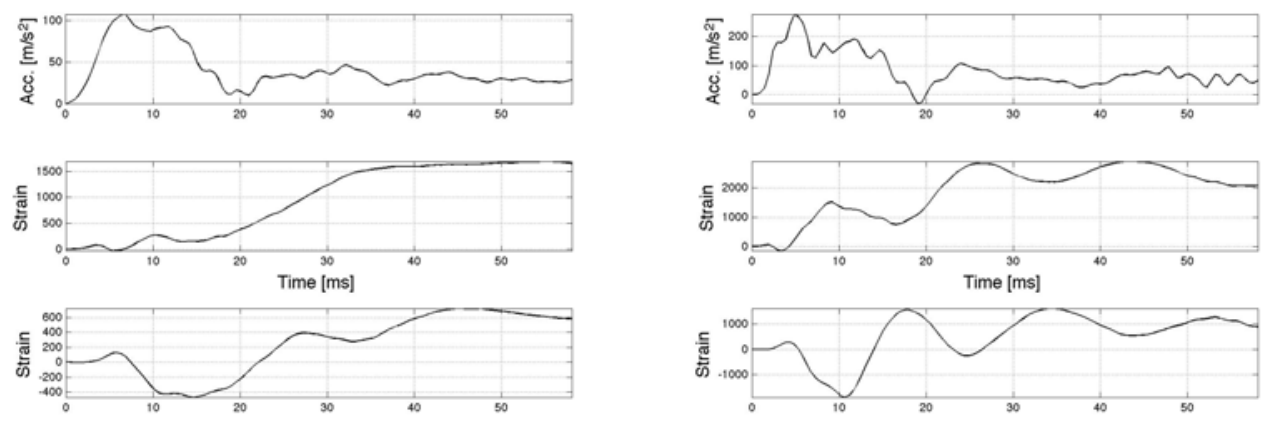

Figure I.25: A2 $\beta 25^{\circ}$ impact height 75 $\mathrm{cm}$

Figure I.28: A2 $\beta 20^{\circ}$ impact height 225 $\mathrm{cm}$
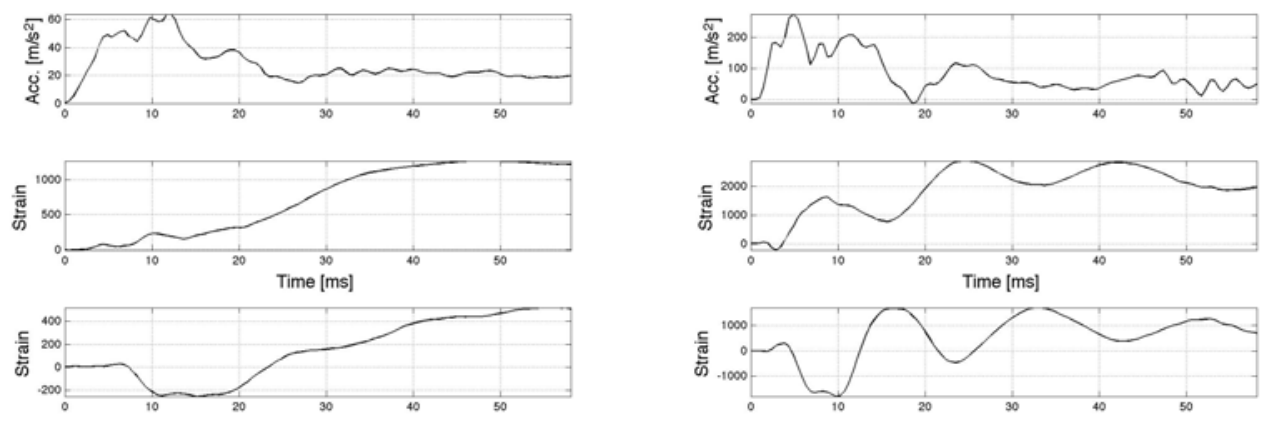

Figure I.26: A2 $\beta 25^{\circ}$ impact height 50 $\mathrm{cm}$

Figure I.29: A2 $\beta 20^{\circ}$ impact height 200 $\mathrm{cm}$
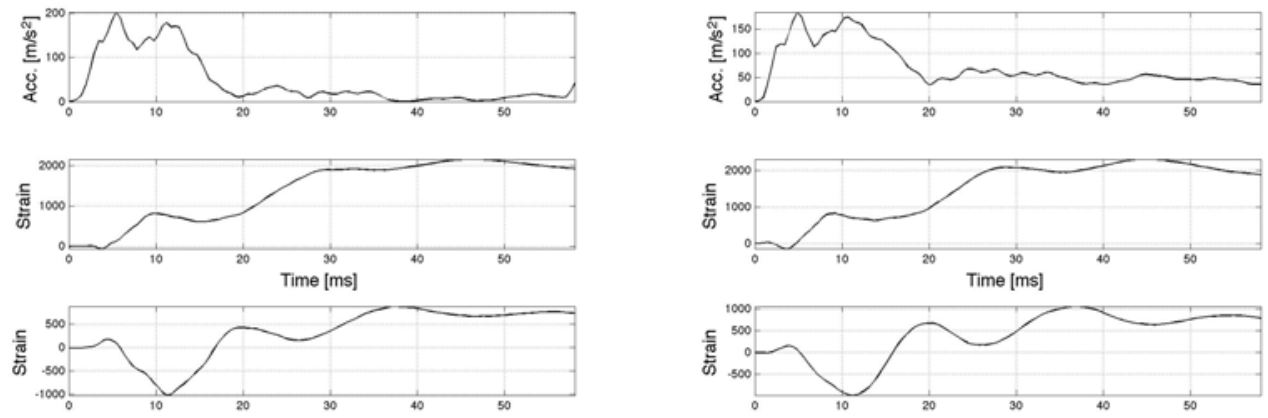

Figure I.27: A2 $\beta 25^{\circ}$ impact height 25 $\mathrm{cm}$

Figure I.30: A2 $\beta 20^{\circ}$ impact height 175 $\mathrm{cm}$ 

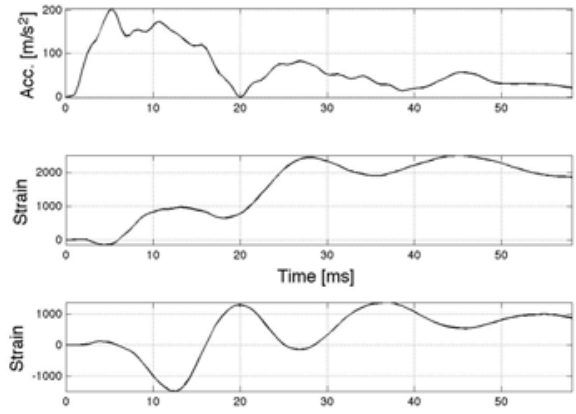

Figure I.31: A2 $\beta 20^{\circ}$ impact height 150 $\mathrm{cm}$
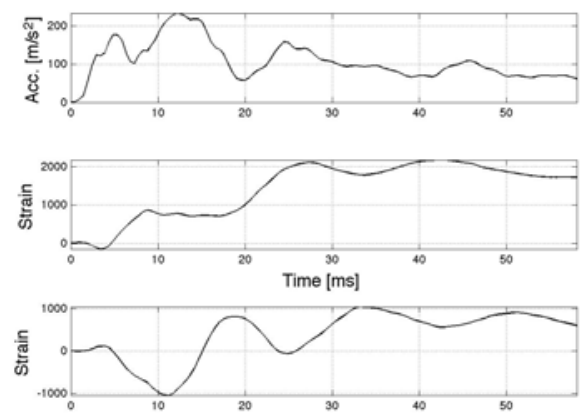

Figure I.32: A2 $\beta 20^{\circ}$ impact height 125 $\mathrm{cm}$
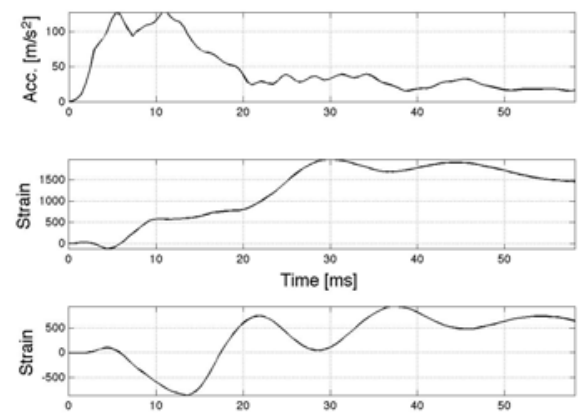

Figure I.33: A2 $\beta 20^{\circ}$ impact height 100 $\mathrm{cm}$
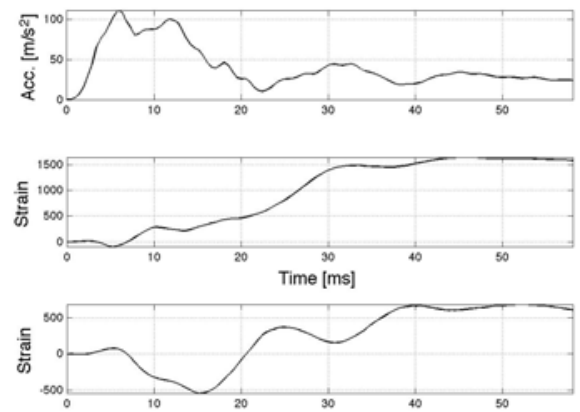

Figure I.34: A2 $\beta 20^{\circ}$ impact height 75 $\mathrm{cm}$
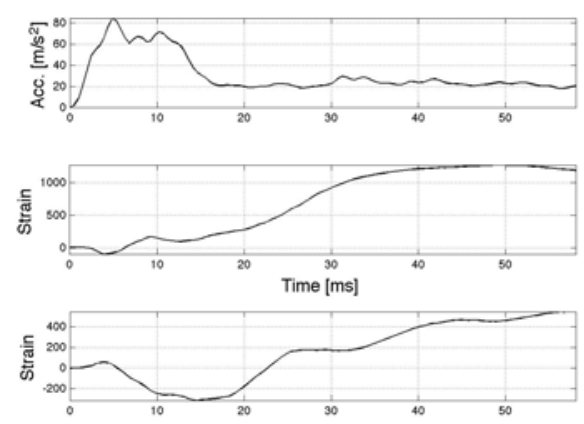

Figure I.35: A2 $\beta 20^{\circ}$ impact height 50 cm
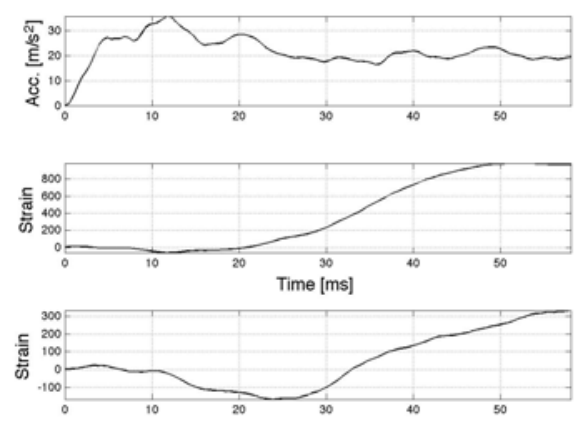

Figure I.36: A2 $\beta 20^{\circ}$ impact height 25 $\mathrm{cm}$ 

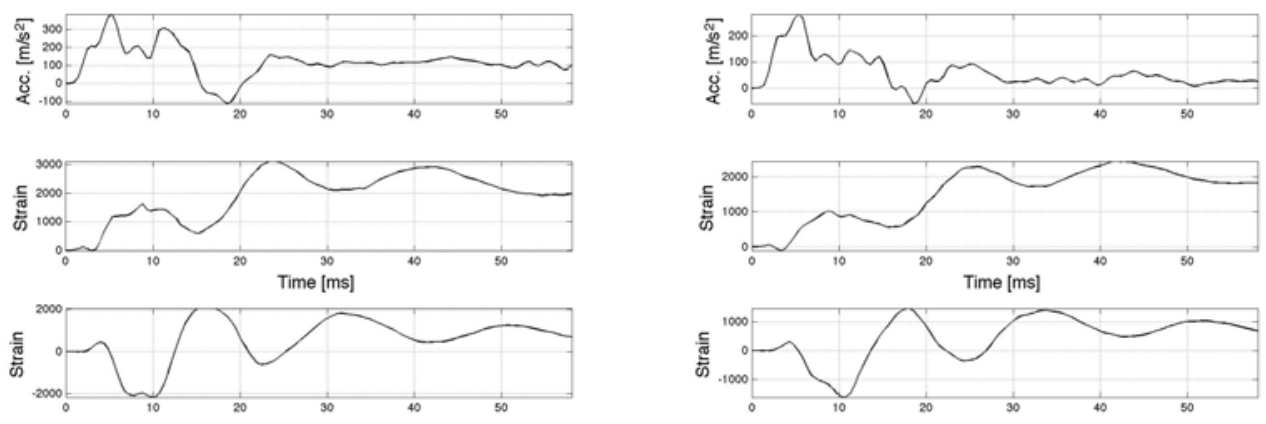

Figure I.37: A2 $\beta 15^{\circ}$ impact height 225 $\mathrm{cm}$

Figure I.40: A2 $\beta 15^{\circ}$ impact height 150 $\mathrm{cm}$
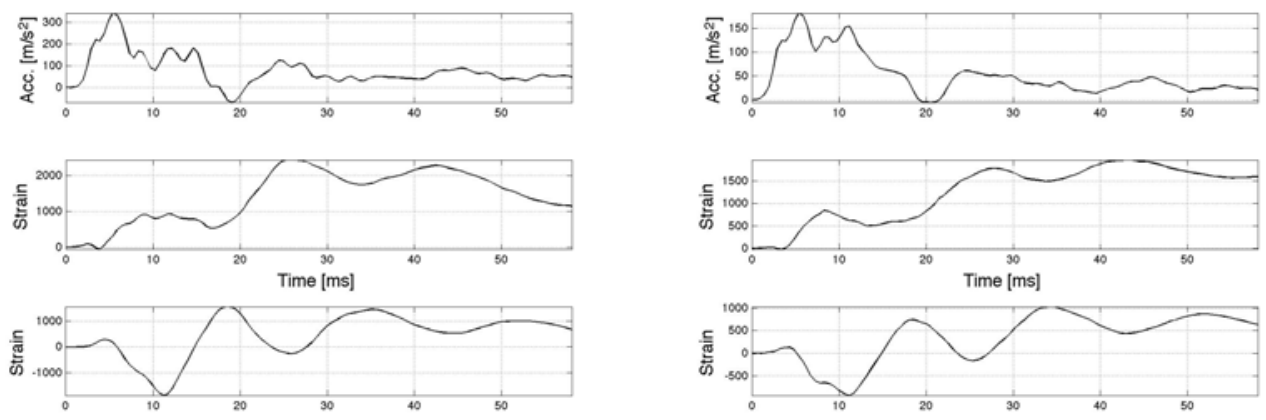

Figure I.38: A2 $\beta 15^{\circ}$ impact height 200 $\mathrm{cm}$

Figure I.41: A2 $\beta 15^{\circ}$ impact height 125 $\mathrm{cm}$
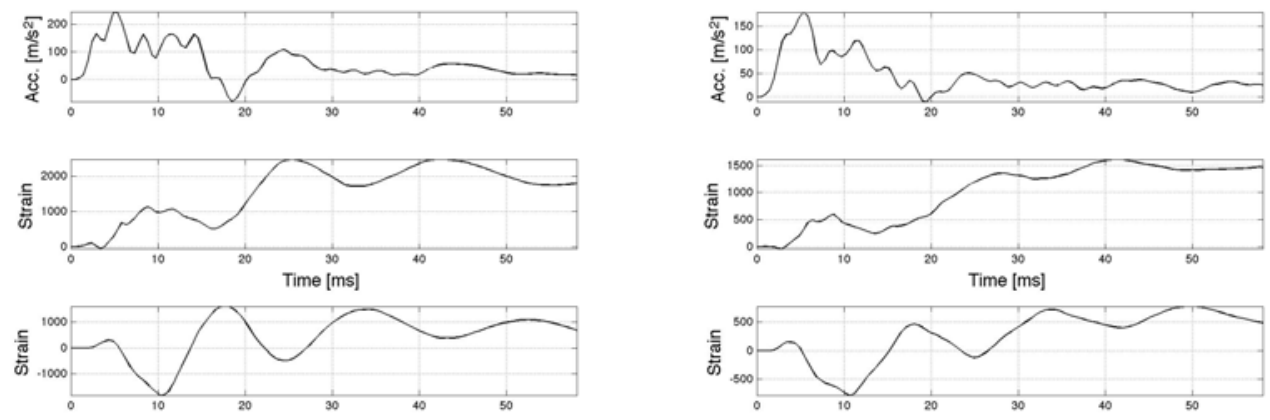

Figure I.39: A2 $\beta 15^{\circ}$ impact height 175 $\mathrm{cm}$

Figure I.42: A $\beta$ 15 $5^{\circ}$ impact height 100 $\mathrm{cm}$ 

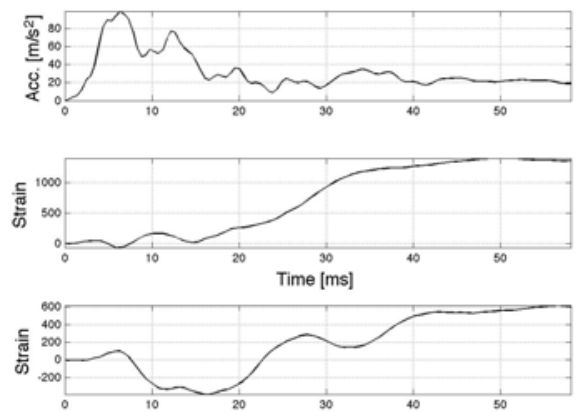

Figure I.43: A2 $\beta 15^{\circ}$ impact height 75 $\mathrm{cm}$
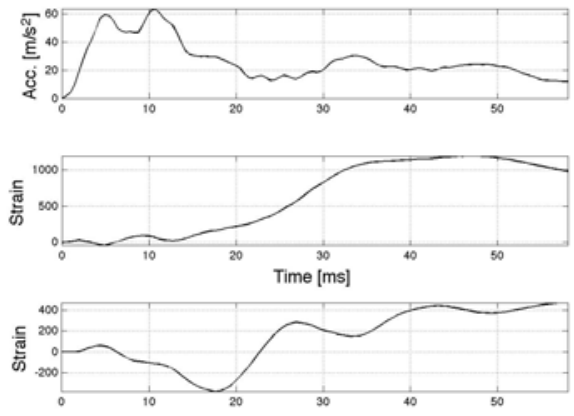

Figure I.44: A2 $\beta 15^{\circ}$ impact height 50 $\mathrm{cm}$
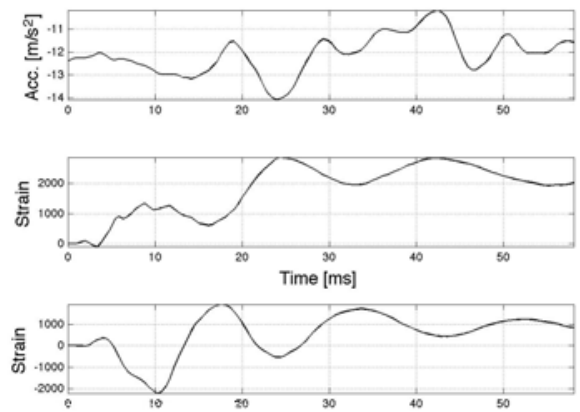

Figure I.45: A2 $\beta 15^{\circ}$ impact height 25 $\mathrm{cm}$ 


\section{Experimental results}

\section{I.2 Composite wedges - Mat}
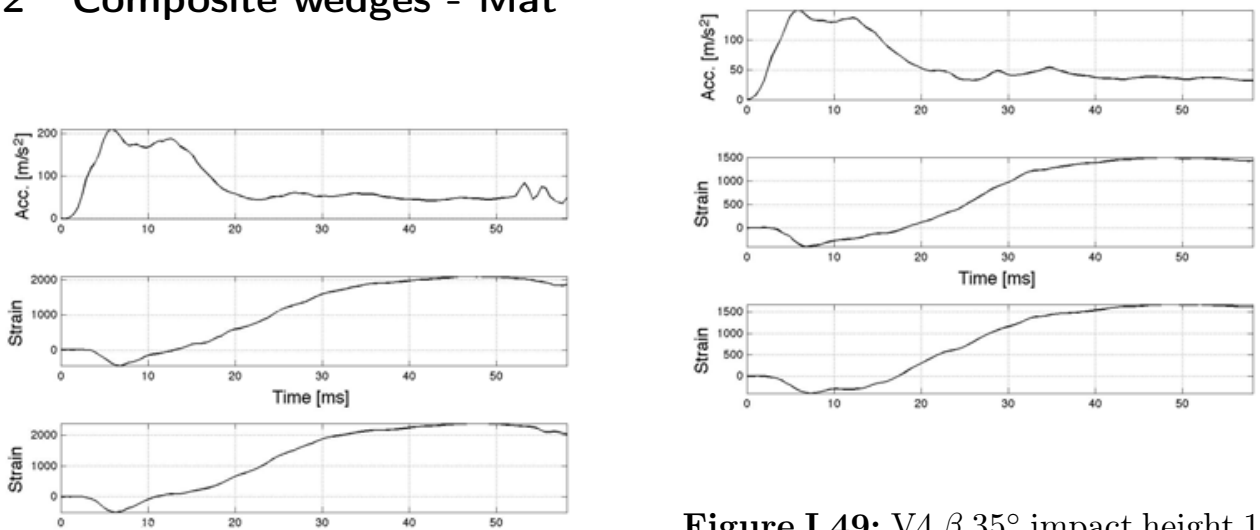

Figure I.49: V4 $\beta 35^{\circ}$ impact height 150 $\mathrm{cm}$

Figure I.46: V4 $\beta 35^{\circ}$ impact height 225 $\mathrm{cm}$
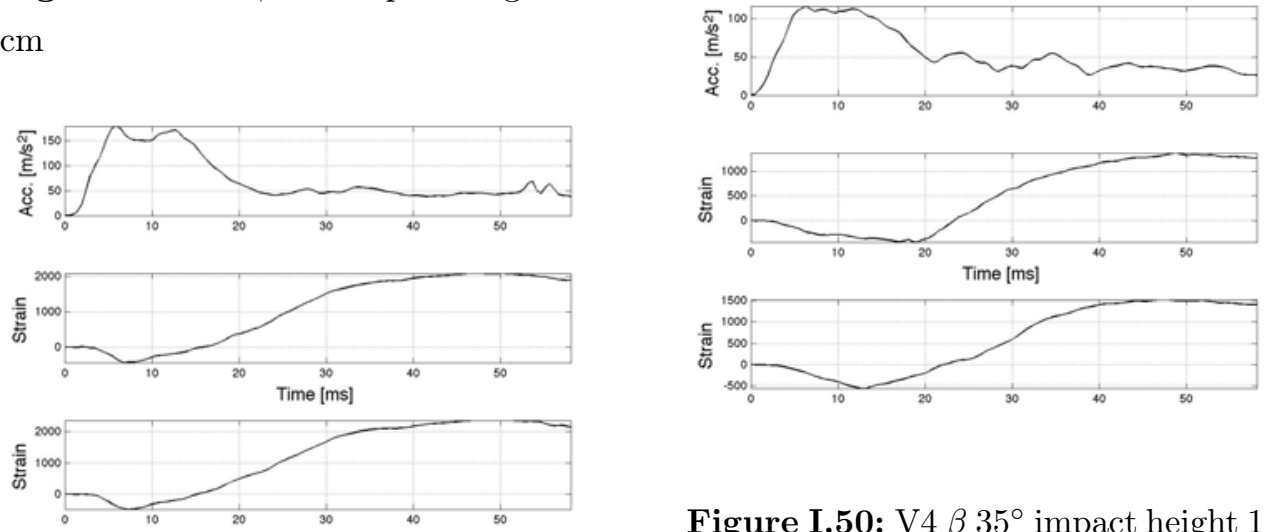

Figure I.50: V4 $\beta 35^{\circ}$ impact height 125 $\mathrm{cm}$

Figure I.47: V4 $\beta 35^{\circ}$ impact height 200 $\mathrm{cm}$
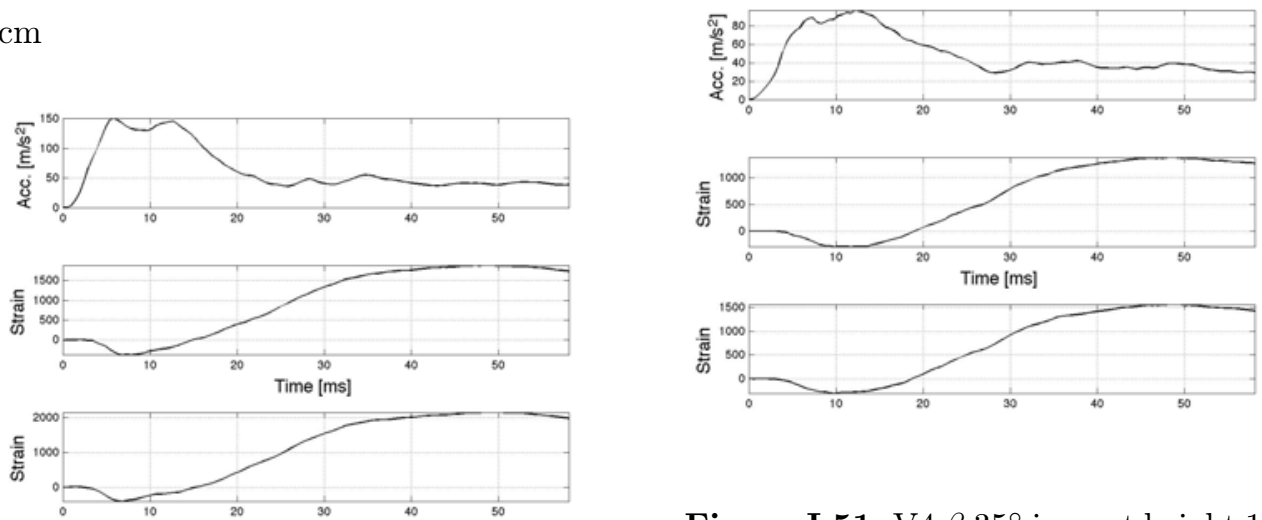

Figure I.51: $\mathrm{V} 4 \beta 35^{\circ}$ impact height 100 $\mathrm{cm}$

Figure I.48: V4 $\beta 35^{\circ}$ impact height 175 $\mathrm{cm}$ 

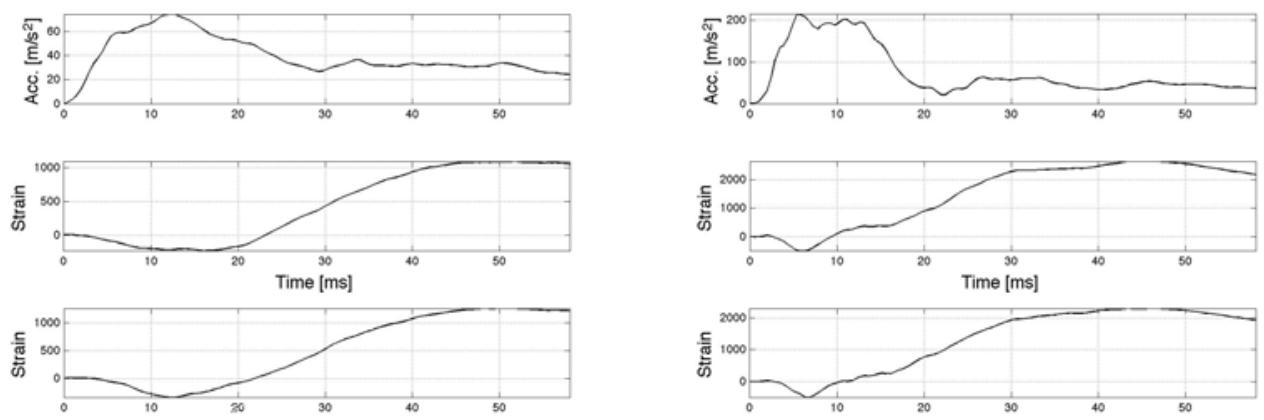

Figure I.52: V4 $\beta 35^{\circ}$ impact height 75 $\mathrm{cm}$

Figure I.55: V4 $\beta 30^{\circ}$ impact height 200 $\mathrm{cm}$
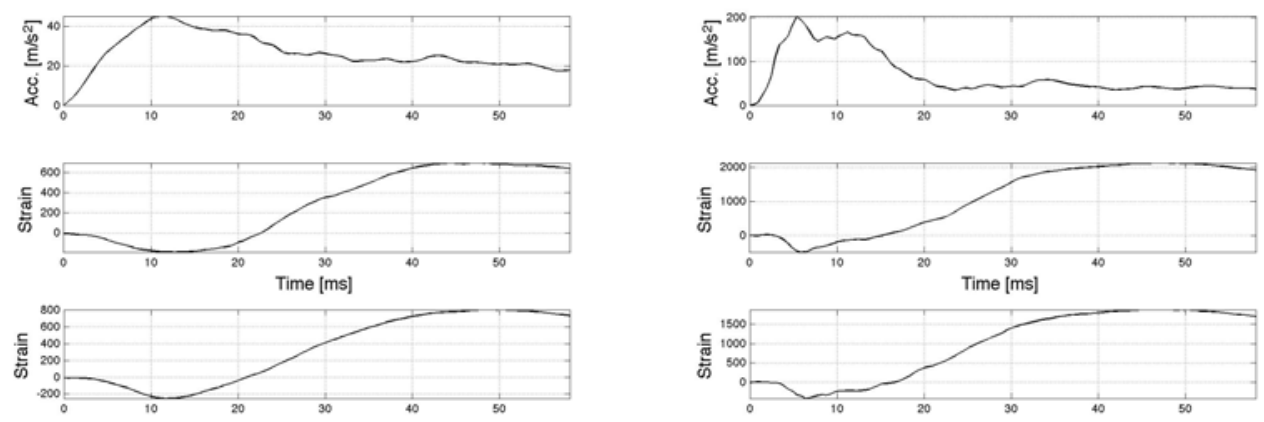

Figure I.53: V4 $\beta 35^{\circ}$ impact height 50 $\mathrm{cm}$

Figure I.56: V4 $\beta 30^{\circ}$ impact height 175 $\mathrm{cm}$
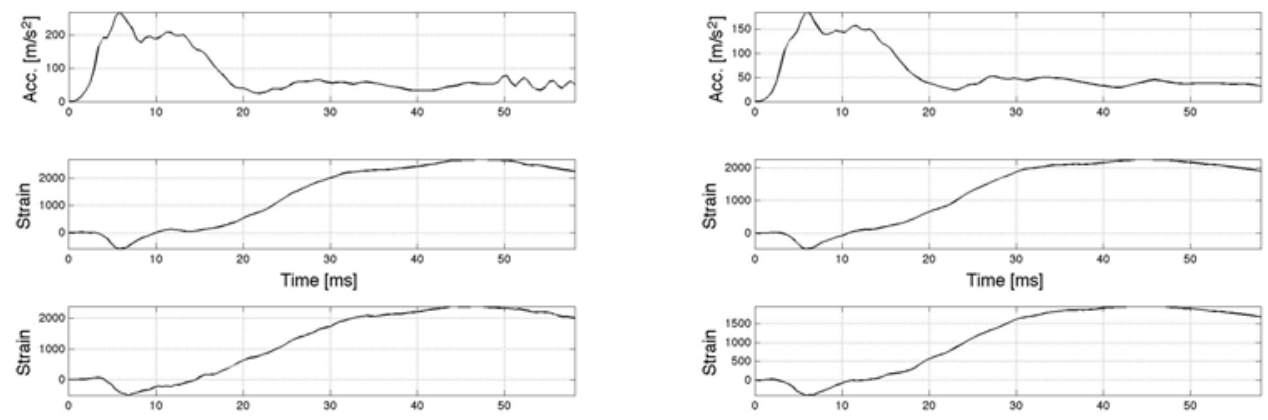

Figure I.54: V4 $\beta 30^{\circ}$ impact height 225 $\mathrm{cm}$

Figure I.57: V4 $\beta 30^{\circ}$ impact height 150 $\mathrm{cm}$ 

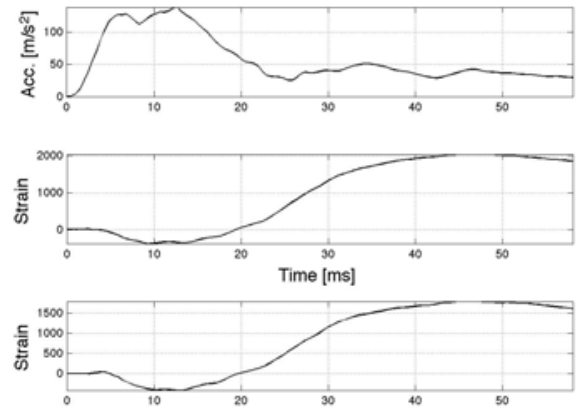

Figure I.58: V4 $\beta 30^{\circ}$ impact height 125 $\mathrm{cm}$
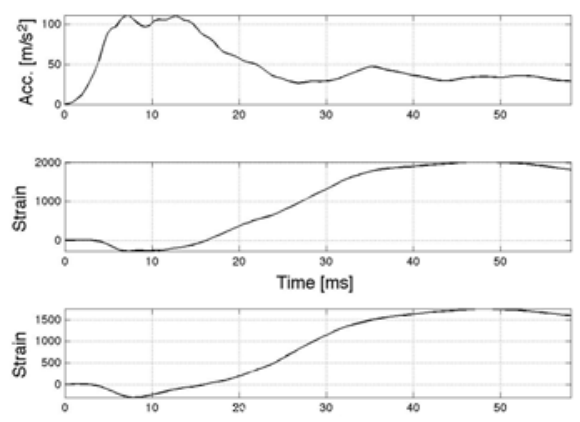

Figure I.59: V4 $\beta 30^{\circ}$ impact height 100 $\mathrm{cm}$
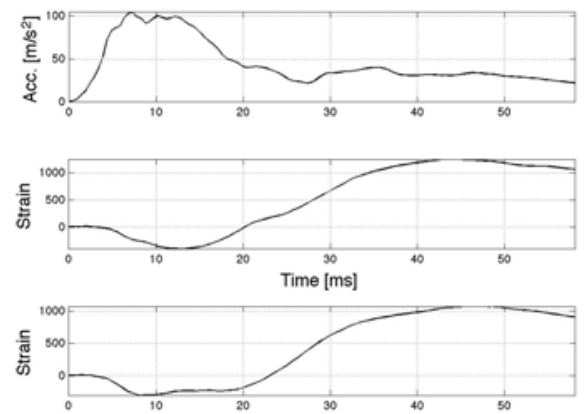

Figure I.60: V4 $\beta 30^{\circ}$ impact height 75 $\mathrm{cm}$
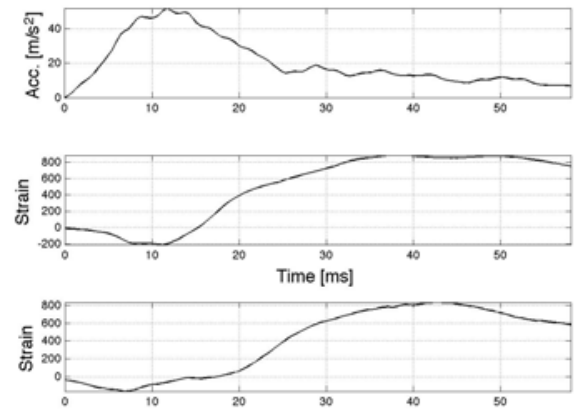

Figure I.61: V4 $\beta 30^{\circ}$ impact height 50 $\mathrm{cm}$
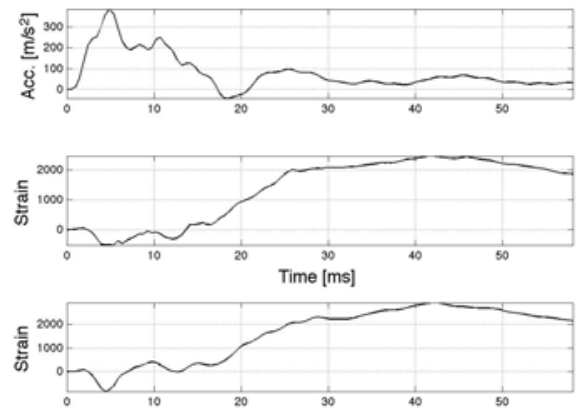

Figure I.62: V4 $\beta 25^{\circ}$ impact height 225 $\mathrm{cm}$
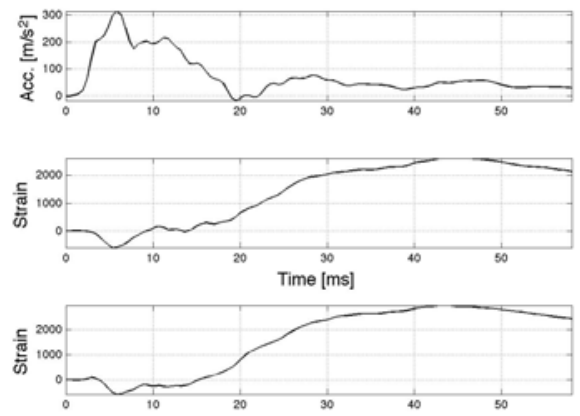

Figure I.63: V4 $\beta 25^{\circ}$ impact height 200 $\mathrm{cm}$ 

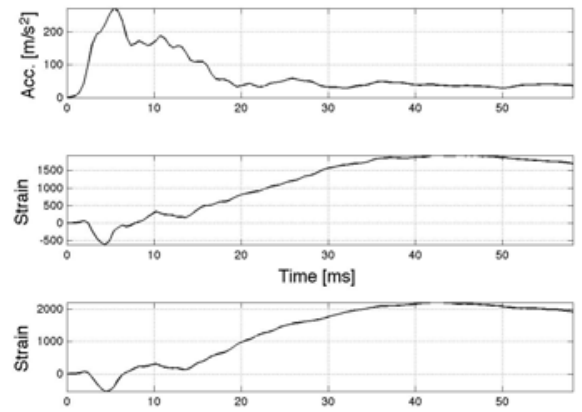

Figure I.64: V4 $\beta 25^{\circ}$ impact height 175 $\mathrm{cm}$
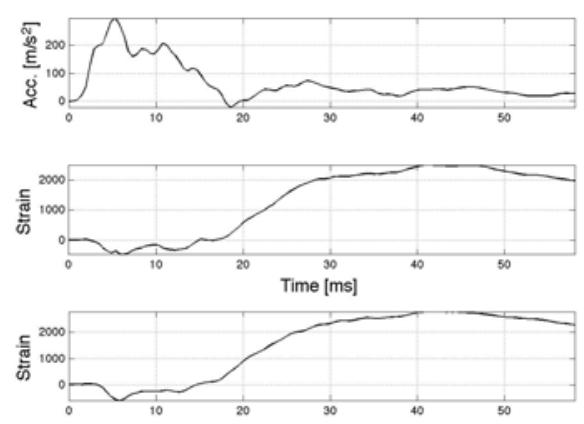

Figure I.65: V $4 \beta 25^{\circ}$ impact height 150 $\mathrm{cm}$
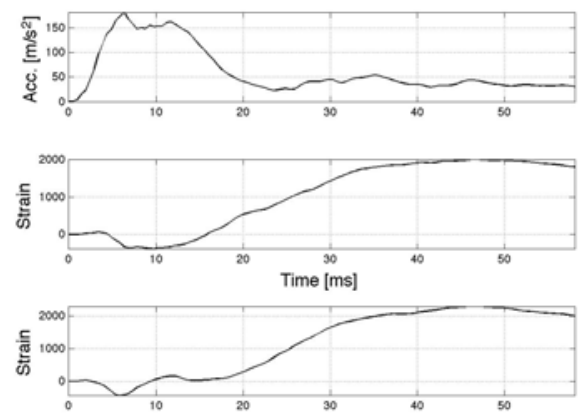

Figure I.66: V $4 \beta 25^{\circ}$ impact height 125 $\mathrm{cm}$
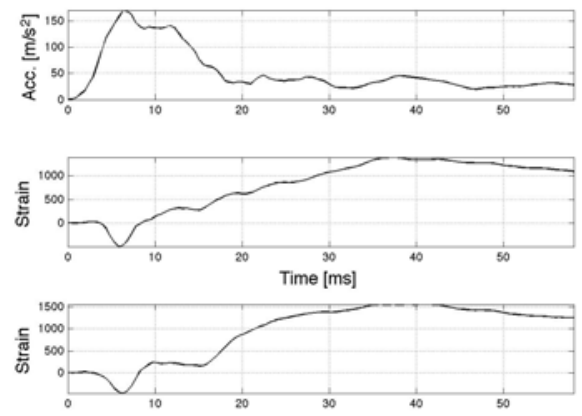

Figure I.67: V4 $\beta 25^{\circ}$ impact height 100 $\mathrm{cm}$
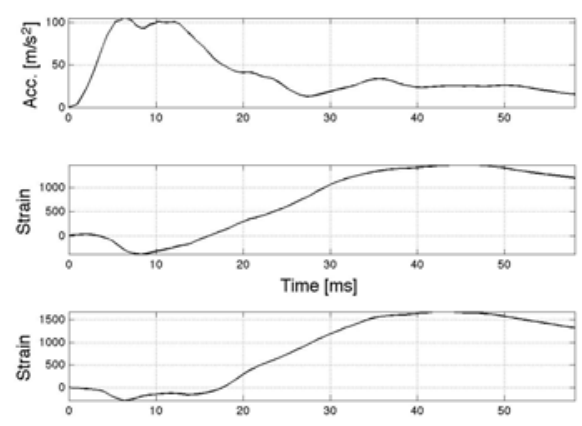

Figure I.68: V4 $\beta 25^{\circ}$ impact height 75 $\mathrm{cm}$
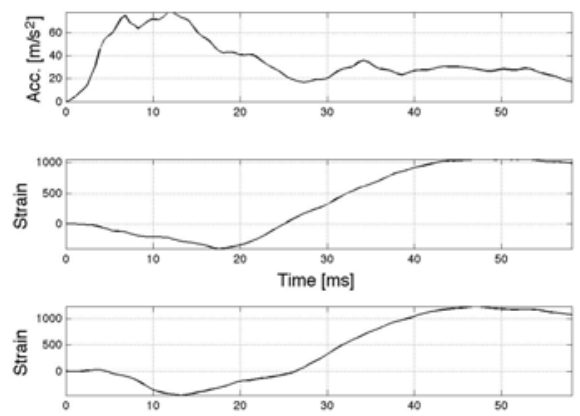

Figure I.69: V4 $\beta 25^{\circ}$ impact height 50 $\mathrm{cm}$ 

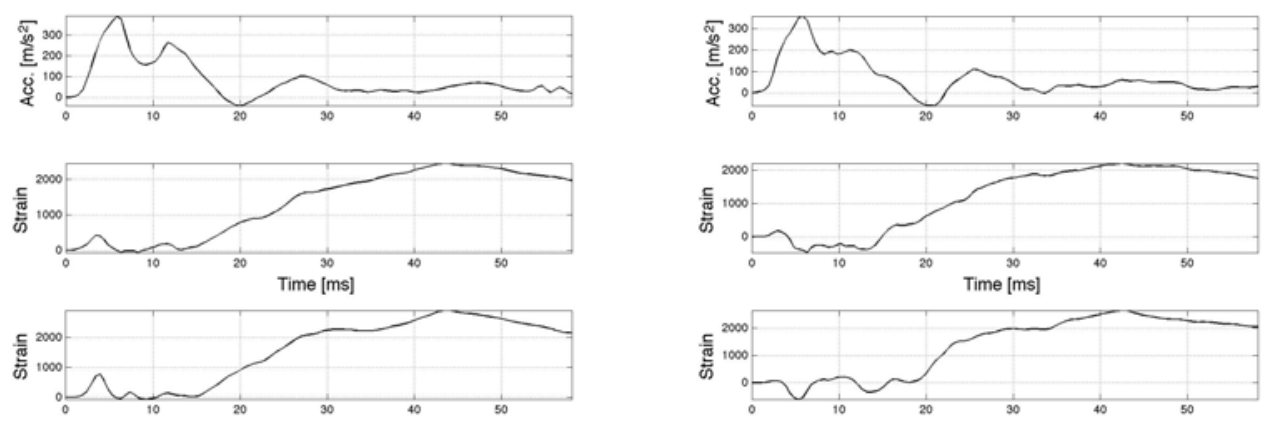

Figure I.70: V $4 \beta 20^{\circ}$ impact height 225 $\mathrm{cm}$

Figure I.73: V $4 \beta 20^{\circ}$ impact height 150 $\mathrm{cm}$
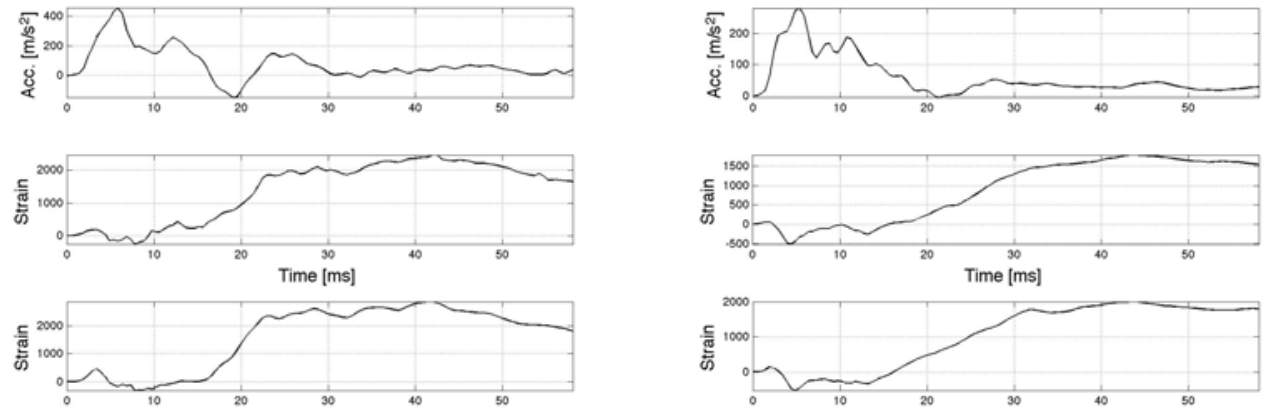

Figure I.71: V4 $\beta 20^{\circ}$ impact height 200 Figure I.74: V4 $\beta 20^{\circ}$ impact height 125 $\mathrm{cm}$

$\mathrm{cm}$
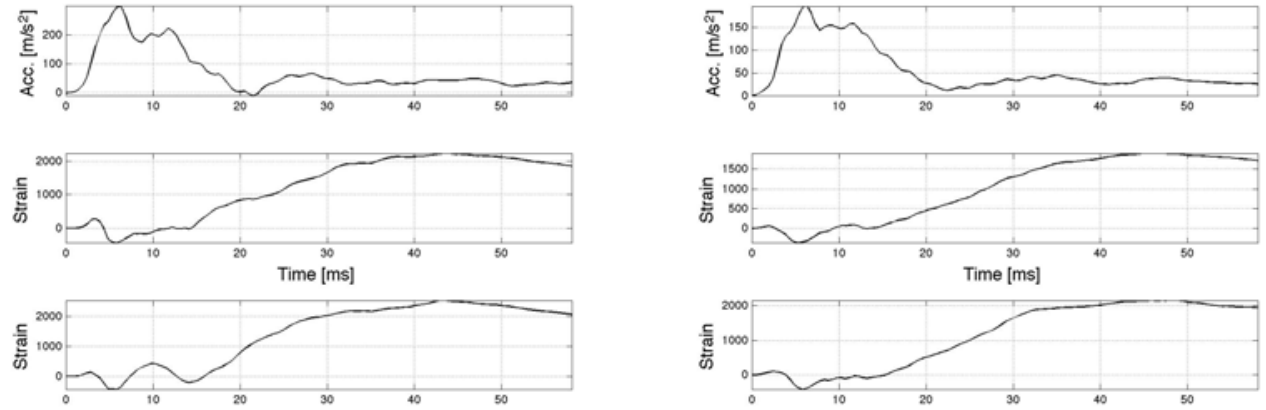

Figure I.72: V4 $\beta 20^{\circ}$ impact height 175 $\mathrm{cm}$

Figure I.75: V4 $\beta 20^{\circ}$ impact height 100 $\mathrm{cm}$ 

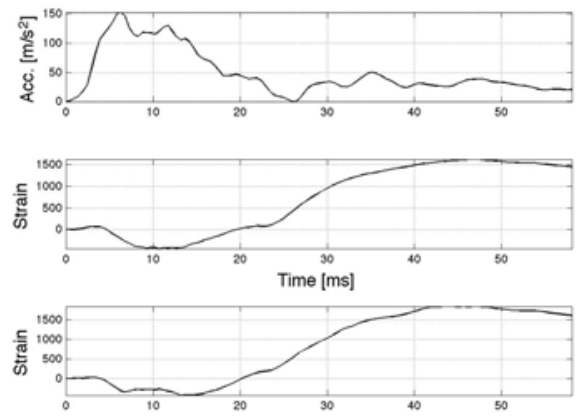

Figure I.76: V4 $\beta 20^{\circ}$ impact height 75 $\mathrm{cm}$
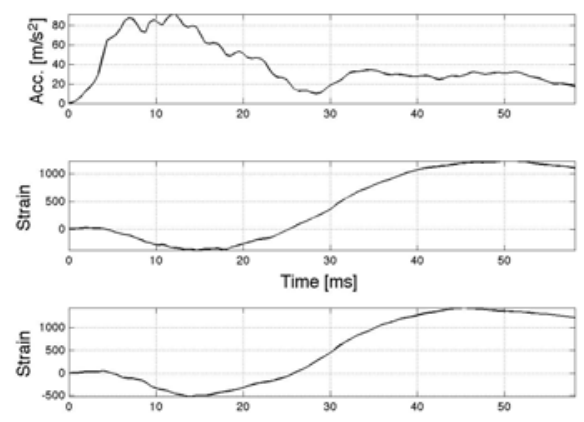

Figure I.77: V4 $\beta 20^{\circ}$ impact height 50 $\mathrm{cm}$
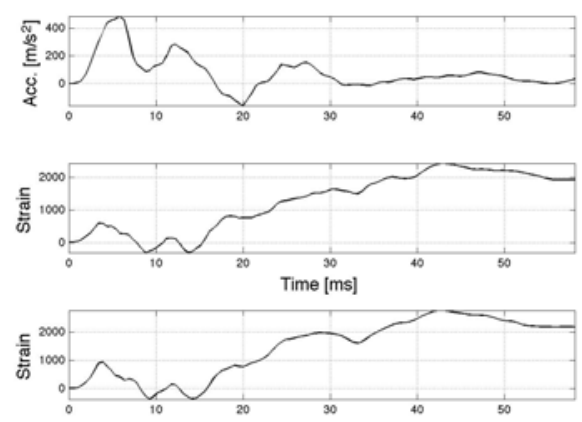

Figure I.78: V $4 \beta 15^{\circ}$ impact height 225 $\mathrm{cm}$
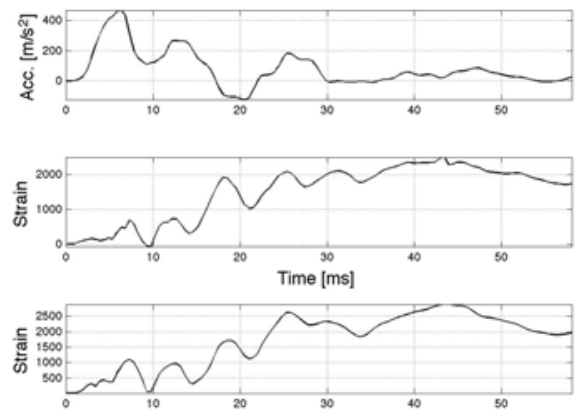

Figure I.79: V $4 \beta 15^{\circ}$ impact height 200 $\mathrm{cm}$
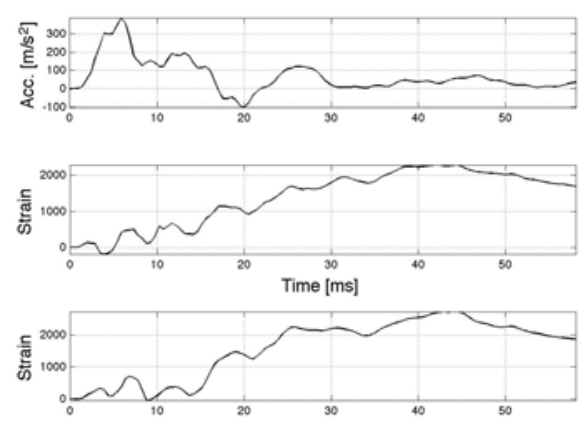

Figure I.80: V4 $\beta 15^{\circ}$ impact height 175 $\mathrm{cm}$
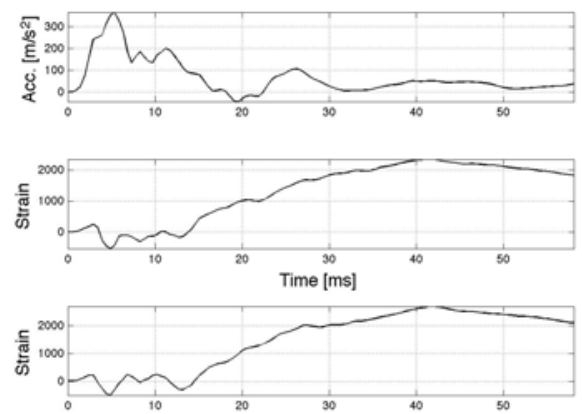

Figure I.81: V4 $\beta 15^{\circ}$ impact height 150 $\mathrm{cm}$ 

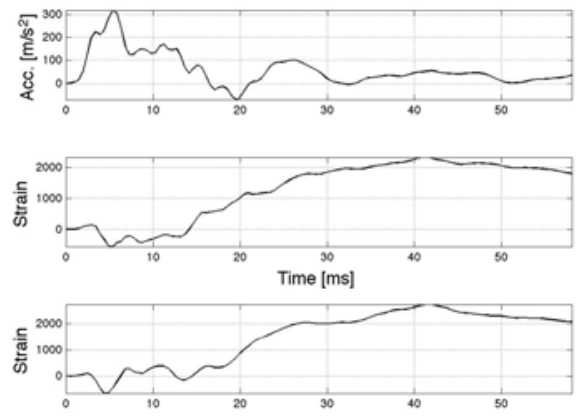

Figure I.82: V4 $\beta 15^{\circ}$ impact height 125 $\mathrm{cm}$
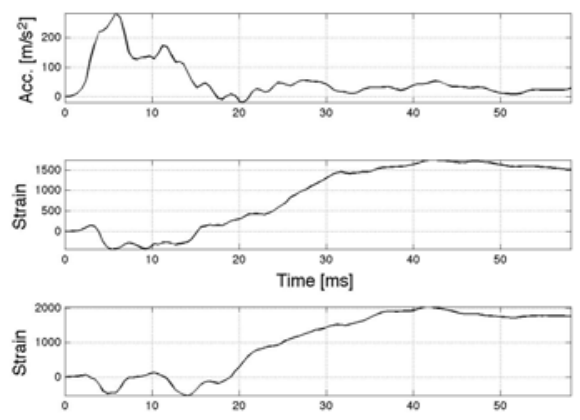

Figure I.83: V4 $\beta 15^{\circ}$ impact height 100 $\mathrm{cm}$
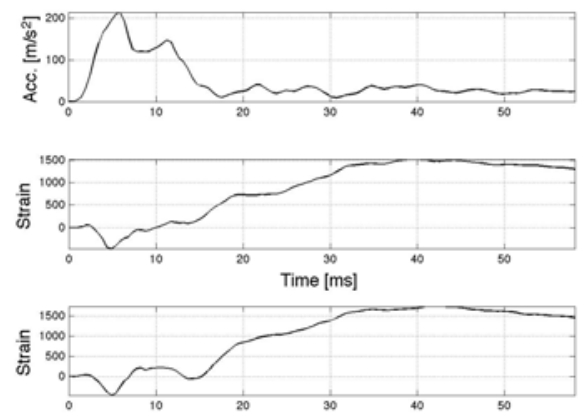

Figure I.84: V4 $\beta 15^{\circ}$ impact height 75 $\mathrm{cm}$
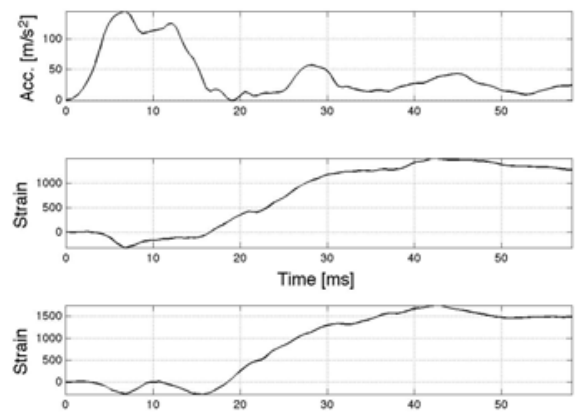

Figure I.85: V4 $\beta 15^{\circ}$ impact height 50 $\mathrm{cm}$
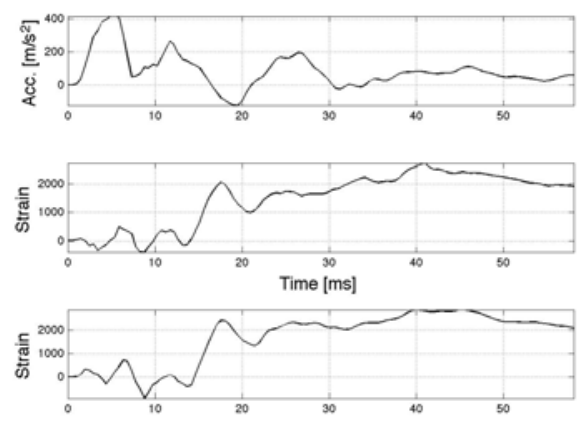

Figure I.86: V4 $\beta 10^{\circ}$ impact height 225 $\mathrm{cm}$
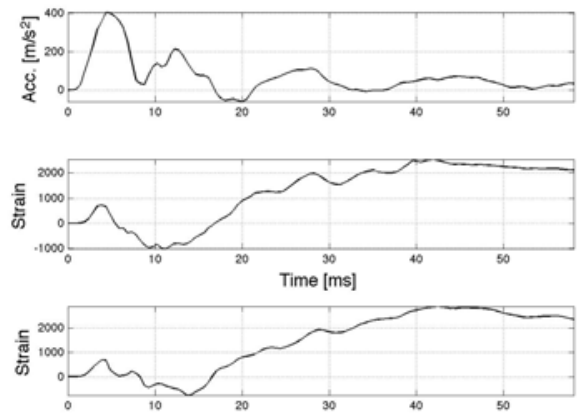

Figure I.87: V4 $\beta 10^{\circ}$ impact height 225 $\mathrm{cm}$ 

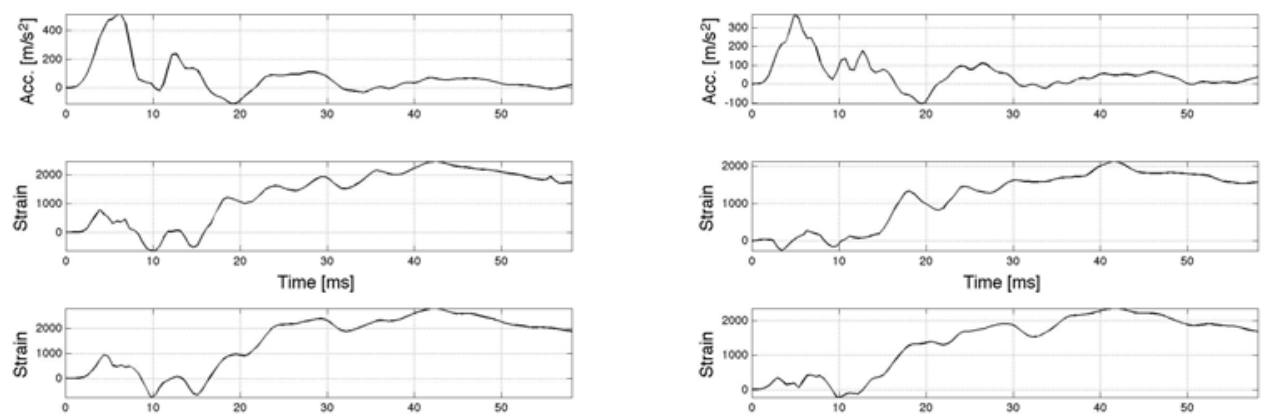

Figure I.88: V4 $\beta 10^{\circ}$ impact height 175 $\mathrm{cm}$

Figure I.91: V4 $\beta 10^{\circ}$ impact height 100 $\mathrm{cm}$
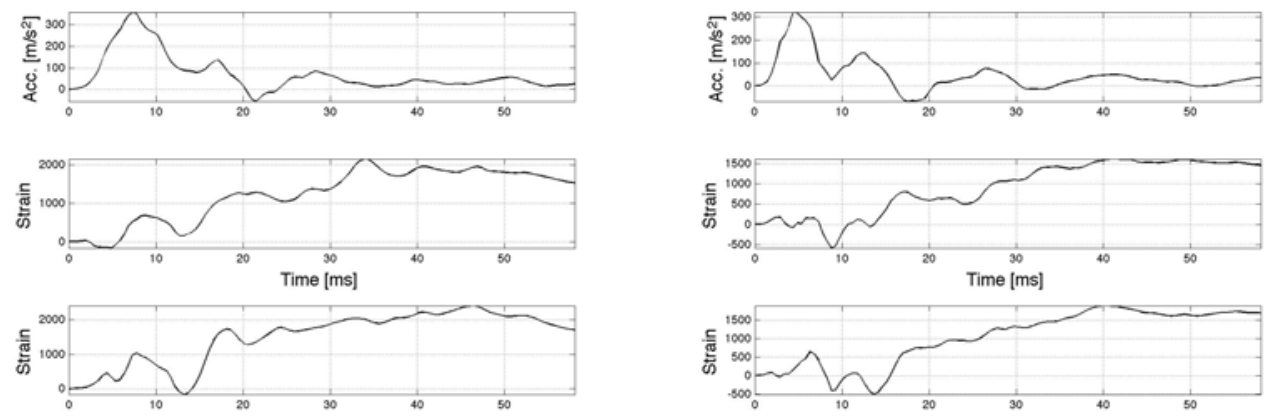

Figure I.89: V4 $\beta 10^{\circ}$ impact height 150 $\mathrm{cm}$

Figure I.92: V4 $\beta 10^{\circ}$ impact height 75 $\mathrm{cm}$
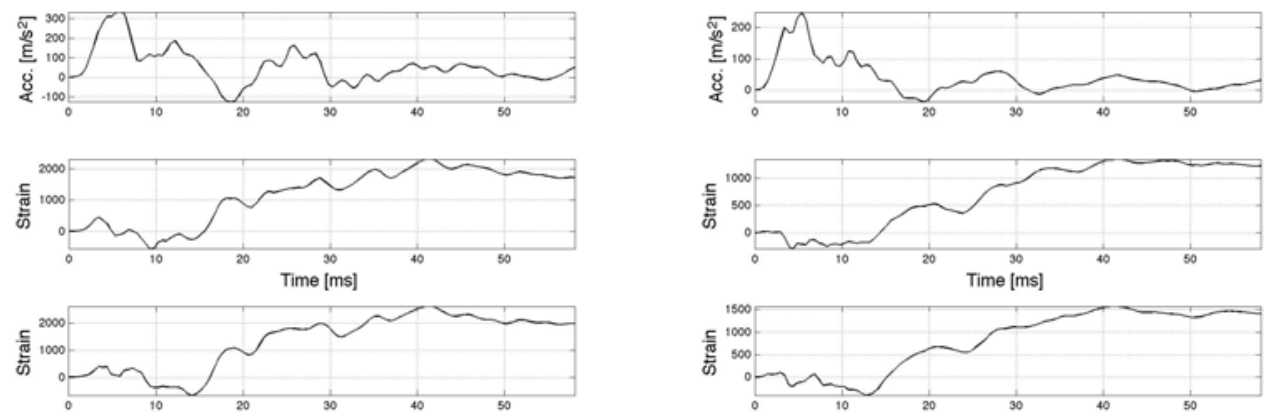

Figure I.90: V4 $\beta 10^{\circ}$ impact height 125 $\mathrm{cm}$

Figure I.93: V4 $\beta 10^{\circ}$ impact height 50 $\mathrm{cm}$ 


\section{I.3 Composite plates - Woven}
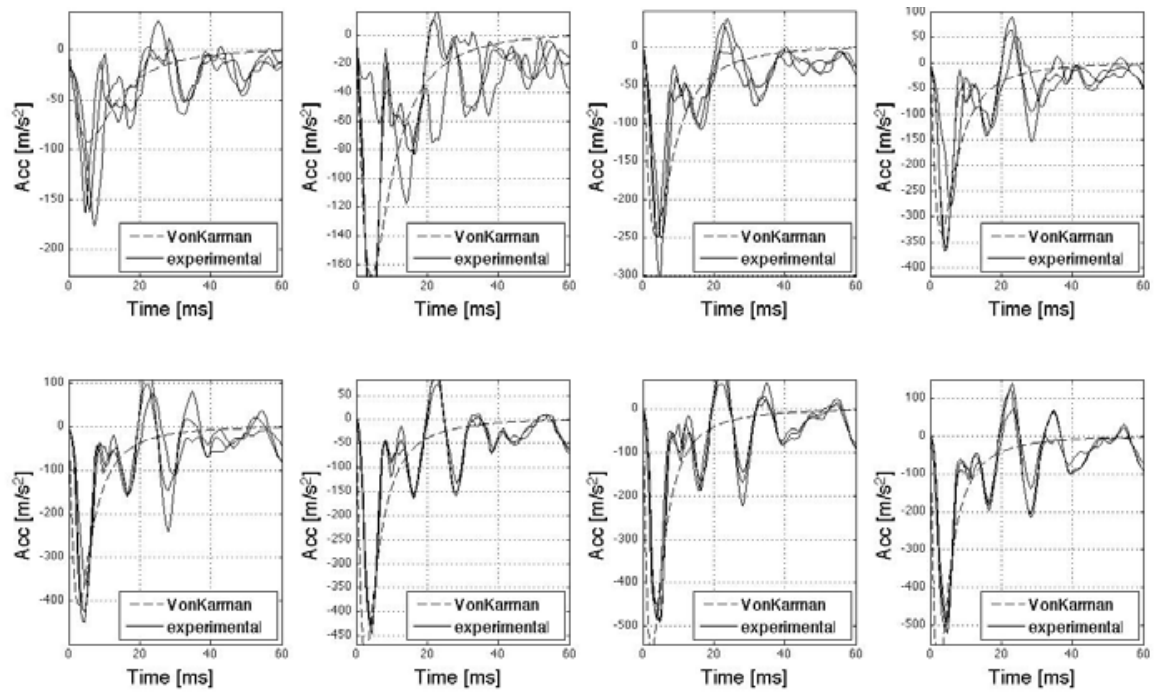

Figure I.94: Repeatability of the impact acceleration and comparison with Von Karman's model - W2 $\beta 20^{\circ}$
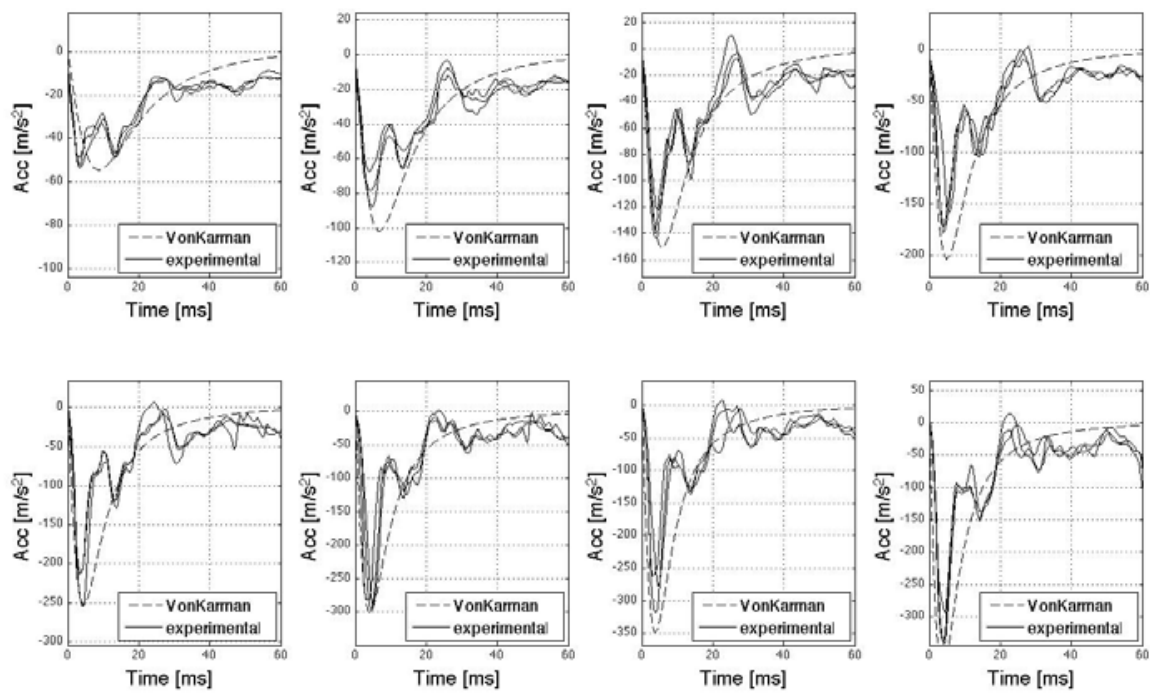

Figure I.95: Repeatability of the impact acceleration and comparison with Von Karman's model - W2 $\beta 30^{\circ}$ 

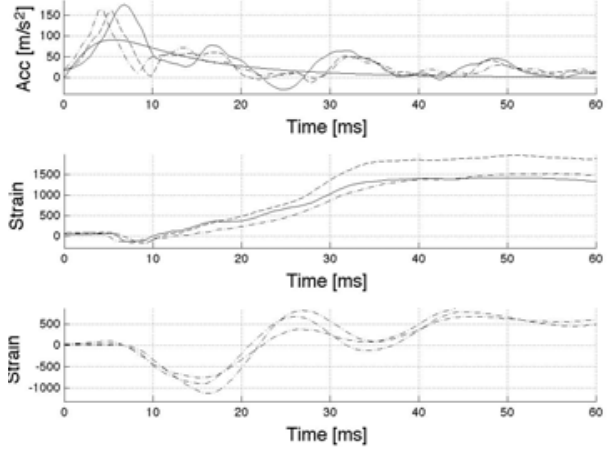

Figure I.96: W2 $\beta 20^{\circ}$ impact height 50 $\mathrm{cm}$
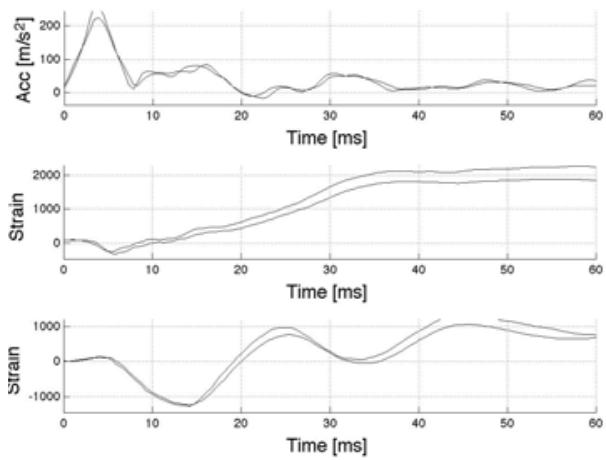

Figure I.97: W2 $\beta 20^{\circ}$ impact height 75 $\mathrm{cm}$
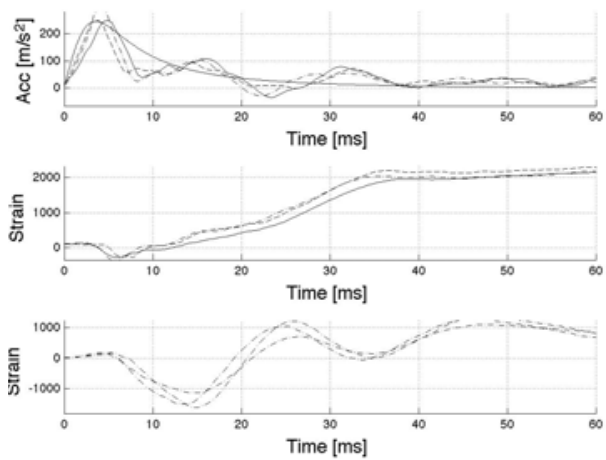

Figure I.98: W2 $\beta 20^{\circ}$ impact height $100 \mathrm{~cm}$
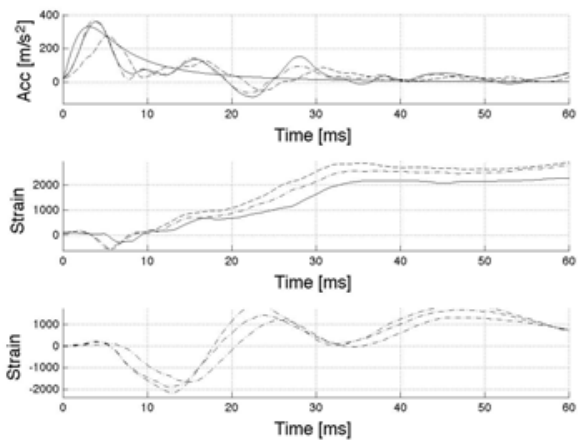

Figure I.99: W2 $\beta 20^{\circ}$ impact height $125 \mathrm{~cm}$

In the next 4 experiments, the strin gauge placed in the middle of the panel broke due to the excessive panel deformation.
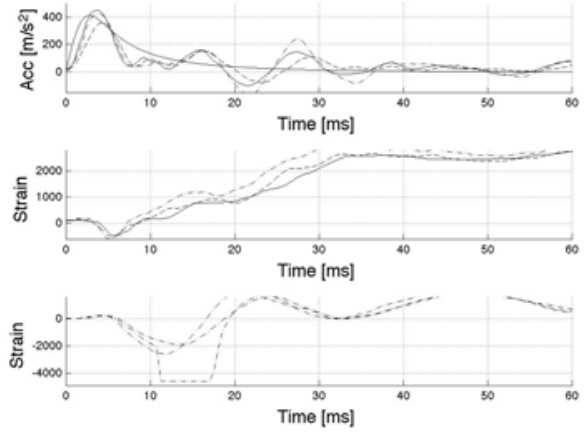

Figure I.100: W2 $\beta 20^{\circ}$ impact height $150 \mathrm{~cm}$ 

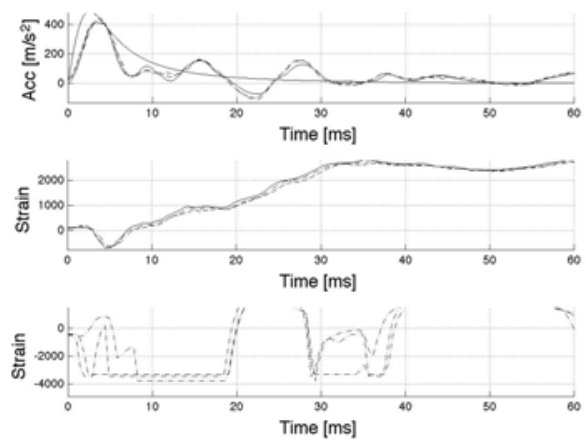

Figure I.101: W2 $\beta 20^{\circ}$ impact height $175 \mathrm{~cm}$
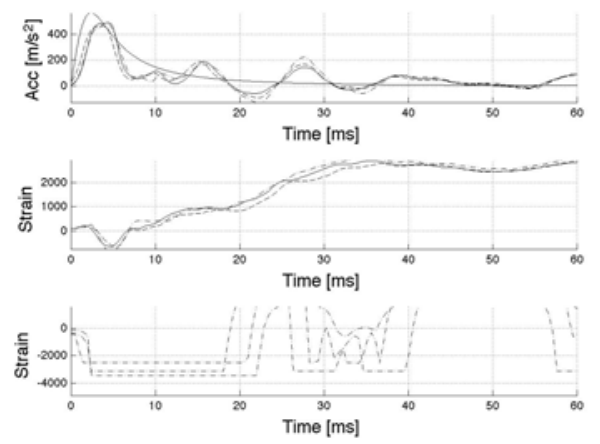

Figure I.102: W2 $\beta 20^{\circ}$ impact height $200 \mathrm{~cm}$
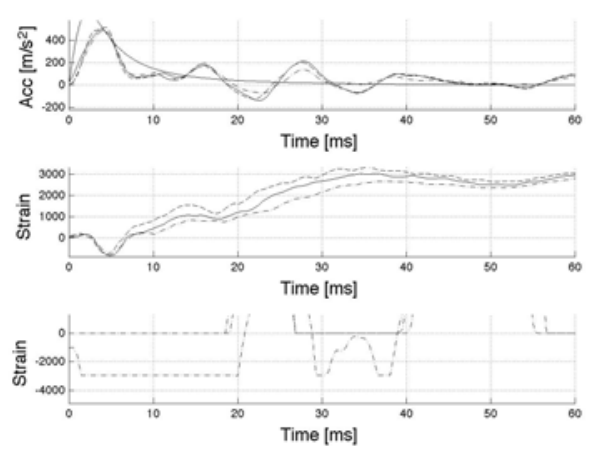

Figure I.103: W2 $\beta 20^{\circ}$ impact height $225 \mathrm{~cm}$

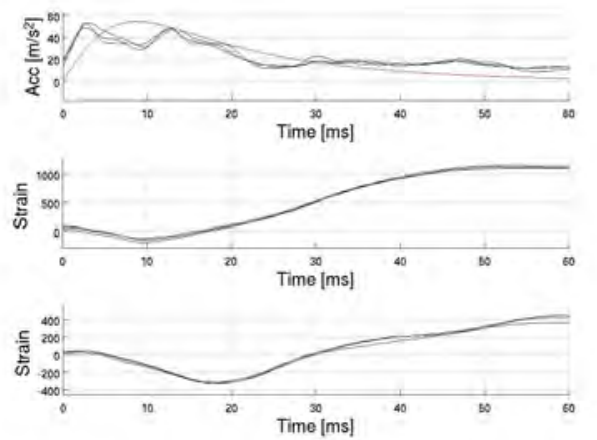

Figure I.104: W2 $\beta 30^{\circ}$ impact height $50 \mathrm{~cm}$
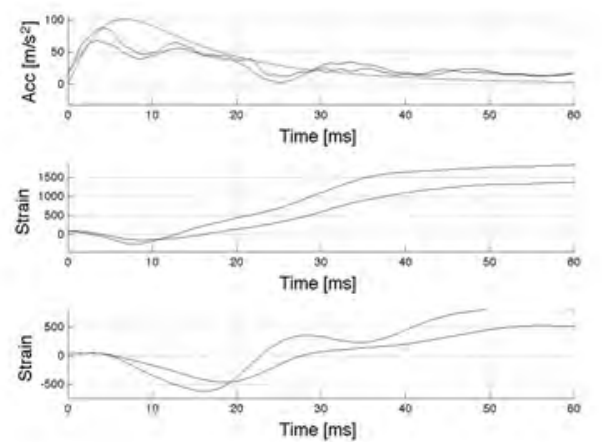

Figure I.105: W2 $\beta 30^{\circ}$ impact height $75 \mathrm{~cm}$
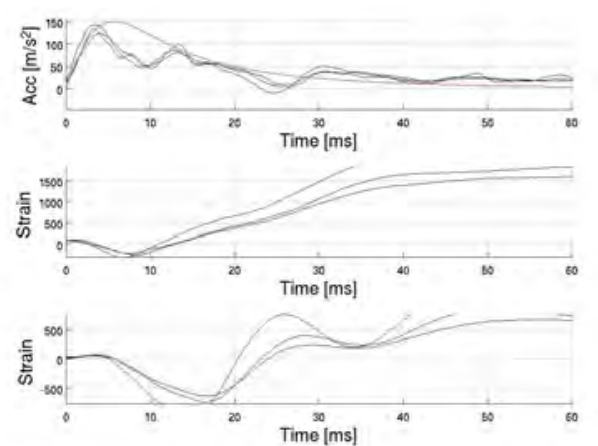

Figure I.106: W2 $\beta 30^{\circ}$ impact height $100 \mathrm{~cm}$ 


\section{Experimental results}
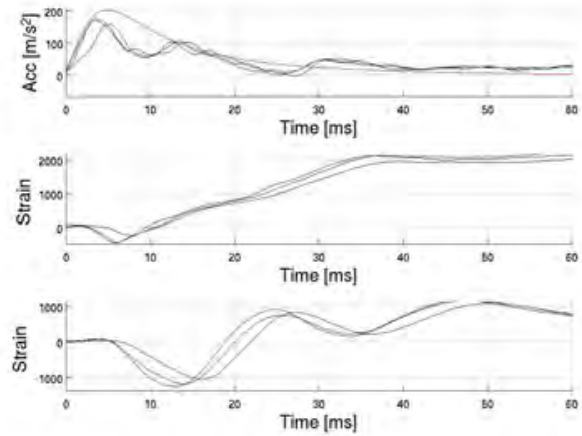

Figure I.107: W2 $\beta 30^{\circ}$ impact height $125 \mathrm{~cm}$
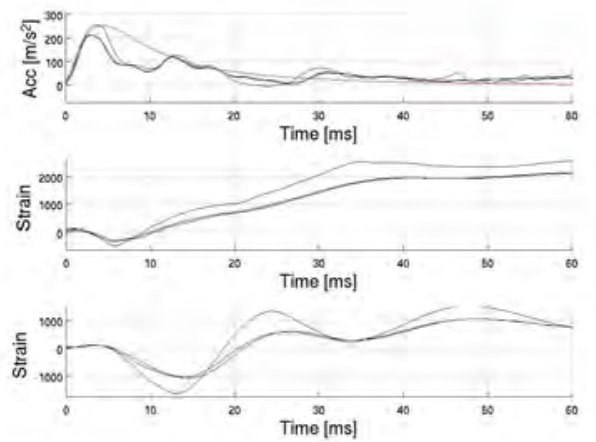

Figure I.108: W2 $\beta 30^{\circ}$ impact height $150 \mathrm{~cm}$
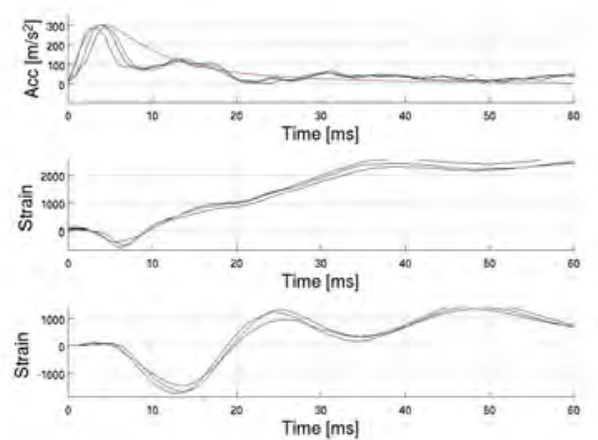

Figure I.109: W2 $\beta 30^{\circ}$ impact height $175 \mathrm{~cm}$
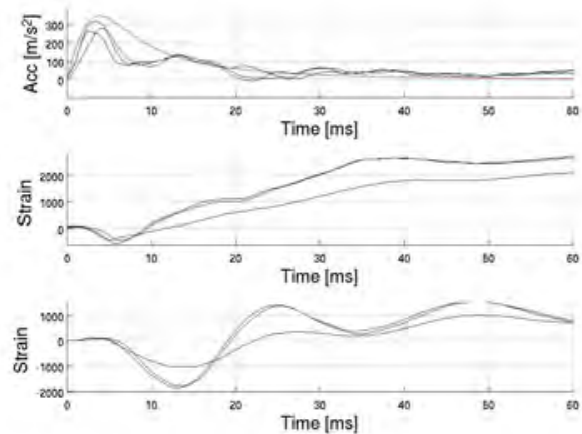

Figure I.110: W2 $\beta 30^{\circ}$ impact height $200 \mathrm{~cm}$
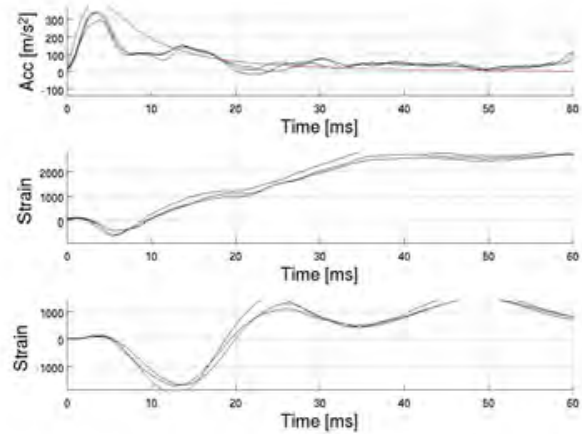

Figure I.111: W2 $\beta 30^{\circ}$ impact height $225 \mathrm{~cm}$ 
